\section{Pacific Northwest}

National Laboratory

Operated by Battelle for the

U.S. Department of Energy

\title{
Flow and Transport in the Hanford 300 Area Vadose Zone-Aquifer-River System
}

S. R. Waichler

S. B. Yabusaki

July 2005

Prepared for the U.S. Department of Energy under Contract DE-AC05-76RL01830 


\title{
DISCLAIMER
}

This report was prepared as an account of work sponsored by an agency of the United States Government. Neither the United States Government nor any agency thereof, nor Battelle Memorial Institute, nor any of their employees, makes any warranty, express or implied, or assumes any legal liability or responsibility for the accuracy, completeness, or usefulness of any information, apparatus, product, or process disclosed, or represents that its use would not infringe privately owned rights. Reference herein to any specific commercial product, process, or service by trade name, trademark, manufacturer, or otherwise does not necessarily constitute or imply its endorsement, recommendation, or favoring by the United States Government or any agency thereof, or Battelle Memorial Institute. The views and opinions of authors expressed herein do not necessarily state or reflect those of the United States Government or any agency thereof.

\author{
PACIFIC NORTHWEST NATIONAL LABORATORY \\ operated by \\ BATTELLE \\ for the \\ UNITED STATES DEPARTMENT OF ENERGY \\ under Contract DE-AC05-76RLO1830
}

This document was printed on recycled paper.

$(9 / 2003)$ 
PNNL-15125

\section{Flow and Transport in the Hanford 300 Area Vadose Zone-Aquifer-River System}

S. R. Waichler

S. B. Yabusaki

July 2005

Prepared for the U.S. Department of Energy under Contract DE-AC05-76RL01830

Pacific Northwest National Laboratory

Richland, Washington 99352 



\section{Executive Summary}

Groundwater in parts of the Hanford Site 300 Area exceeds the $30 \mu \mathrm{g} \mathrm{L}{ }^{-1}$ uranium drinking water standard. Field evidence suggests that contaminant migration in the 300 Area unconfined aquifer is strongly linked to fluctuations in the Columbia River stage (water level). The objectives of this study were to investigate flow and transport interactions among the river, aquifer, and vadose zone in a limited but representative area and time period, and to prepare for future geochemical modeling by identifying the most important transport characteristics of the flow system. A two-dimensional saturated-unsaturated water flow and tracer transport model was developed for a $1.1 \mathrm{~km}$-long by $60 \mathrm{~m}$-tall vertical cross section aligned west-east across the Hanford Site 300 Area, nearly perpendicular to the river.

The Subsurface Transport Over Multiple Phases (STOMP) simulator was used to model this hydrologic system for one year, from $3 / 1 / 92$ to $2 / 28 / 93$, a period when hourly data were available for both groundwater and river levels. Three cases were simulated: 1) base case, 2) lower river stage ("low-river") case, and 3) high hydraulic conductivity ("high-K") case. The base case was the primary simulation and used well and river water level measurements for model boundary conditions and available estimates of aquifer properties. The other two cases were used to explore model sensitivity to river stage and Hanford formation permeability, respectively.

Two model domains were tested to find the most efficient domain that would adequately represent the flow system. Grid 1 was larger, extending east to the middle of an island in the Columbia River and down to the upper basalt formation that underlies Hanford and Ringold sedimentary formations. Grid 2 extended east only to the middle of the first river channel and down only to the top of the lower Ringold mud unit, a low-permeability formation that overlies the basalt and underlies the more permeable Ringold gravel/sand/silt B/D unit. For both grids the western hydraulic boundary condition was defined by water levels in well 399-6-1, the eastern boundary was defined by the Columbia River stage recorded at river gage SWS-1, and the top boundary was the ground surface or riverbed. Influx to the model domain was predominantly lateral groundwater flow from the west plus some natural recharge at the top boundary (over land) and minor upward recharge at the bottom boundary.

Hydraulic head data indicate a regional gradient toward the river that results in net flow from the aquifer to the river. The mean drop in head from west to east during the simulated period was $13.9 \mathrm{~cm}$, for an average gradient of approximately $1.13 \mathrm{e}-4 \mathrm{~m} / \mathrm{m}$ (base case). However, river levels have a strong diurnal variation due to variable releases at Priest Rapids and McNary dams from power generation operations. The mean 24-hour change in river stage during the simulated year was $0.48 \mathrm{~m}$, or more than three times the average head drop of the water table from well 399-6-1 to the river, and the maximum 24-hr change was $1.32 \mathrm{~m}$. Groundwater levels $1.1 \mathrm{~km}$ inland (well 399-6-1) are influenced by large river level variations, albeit with time lags and damped amplitudes.

The simulated subsurface flow field responded strongly to these imposed diurnal changes in river stage, with large swings in simulated groundwater velocity magnitude and direction. Most of the simulated water and tracer flux occurred within the highly permeable U1 Hanford gravel/sand unit, the uppermost unit in the flow system. Within $300 \mathrm{~m}$ of the river, a zone where the 
principal disposal facilities are located, maximum pore velocities in the base case ranged from $4 \mathrm{~m} \mathrm{~d}^{-1}$ farthest from the river to more than $20 \mathrm{~m} \mathrm{~d}^{-1}$ next to the river during typical river-stage fluctuation. Groundwater velocity magnitude and direction were typically not sustained for more than a few hours because of the short cycles of river level change. The high velocities and relatively high-frequency fluctuations enhanced the intrusion and mixing of river water with groundwater, and thus controlled the overall size of the simulated mixing zone of aquifer and river water. When the boundary conditions were defined by daily or monthly averages instead of hourly values, the lack of large and frequent fluctuations drastically reduced the incursion of river water into the aquifer and limited the size of the zone where river water mixed with groundwater. Under hourly forcing, the inland extent of the river tracer was $150 \mathrm{~m}$, but under monthly forcing the mixing zone essentially disappeared. This contrast in mixing zone size highlights the importance of using higher-frequency boundary conditions when it is important to discern water quality, as in geochemical modeling. In this case, solution chemistry ranging between the aquifer and river end members results in a large range of uranium mobility. Thus, the accurate depiction of mixing of aquifer water and the much more dilute river water is fundamentally important to predicting uranium transport in the 300 Area aquifer.

Although the large, high-frequency fluctuations in river stage were essential for developing the mixing zone over the long-term, the short duration of the fluctuations resulted in little diurnal change in the size and position of the mixing zone. However, seasonal changes in average water level did lead to significant changes in the mixing zone. For example, the $20 \%$ concentration contour of the river tracer plume reached $170 \mathrm{~m}$ inland during the high river-stage months of January and June but only $70 \mathrm{~m}$ inland during the low river-stage month of September.

In addition to the base case, two sensitivity analysis cases were performed to address important issues. After a data discrepancy was identified wherein long-term averages of measured water levels in near-shore wells were found to be lower than the river stage at river gage SWS-1 by $11.9 \mathrm{~cm}$, the low-river case was developed to test model sensitivity to a lower river-stage boundary condition. The high-K case was used to evaluate the effect of a highly transmissive Hanford U1 gravel/sand unit with hydraulic conductivity 10 times greater than the base case, a possibility that was suggested by previous aquifer tests.

In both the base and low-river cases, the overall match of simulated heads to observed heads in wells near the transect was good, but the match was somewhat better for the low-river case. For the three wells with hourly data, the mean bias (simulated - observed) water level was $9.5 \mathrm{~cm}$ in the base case and $-2.1 \mathrm{~cm}$ in the low-river case. Net water flow to the river (per $1 \mathrm{~m}$ width of shoreline) was $159 \mathrm{~m}^{3} \mathrm{y}^{-1}$ in the base case, $291 \mathrm{~m}^{3} \mathrm{y}^{-1}$ in the low-river case, and $191 \mathrm{~m}^{3} \mathrm{y}^{-1}$ in the high-K case. The simulated cumulative exchange or absolute sum of flow back and forth across the riverbed was 34 times greater than the net flux to the river in the base case, 18 times greater in the low-river case, and 80 times greater in the high-K case. Simulated mass flux, groundwater velocities, and extent of tracer plumes all indicated that the diurnal river-stage cycles and the highly permeable Hanford formation are important aspects of the hydrologic system, in addition to seasonal fluctuations of average water levels.

This study identified and described the salient features of the vadose zone-aquifer-river flow system and will serve as a foundation for future reactive transport modeling of the uranium plume in the 300 Area. 


\section{Acknowledgments}

We thank the following individuals for their assistance. Paul Thorne provided geology information from the EarthVision database; Mark Rockhold provided water level data and material property values and reviewed the manuscript; John P. McDonald provided additional water level data and helpful comments on their quality; and Duane Ward provided Figure 1.1. This study was supported by the U.S. Department of Energy under Contract DE-AC05-76RLO1830.

This report is available in Portable Document Format (PDF) from the PNNL publications ${ }^{(a)}$ external website. The electronic version contains hyperlinks to facilitate navigation between all cross-referenced material, including section headings, figures, tables, and references.

(a) http://www.pnl.gov/main/publications/ 



\section{Abbreviations and Acronyms}

EDR data provided by R.E. Edrington/Fluor Hanford

GPS global positioning system

HEIS Hanford Environmental Information System (data source)

MAE mean absolute error (see Appendix C)

NAD83 North American Datum of 1983

NAVD88 North American Vertical Datum of 1988

NGVD29 National Geodetic Vertical Datum of 1929

PNNL Pacific Northwest National Laboratory

SAC System Assessment Capability

SGM Site-Wide Groundwater Flow Model

SIM simulated values (model output)

STOMP Subsurface Transport Over Multiple Phases simulator

\section{Notation}

$\mathrm{E}_{1} \quad$ first-degree efficiency (see Appendix $\mathrm{C}$ )

$K_{l} \quad$ lateral hydraulic conductivity (L/T) 



\section{Contents}

Executive Summary . . . . . . . . . . . . . . . . . iii

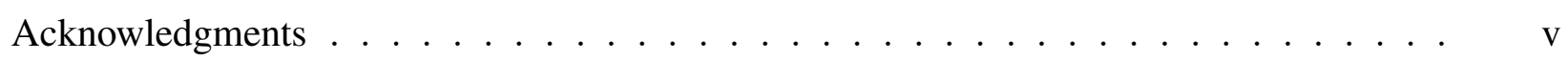

Abbreviations and Acronyms ................................ vii

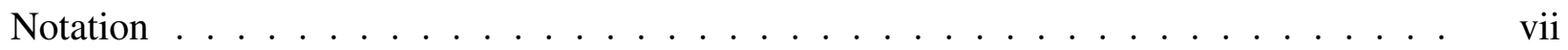

1.0 Introduction . . . . . . . . . . . . . . . . . . . . . . . 1.1

2.0 Groundwater and River Data $\ldots \ldots \ldots$. . . . . . . . . . . . . 2.1

3.0 Model Development $\ldots \ldots \ldots$. . . . . . . . . . . . . . . . . . . . . 3.1

3.1 Fluid and Aquifer Properties $\ldots \ldots \ldots . \ldots \ldots . \ldots \ldots$

3.2 Model Domain . . . . . . . . . . . . . . . . . . . . 3.1

3.3 Boundary Conditions . . . . . . . . . . . . . . . . . 3.3

3.4 Initial Conditions . . . . . . . . . . . . . . . . . . . 3.4

3.5 Preliminary Results for Full Model Domain . . . . . . . . . . . . . . . . . . . . 3.4

3.6 Reduced Model Domain . . . . . . . . . . . . . . . . . . . . . . . . . 3.4

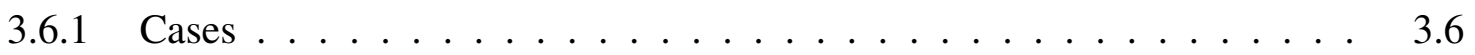

3.6.2 Preliminary Results . . . . . . . . . . . . . . . 3.7

4.0 Model Results . . . . . . . . . . . . . . . . . . . . . . . . . . . . 4.1

4.1 Base Case . . . . . . . . . . . . . . . . . . . . . 4.1

4.2 Low-river Case . . . . . . . . . . . . . . . . . . . . . . . . . . . 4.4

4.3 High-K Case . . . . . . . . . . . . . . . . . . . . 4.5

5.0 Discussion . . . . . . . . . . . . . . . . . . . . . 5.1

6.0 References ................................. 6.1

Appendix A - Water Level Hydrographs and Statistical Plots . . . . . . . . . . . . . A.1 
Appendix B - Resurvey of Selected 300 Area Water Level Measurement Points . . . . .

B. 1

Appendix C - Definitions for Goodness-of-Fit Statistics . . . . . . . . . . . . . .

C.1 


\section{Figures}

$1.1 \quad$ Hanford Site 300 Area . . . . . . . . . . . . . . . . . . . . . . . . . . 1.2

1.2 Extent of river water intrusion as determined from nitrate concentrations $\ldots \ldots . . .3$

$2.1 \quad$ Hanford Site and Columbia River . . . . . . . . . . . . . . . . . . . . . 2.2

2.2 Water levels at well 399-6-1 and river gage SWS-1, 1992-1993 . . . . . . . . . . 2.3

2.3 Cross-correlation between water levels at SWS-1 and 399-6-1. . . . . . . . . . . . 2.4

$2.4 \quad$ Mean water levels at near-shore wells and SWS-1 $\ldots \ldots \ldots \ldots$

2.5 Monthly mean water levels at SWS-1 and 399-4-9 . . . . . . . . . . . . . . . . 2.6

2.6 Manual and electronic measurements of water levels at 399-6-1 . . . . . . . . . . 2.7

2.7 a Simulated and observed heads for selected wells, base case $\ldots \ldots \ldots$

$2.7 \mathrm{~b}$ Simulated and observed heads for selected wells, base case $\ldots \ldots \ldots$

3.1 Geology for vertical 2D cross section, derived from EarthVision database . . . . . . 3.2

$3.2 \quad$ Discretized geology and STOMP boundary conditions, Grid $1 \ldots \ldots .3$

$3.3 \quad$ Nodes for Grid $1 \ldots \ldots \ldots \ldots \ldots$

3.4 Spinup of model to interannual steady state $\ldots \ldots \ldots \ldots \ldots \ldots$

3.5 Darcy velocity vectors for steady state heads, nonuniform geology $\ldots \ldots . . \ldots$

3.6 Discretized geology and model boundary conditions, Grid $2 \ldots \ldots$. . . . . . 3.6

$3.7 \quad$ Hydraulic head at end of simulation, $3 / 1 / 93 \ldots \ldots \ldots \ldots \ldots$

3.8a Simulated and observed heads for selected wells, low-river case . . . . . . . . . . . 3.9

3.8b Simulated and observed heads for selected wells, low-river case . . . . . . . . . 3.10

4.1 Comparison of simulated fluxes for hourly, daily, monthly boundary conditions . . . 4.2

4.2 River water tracer concentration at end of simulation $(3 / 1 / 93) \ldots \ldots$. . . . . . . . 4.3

4.3 Diurnal cycle of river levels on $11 / 22 / 92 \ldots \ldots \ldots \ldots . \ldots \ldots$ 
4.4 Base case diurnal groundwater velocities, 11/22/92 00:00-11:00 . . . . . . . . 4.6

$4.5 \quad$ Base case diurnal groundwater velocities, 11/22/92 12:00-23:00 . . . . . . . . 4.7

4.6 Base case monthly river tracer concentration contours $\ldots \ldots \ldots$

$4.7 \quad$ Comparison of simulated fluxes for base and low-river cases . . . . . . . . . . . 4.9

$4.8 \quad$ River tracer concentration contours at end of simulation $(3 / 1 / 93) \quad \ldots . . . . .44 .10$

4.9 Groundwater tracer concentration contours at end of simulation $(3 / 1 / 93)$. . . . . 4.11

4.10 Comparison of simulated fluxes for base and high-K cases . . . . . . . . . . . . 4.12

4.11 High-K case monthly river tracer concentration contours . . . . . . . . . . . . . . 4.14

A.1 River and well 399-6-1 water levels, 1991-1994 . . . . . . . . . . . . . . . A.2

A.2 River and well 399-6-1 water levels, 1995-1998 . . . . . . . . . . . . . . . A.3

A.3 River and well 399-6-1 water levels, 1999-2002 . . . . . . . . . . . . . . . . A.4

A.4 River and well 399-6-1 water levels, 2001-2004 . . . . . . . . . . . . . . . . A.5

A.5 Mean monthly river stage at SWS-1, 1991-2003 . . . . . . . . . . . . . . . A.6

A.6 Monthly mean stage $1991-2003 \ldots \ldots \ldots$. . . . . . . . . . . . . . . .

A.7 Boxplot of mean monthly stages by month, 1991-2003 . . . . . . . . . . . . . A.7

A.8 Boxplot of mean daily stages by month, 1991-2003 . . . . . . . . . . . . . . . A.7

A.9 Boxplot of maximum daily stages by month, 1991-2003 . . . . . . . . . . . A.8

A.10 Boxplot of daily stage ranges by month, 1991-2003 . . . . . . . . . . . . . A.8

A.11 Histogram of daily mean stage, 1991-2003 . . . . . . . . . . . . . . A.9

A.12 Histogram of daily $\max$ stage, $1991-2003 \ldots \ldots$. . . . . . . . . A.9

A.13 Histogram of range in daily stage, 1991-2003 . . . . . . . . . . . . . A.10

A.14 Histogram of mean monthly stage, 1991-2003 . . . . . . . . . . . . . A.10 


\section{Tables}

2.1 Summary statistics of water levels at well 399-6-1 and river gage SWS-1 . . . . . 2.4

$3.1 \quad$ Key material properties for STOMP simulations $\ldots \ldots \ldots . . \ldots \ldots$

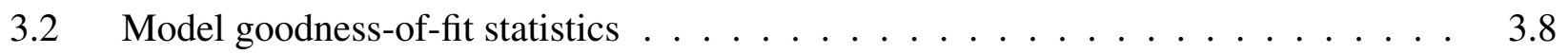

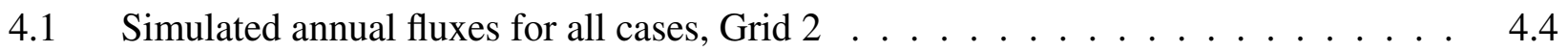

B.1 Results of resurvey of selected 300 Area measurement locations . . . . . . . . . . B.1

B.2 Quality assurance for resurvey of selected 300 Area measurement locations . . . . . B.1 



\subsection{Introduction}

This report documents a modeling study of saturated-unsaturated flow in the Hanford Site 300 Area vadose zone-aquifer-river system. Water movement and tracer transport were simulated along a two-dimensional (2D), vertical cross section extending from a well $1.1 \mathrm{~km}$ inland through a river-stage gaging station to the middle of a river island. The hydraulic model described here is a first step in developing a comprehensive reactive transport model for characterizing the 300 Area uranium plume and predicting its future behavior.

Two important hydrogeologic characteristics of the 300 Area are rapid water movement through the highly permeable Hanford formation and reversal of groundwater flow at times of high river levels (Schalla et al. 1988, Lindberg and Bond 1979, Haney 1957). A 1993 study by Westinghouse (WHC 1993) used modeling to predict the fate of the uranium plume, and a Record of Decision (ROD) (EPA 1996) for 300-FF-5 based in part on the Westinghouse study required continued monitoring of groundwater and institutional controls on groundwater use until further review in 2006. WHC (1993) sought to predict "reasonably conservative maximum values" for uranium in the groundwater between 1992 and 2018. The study assumed that source control measures would prevent surface or vadose zone contamination from impacting the underlying groundwater. Flow and transport in the saturated, unconfined aquifer were simulated; the vadose zone, bank storage, and springs were not. Mean monthly river stage was used as the river boundary condition. The simulation used the 1991 uranium concentration map as the initial conditions and assumed no further additions of uranium to groundwater. Uranium mobility was modeled with a constant equilibrium sorption isotherm $(\mathrm{Kd})$, assumed to be reversible and independent of water chemistry and mineralogy. Under these simulated conditions, the uranium plume in groundwater was predicted to disperse and attenuate fairly rapidly, leading to much lower uranium concentrations within a decade. The observed development of the uranium plume since then has been quite different, with continued high uranium concentrations at many wells leading to renewed efforts to understand the source and transport of uranium in the 300 Area.

Several perturbations to the process trench source areas have occurred since the early 1990s, including source excavation, removal of contaminated soil, and backfilling. During this time, uranium concentrations have not exhibited the kind of exponential attenuation that would be expected with gradual flushing of a groundwater plume having no continuing source. Recent scrutiny of the groundwater plume shape and concentrations over time have led to the hypothesis that the portion of the vadose zone that is periodically saturated by rising river levels is a source for uranium, and that this infrequent "flushing" remobilizes it. This new conceptual model implies that river-aquifer interaction is central to the plume behavior, and this study explores that interaction from a hydraulic perspective. Future work will couple these hydraulic results to a geochemical model to investigate the chemical consequences of mixing groundwater and river water on the fate and transport of uranium.

A variably saturated, 2D subsurface flow model was developed for a west-east vertical cross section nearly perpendicular to the river between well 399-6-1 and an island offshore from the 300 Area (Figure 1.1). Model simulations were performed with the Subsurface Transport Over Multiple Phases (STOMP) (White and Oostrom 2000, 2004) simulator, using the Richards equation 


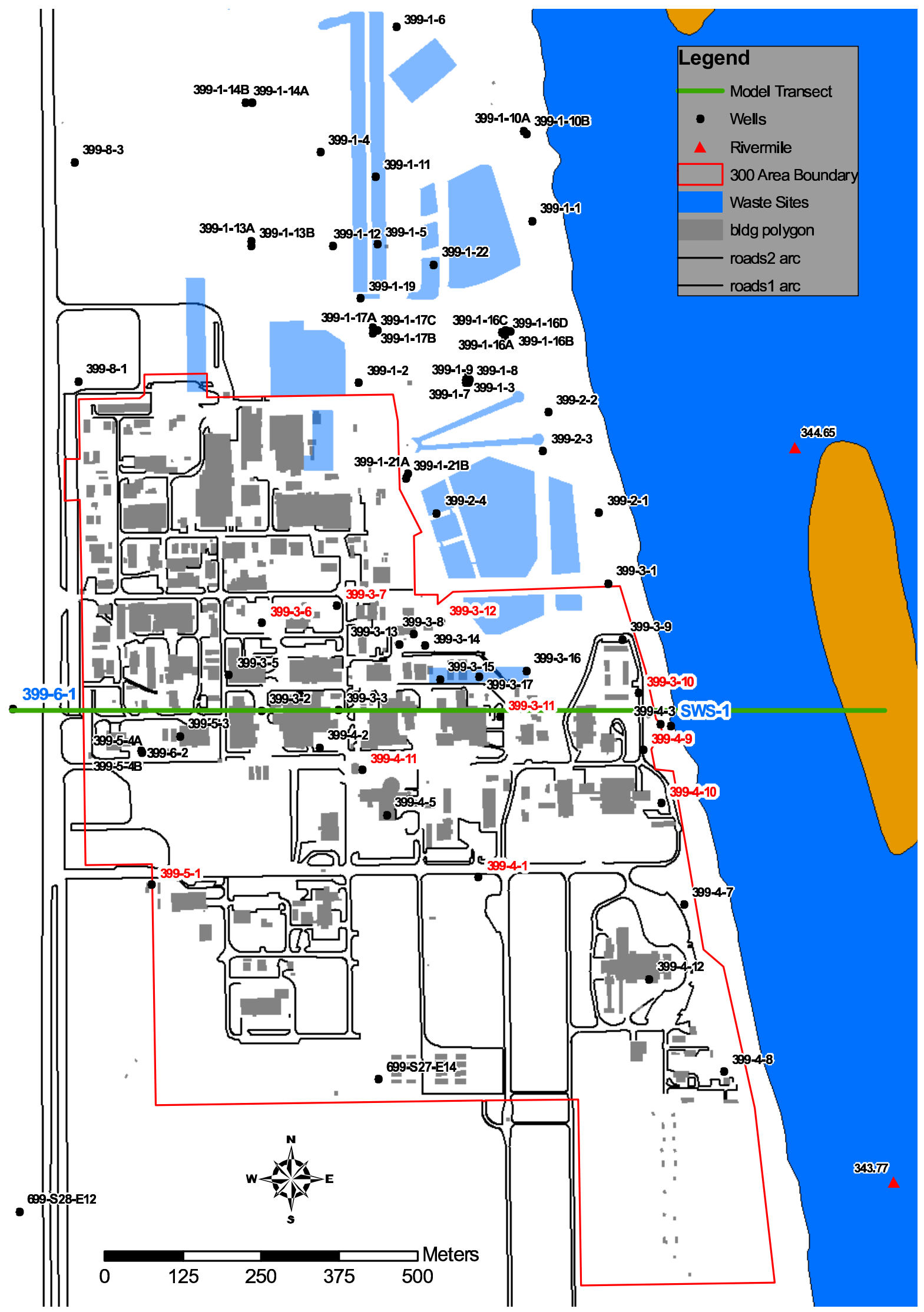

Figure 1.1. Hanford Site 300 Area and model transect (Grid 1) from well 399-6-1 to river island. 
solution mode. A somewhat similar application of STOMP was done for the Hanford 100-H Area by Peterson and Connelly (2004). The simulations here include water flux and hypothetical, conservative tracers associated with groundwater and river water to better understand the nature of mixing of these waters in the area near the river. This study represents the river-aquifer mixing zone at higher temporal and spatial resolution than previous studies. The importance of river water intrusion on aquifer chemistry and the significant extent of the mixing zone are indicated by the inland extent of nitrate plume dilution by river water in 2002 (Figure 1.2). A similar conclusion is obtained from specific conductance measurements in near-shore wells having shallow and deep sampling zones. In these wells the shallow groundwater tends to have a much wider range of specific conductance during the year than the deep groundwater, suggesting that shallow groundwater is subject to periodic dilution with intruding river water while the deep groundwater is less affected.

Hourly water levels at well 399-6-1 and river gage SWS-1 were the primary boundary conditions driving the flow field. The 2D cross section passed through wells 399-6-1, 399-3-2, 399-3-3, 399-3-11, and the river gage SWS-1, which made spatial interpolation of boundary conditions unnecessary and afforded several observation locations to compare hydrologic, transport, and chemistry information. The base case and two sensitivity cases were simulated using the final grid and model domain. The first sensitivity case ("low-river") involved a lower river water level

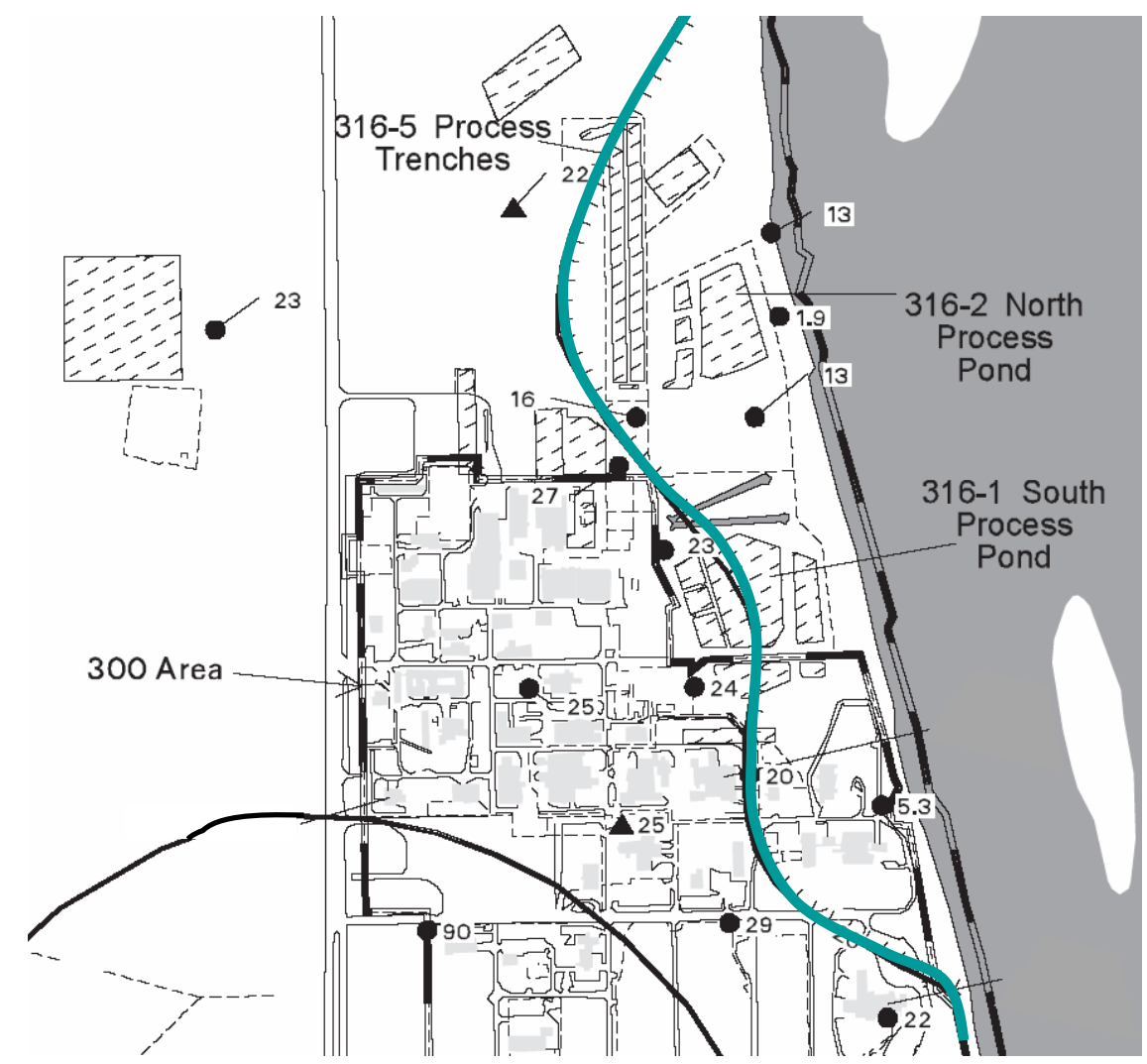

Figure 1.2. Extent of river water intrusion as determined from nitrate concentrations, 2002.

Wells east of the thick contour had more diluted concentrations of nitrate than wells west of the line. 
boundary condition to account for the possibility that the river stage datum is inconsistent with the well measurements. The second sensitivity case ("high-K") used a hydraulic conductivity for the Hanford formation that was 10 times larger than the base case. 


\subsection{Groundwater and River Data}

The Hanford Site 300 Area is located between river miles 343.8 and 344.7 of the Columbia River (Figure 2.1). River flow and water surface elevation here are primarily governed by releases at Priest Rapids Dam and by pool elevation at McNary Dam. Water release at Priest Rapids Dam is heavily influenced by power generation needs and thus has a strong diurnal cycling during much of the year in addition to having seasonal peaks caused by higher inflows to the dam

during spring and early winter. The stage at McNary Dam influences stage in the Hanford Reach via a backwater effect. For example, at the median river flow rate, river stage at the 300 Area corresponding to the 5 percentile McNary Dam level is approximately $40 \mathrm{~cm}$ lower than the stage corresponding to the 95 percentile McNary Dam level.

The west-east cross section used to model vadose zone, groundwater, and river interaction extended from well 399-6-1 to the middle of a river island (Figure 1.1). An hourly water level dataset for the model boundary conditions was needed, and the only period for which such data were available in 399-6-1 and other wells was 3/1/92-2/28/93, when a field study by R. S. Edrington/Westinghouse measured water levels at 30 wells plus the river location. This dataset of hourly electronic measurements is hereafter labeled as EDR. Of the wells directly along the transect, only 399-6-1 had an hourly water level dataset available, but some nearby wells were monitored in that study. In addition, manual measurements during the simulation period are available monthly at 399-6-1 and quarterly or less frequently at other wells of interest from the Hanford Environmental Information System (HEIS). Water levels at the river stage recorder SWS-1 have been measured hourly since November 1991.

The hourly hydrographs from the study period show typical patterns for water levels at these locations (Figure 2.2). While there is a general seasonal trend of a primary river-stage peak in May-June and a secondary peak in December-January, river stage is dominated by higherfrequency diurnal fluctuations that are principally the result of water released at Priest Rapid Dam to match power generation needs. The magnitude of these diurnal river-stage fluctuations can, on occasion, exceed the seasonal fluctuation of monthly average river stages. During the simulation period the mean 24-hour change (difference between minimum and maximum hourly values) in river stage was $0.48 \mathrm{~m}$, and the maximum 24-hour change was $1.32 \mathrm{~m}$ (Table 2.1). Groundwater levels are significantly correlated with river stage, albeit with a lag in time and decreased amplitude of fluctuations. The cross-correlation coefficient between mean daily water levels at the river and well 399-6-1 has a maximum value of 0.87 at a lag of 3 days (Figure 2.3). Water levels in wells such as 399-6-1 more than a kilometer away from the river can have multiple damped peaks during the course of a month, each associated with the occurrence of a significant river-stage peak followed by a significant drop. The mean drop in water level from 399-6-1 to SWS-1 during the simulation period was $13.9 \mathrm{~cm}$ for an average gradient of approximately $1.13 \mathrm{e}-4 \mathrm{~m} / \mathrm{m}$. Complete hydrographs for river gage SWS-1 and well 399-6-1 and statistical characterization of river levels are given in Appendix A. More information about historical river levels and a hydrodynamic simulation of the entire Hanford Reach of the Columbia River can be found in Waichler et al. (2005).

In contrast to the relatively long distance that the pressure wave propagates into the aquifer from 


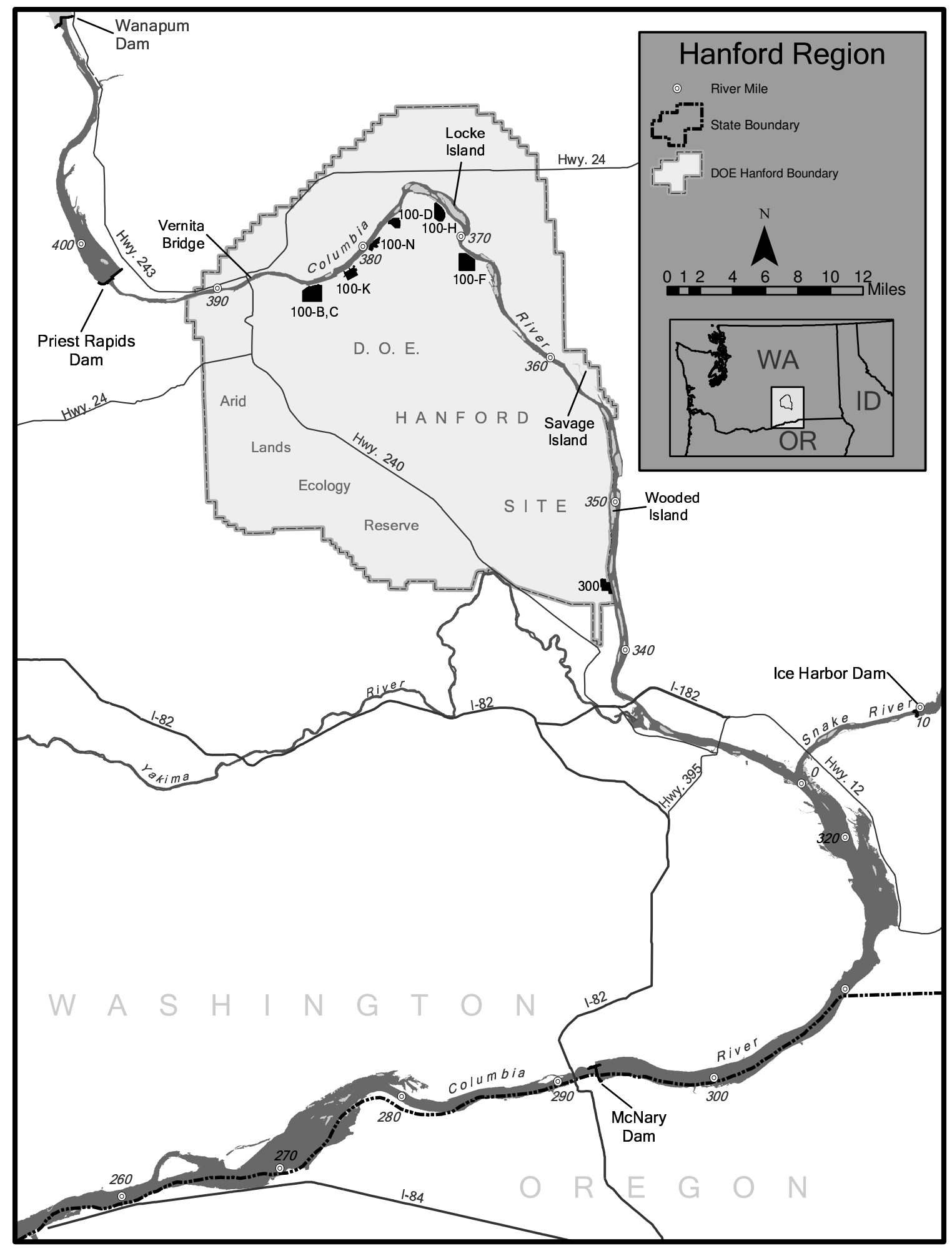

Figure 2.1. Hanford Site and Columbia River. 


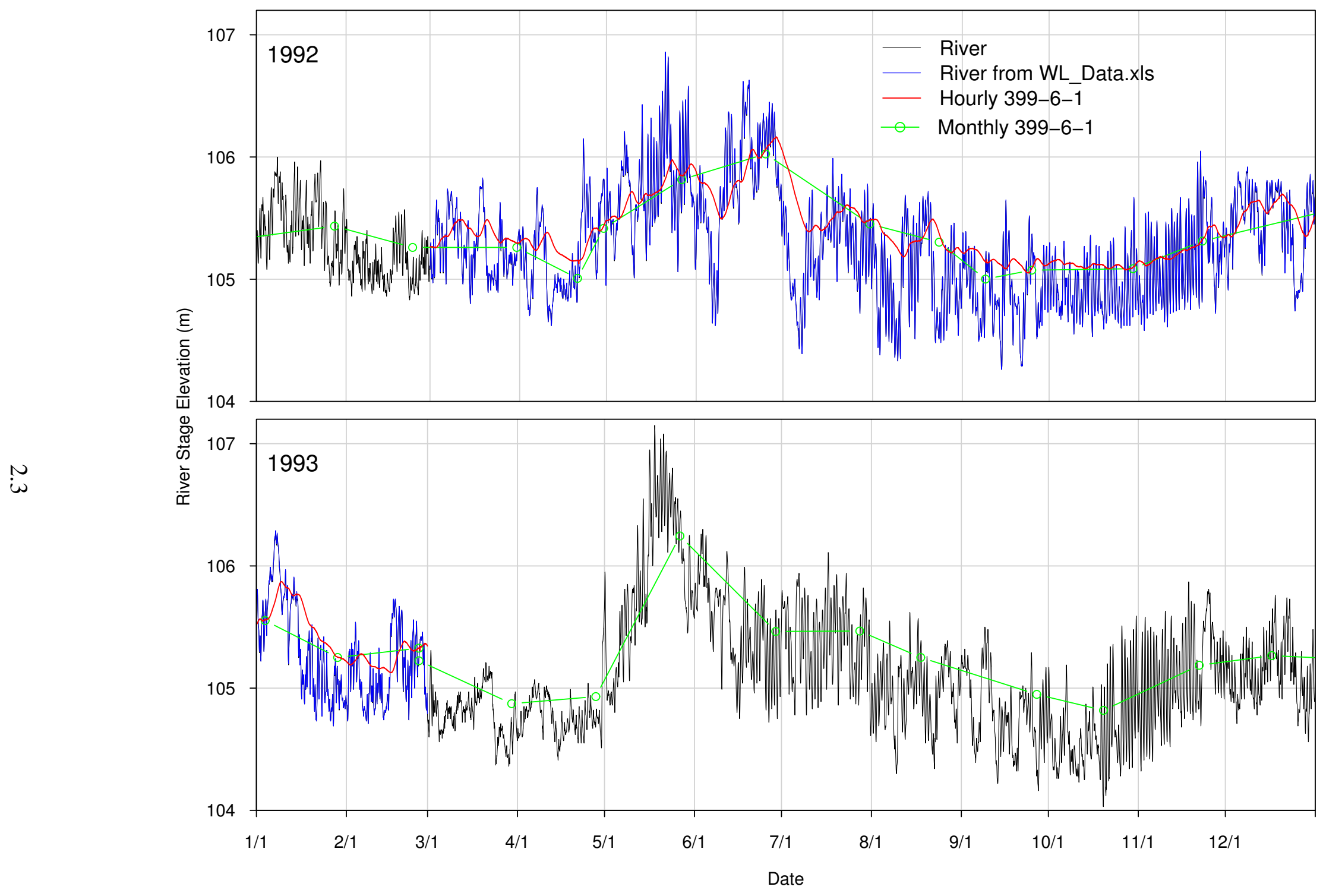

Figure 2.2. Water levels at well 399-6-1 and river gage SWS-1, 1992-1993. Elevations in m NAVD88. 
Table 2.1. Summary statistics of water levels at well 399-6-1 and river gage SWS-1 (m NAVD88).

\begin{tabular}{lccc}
\hline Statistic & $399-6-1$ & SWS-1 & SWS-1 \\
& $3 / 1 / 92-2 / 28 / 93$ & $3 / 1 / 92-2 / 28 / 93$ & $11 / 7 / 1991-3 / 31 / 04$ \\
\hline Min hourly elev. & 105.05 & 104.26 & 104.03 \\
Mean hourly elev. & 105.41 & 105.28 & 105.39 \\
Max hourly elev. & 106.17 & 106.86 & 108.36 \\
Min daily elev. change & 0.00 & 0.07 & 0.00 \\
Mean daily elev. change & 0.03 & 0.48 & 0.50 \\
Max daily elev. change & 0.09 & 1.32 & 2.06 \\
\hline
\end{tabular}

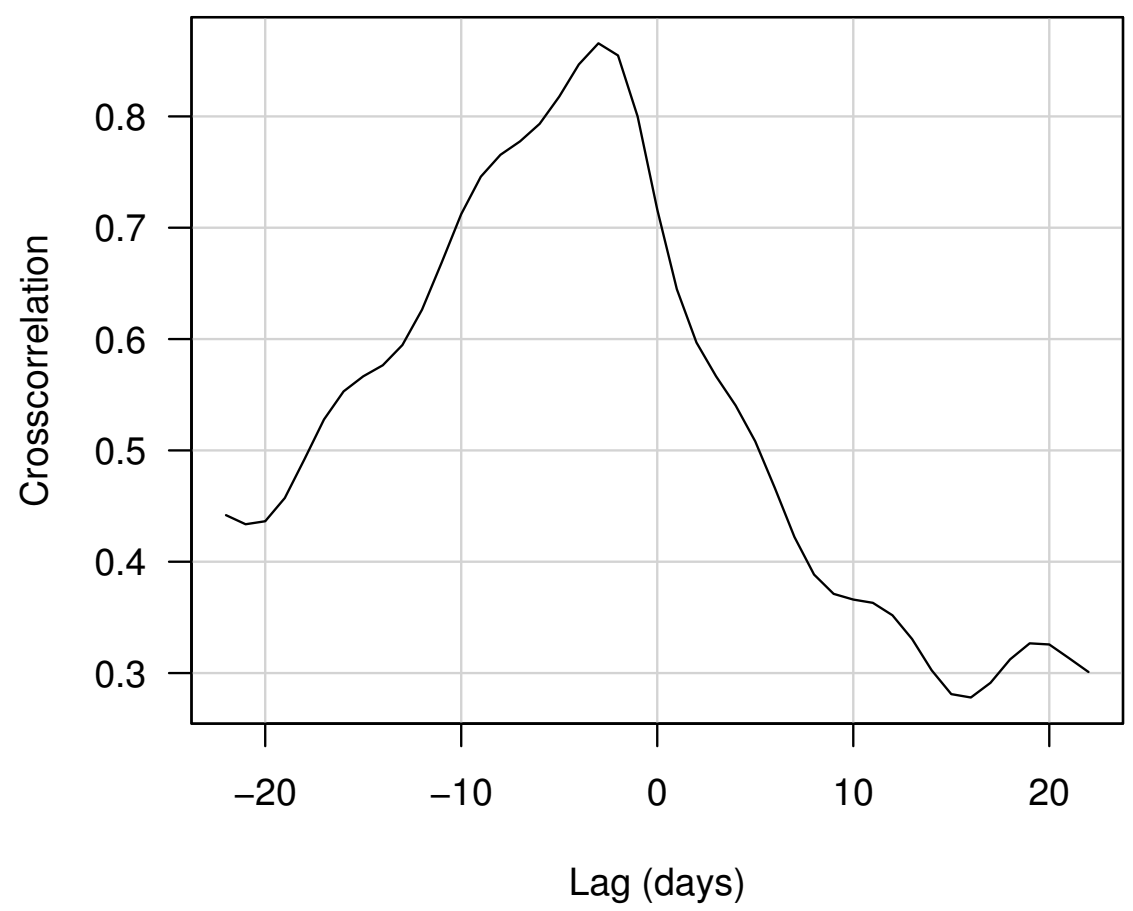

Figure 2.3. Cross-correlation between daily water levels at SWS-1 and 399-6-1. The largest correlation is 0.866 for 399-6-1 trailing SWS-1 by 3 days. 
the river, specific conductivity measurements of 300 Area wells indicate that the intrusion of river water into the aquifer is generally limited to a zone near the river. Notable exceptions are for infrequent high river-stage events (e.g., 1997 and 2002) when significant drops in the conductivity measurements were detected $\sim 350 \mathrm{~m}$ from the river (e.g., well 399-1-17A).

Two issues were encountered with the water level data: 1) a general discrepancy between nearshore groundwater levels and the river stage at SWS-1 and 2) significant differences between electronic and manual measurements. Mean water levels from 3/92 to 2/93 in all wells close to SWS-1 were lower than SWS-1 (Figure 2.4). Over a long period of time, any time-phase errors in the hourly water levels between the river and the wells will average out. Unless there is some inland sink, the river should be the lowest elevation. The fact that it is not the lowest elevation indicates a discrepancy. The average water level in the near-shore wells is generally consistent and decreases monotonically along with the slope of the river along the 300 Area, indicating that the inconsistency is between the river measurement and the well measurements (Figure 2.4). For example, at well 399-4-9, just $60 \mathrm{~m}$ from the river, the difference ranges from 3 to $18 \mathrm{~cm}$ (Figure 2.5). Unfortunately, the magnitude of the discrepancy is not consistent on a monthly basis, so it is difficult to determine a suitable correction to the SWS-1 data that could be applied uniformly. The mean monthly difference of $11 \mathrm{~cm}$ is significant compared with the recorded average annual head drop from 399-6-1 to SWS-1 of $13.6 \mathrm{~cm}$.

To check the possibility of error in the assumed datum and reference point elevations, a resurvey of selected reference points near SWS-1 was performed with high-precision GPS methods in December 2004. Appendix B contains the results and quality assurance for the resurvey. Within measurement error, the resulting horizontal and vertical coordinates were the same as the available data from conventional theodolite surveys. In response to the absence of a definitive

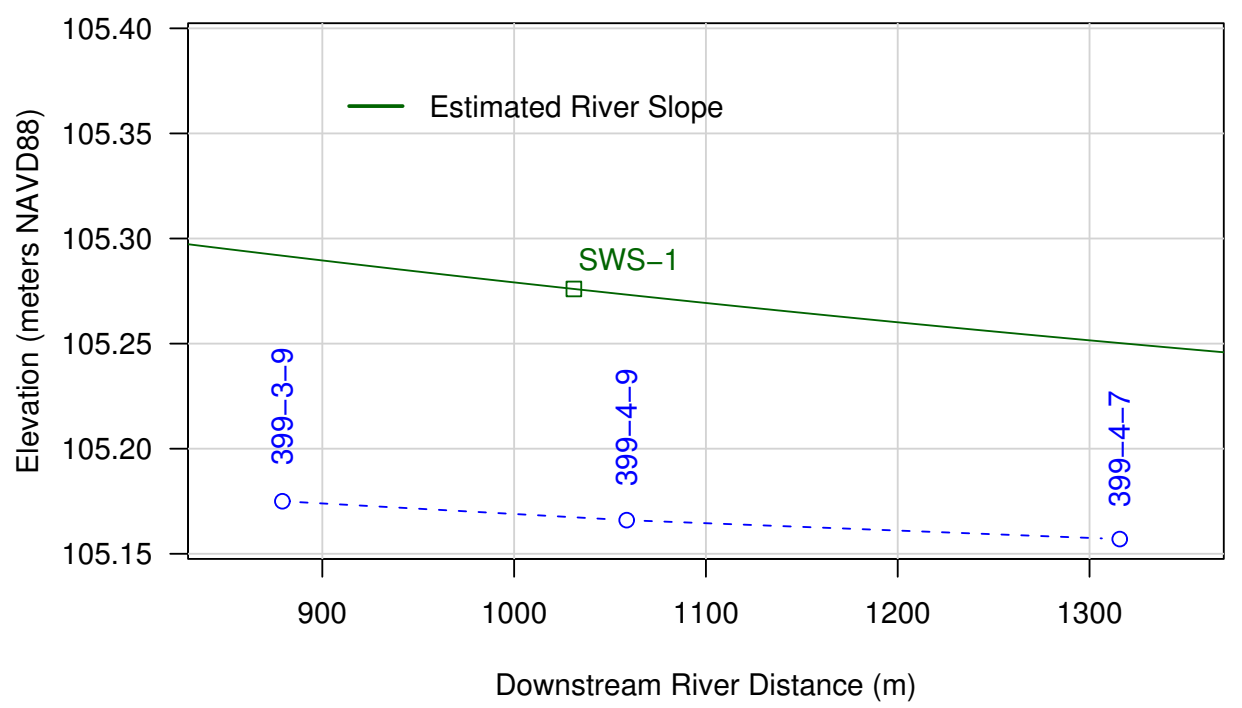

Figure 2.4. Mean water levels at near-shore wells and SWS-1, 3/92-2/93. River surface profile is estimated from a simulation using the MASS1 river model (Waichler et al. 2005). Downstream river distance is from arbitrary point $50 \mathrm{~m}$ upstream of 399-1-10B. 


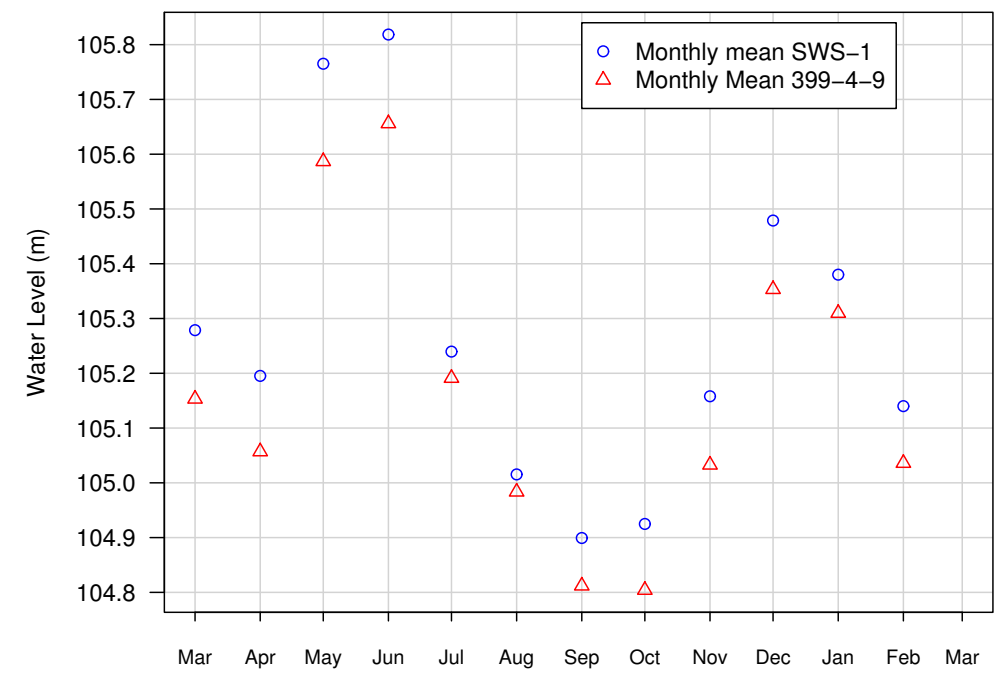

Figure 2.5. Monthly mean water levels at SWS-1 and 399-4-9, 3/92-2/93. 399-4-9 is $60 \mathrm{~m}$ inland from the river and SWS-1.

correction to the historical water levels, we included a lower river-stage sensitivity case ("lowriver") in the study, where the river boundary condition head was decreased by $11.9 \mathrm{~cm}$, the mean difference between hourly simulated and observed heads at 399-4-9.

The other data discrepancy encountered was the significant difference between groundwater water levels measured manually and electronically. Measurements in 399-6-1 are typical for having general agreement between the trends of the manual and electronic data, but inconsistent differences between these measurements through time (Figure 2.6). The differences for three other wells in the vicinity of the model transect are shown in Figures $2.7 \mathrm{a}$ and 2.7b. To compare these data numerically, the hourly data were interpolated linearly to the times of the manual measurements (only HEIS measurements with recorded time are included). In wells 399-312 and 399-4-1, more than $300 \mathrm{~m}$ from the mean shoreline, the electronic data were $7.6 \mathrm{~cm}$ higher than the the manual measurements on average. These discrepancies are relatively large compared with the total head drop between 399-6-1 and the river, but lacking a satisfactory way to reconcile the data, the original electronic data at 399-6-1 were used to be consistent with the electronic river data and to have hourly values. 


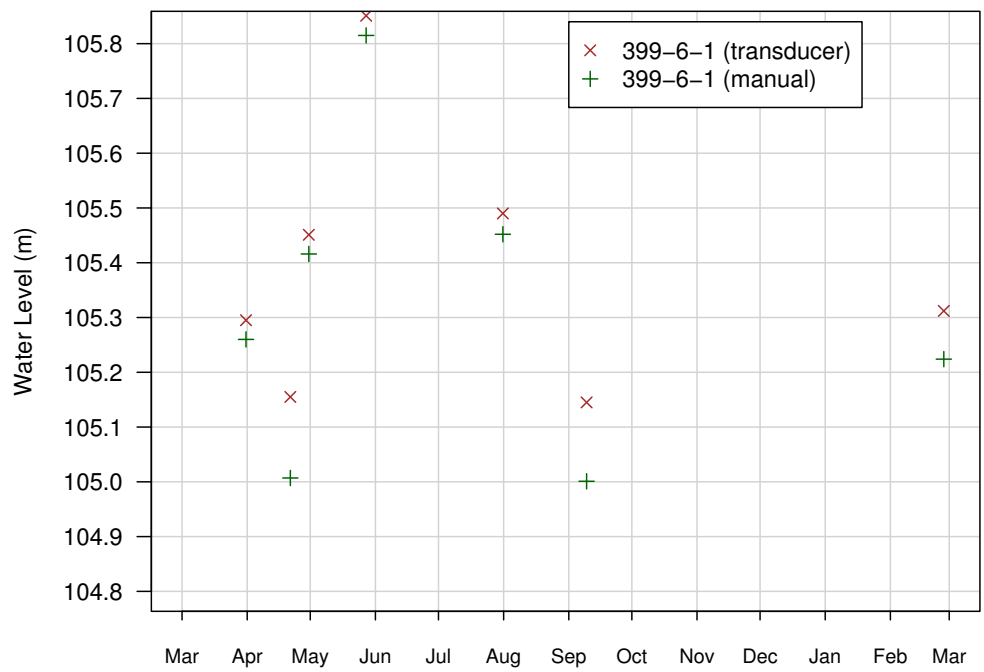

Figure 2.6. Manual and electronic measurements of water levels at 399-6-1, 3/92-2/93. Manual measurements by steel tape and electronic measurements interpolated to manual measurement times. The mean difference was $7.1 \mathrm{~cm}$. 


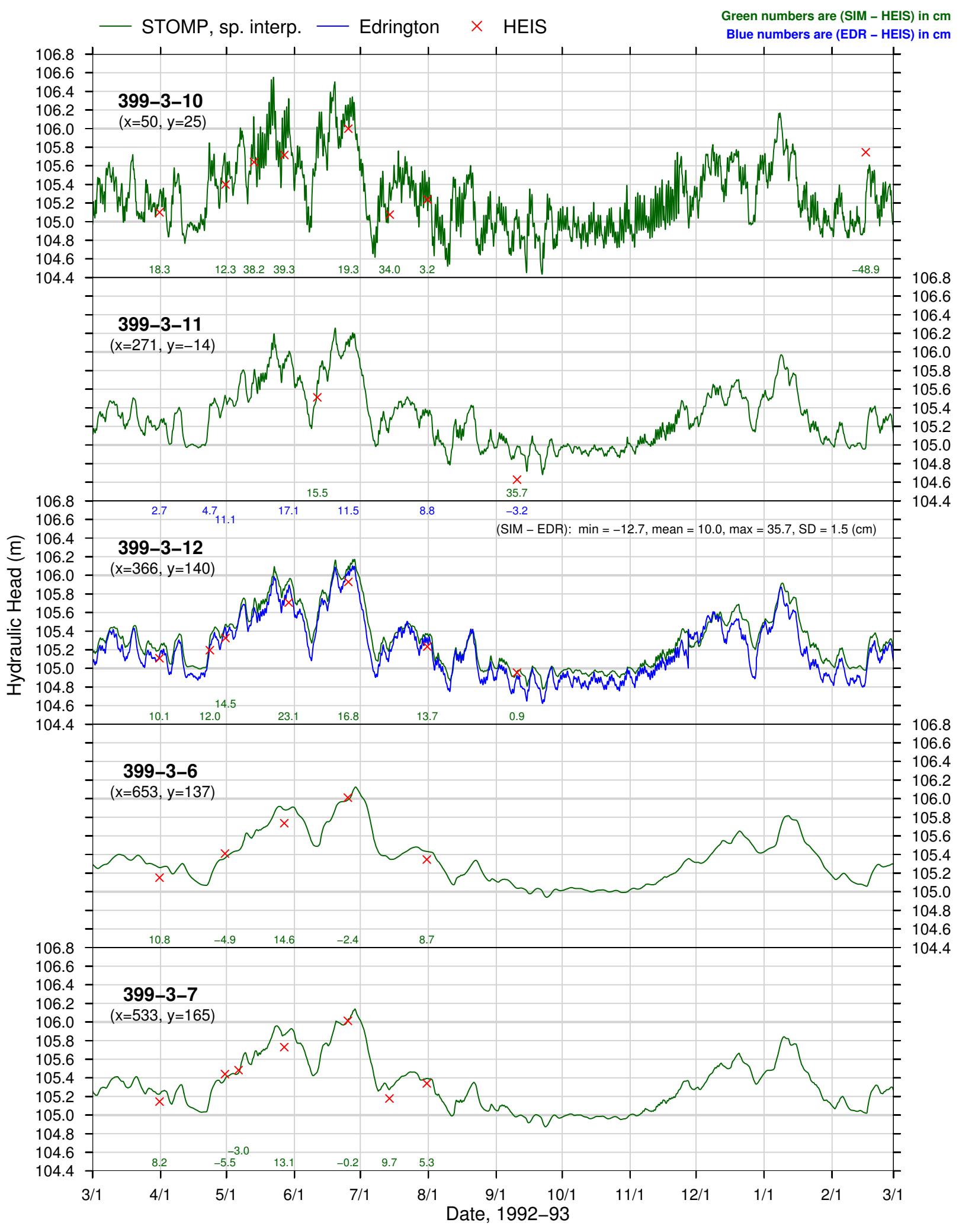

Figure 2.7a. Simulated and observed heads for selected wells, base case. SIM = simulated, EDR = hourly data, HEIS = manual data; $x$ and $y$ below well number are easting distance from shoreline and distance in meters north (south if negative) of cross-section line, respectively. 


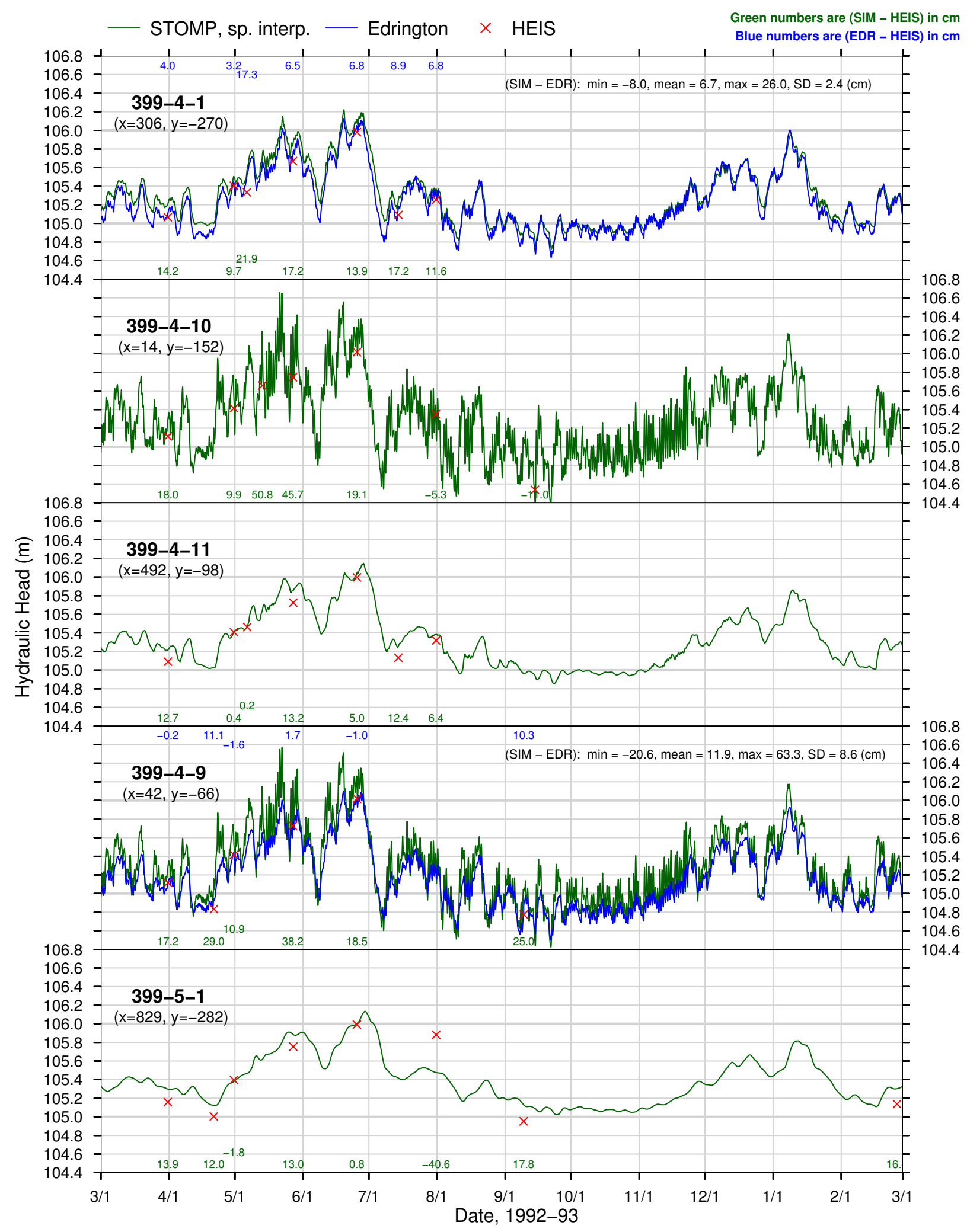

Figure 2.7b. Simulated and observed heads for selected wells, base case. SIM = simulated, $\mathrm{EDR}=$ hourly data, HEIS = manual data; $\mathrm{x}$ and $\mathrm{y}$ below well number are easting distance from shoreline and distance in meters north (south if negative) of cross-section line, respectively. 



\subsection{Model Development}

The previous chapter showed that the average diurnal change in the Columbia River stage $(0.48 \mathrm{~m})$ along the 300 Area is significantly greater than the average head drop from $1 \mathrm{~km}$ inland to the river $(0.14 \mathrm{~m})$. In the context of the highly transmissive sediments of the Hanford formation, this leads to a hydrologic system driven principally by changes in river stage. The large magnitude of these river-stage fluctuations and the occurrence of interannual high river-stage events can result in a significant component of flow through unsaturated porous media. Furthermore, the relatively high frequency of river-stage fluctuation results in riverbank storage during high stage followed by seepage out of the freshly exposed bank faces during low stage. Vadose zone flow and transport processes also affect the leaching and migration of uranium from contaminated sediments above the water table. Given these flow processes and concerns for transport through the vadose zone as well as the unconfined aquifer, the STOMP simulator (White and Oostrom 2000, 2004) was considered appropriate to address the multidimensional flow and transport through the saturated and unsaturated 300 Area sediments driven principally by river-stage fluctuations.

\subsection{Fluid and Aquifer Properties}

River and groundwater are assumed to be incompressible, with constant density and viscosity of water at $15^{\circ} \mathrm{C}$ : fluid density $=999.21 \mathrm{~kg} \mathrm{~m}^{-3}$ and absolute viscosity $=1.002 \mathrm{e}-3 \mathrm{~Pa}$. Preliminary tests comparing the compressible and incompressible cases showed minimal impact $(\sim 1 \%)$ to the calculated water flux to the river. These assumptions simplify the specification of hydraulic head values at the groundwater and river boundaries, allowing the direct use of the well 399-6-1 and river gage SWS-1 water level data for total hydraulic head at the boundaries.

Material hydraulic properties summarized in Table 3.1 are based primarily on a current characterization effort by Mark Rockhold and Paul Thorne of Pacific Northwest National Laboratory (PNNL). A total of six geologic units were represented, including basalt (Figure 3.1). Basalt properties are based on the Hanford Site-Wide Groundwater Flow Model (SGM) (Vermeul et al. 2003). There was no attempt to calibrate the flow model by adjusting parameter values, but simulated and observed heads at wells were compared to evaluate the model goodness-of-fit.

\subsection{Model Domain}

A 2-D, vertical, cross-sectional model domain was developed to capture the principal dynamics of flow to and from the river as well as the zone where groundwater and river water mix (Figure 3.2). In this case, an infinite dimension perpendicular to the cross-sectional plane is assumed that neglects any fluxes and/or spatial variations in that dimensional direction. All fluxes are therefore reported per a 1-m width of aquifer, riverbed surface, etc.

A computational grid for the 2-D model domain was constructed to honor the 1) geometry of the major hydrostratigraphic units, including surface topography; 2) boundaries where timedependent observations can be used directly, 3) flow and transport through the vadose zone in the 
Table 3.1. Key material properties for STOMP simulations. Vertical hydraulic conductivities were set to $10 \%$ of the lateral values. Longitudinal and transverse dispersivities for all formations were 0.1 and $0.01 \mathrm{~m}$, respectively. The molecular diffusion coefficient for both groundwater and river tracers was $7.94 \mathrm{E}-10 \mathrm{~m}^{2} \mathrm{~s}^{-1}$.

\begin{tabular}{lccccc}
\hline Material & $\begin{array}{c}K_{l}^{(\mathrm{a})} \\
\left(\mathrm{m} \mathrm{d}^{-1}\right)\end{array}$ & $\phi^{(\mathrm{b})}$ & $\begin{array}{c}\psi^{(\mathrm{c})} \\
(\mathrm{cm})\end{array}$ & $\lambda^{(\mathrm{d})}$ & $\theta_{r}^{(\mathrm{e})}$ \\
U1, Hanford gravel/sand & 1500 & 0.25 & 23.04 & 0.7465 & 0.1471 \\
U1, Hanford gravel/sand & $15000^{(\mathrm{f})}$ & 0.25 & 23.04 & 0.7465 & 0.1471 \\
U5, Ringold gravel/sand/silt (C/E) & 150 & 0.18 & 71.31 & 0.5193 & 0.1299 \\
U6, Ringold overbank mud & 0.01 & 0.18 & 71.31 & 0.5193 & 0.1299 \\
U7, Ringold gravel/sand/silt (B/D) & 43 & 0.18 & 71.31 & 0.5193 & 0.1299 \\
U8, Lower Ringold mud & $5 \mathrm{e}-5$ & 0.18 & 71.31 & 0.5193 & 0.1299 \\
Basalt & $5 \mathrm{e}-5$ & 0.18 & 71.31 & 0.5193 & 0.1299 \\
\hline
\end{tabular}
(a) Lateral hydraulic conductivity.
(b) Total and diffusive porosity.
(c) Entry head, minimum drainage capillary head.
(d) Pore size distribution parameter.
(e) Minimum saturation.
(f) High $K_{l}$ sensitivity case.

vicinity of known disposal facilities, 4) mixing processes at the vadose zone-aquifer interface, and 5) mixing processes at the aquifer-river interface.

The resulting grid encompassed a model domain of $1400 \mathrm{~m}$ lateral (west-east) and $62 \mathrm{~m}$ vertical represented by 88,910 grid cells (62,536 active). This included the 200 -m-wide west river channel and half of the island close to the Hanford shore. Variable grid spacing was used, with the finest resolution of 0.5 by $0.5 \mathrm{~m}$ specified in the hyporheic zone (Figure 3.3).

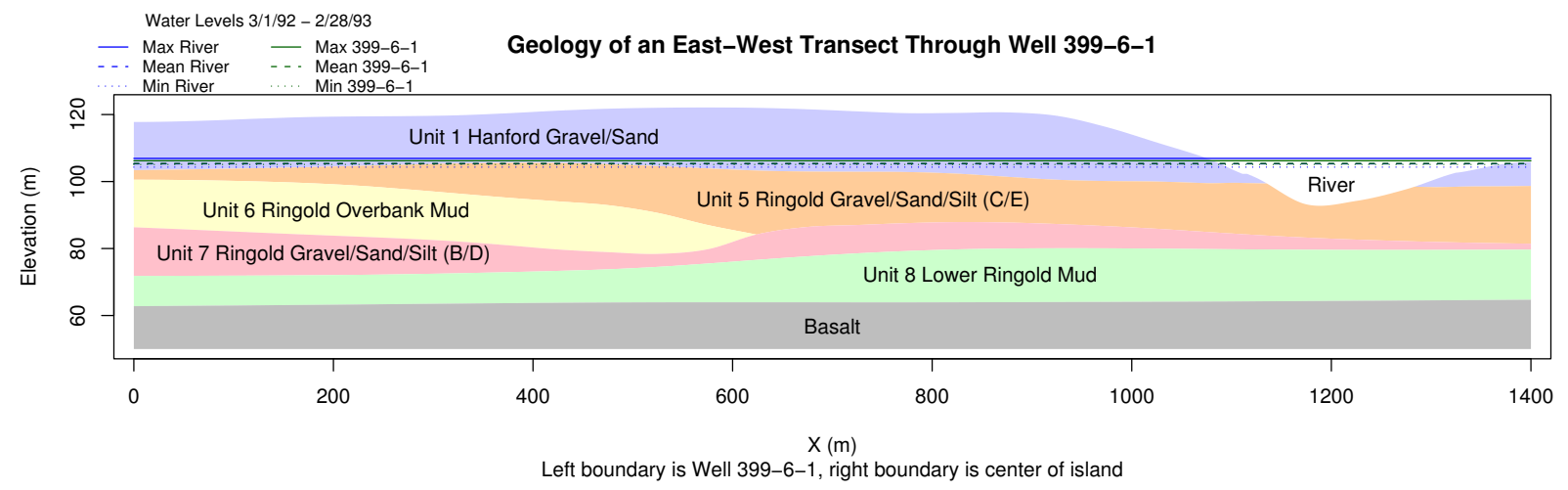

Figure 3.1. Geology for vertical 2D cross section, derived from EarthVision database. Domain shown was used for Grid 1. 


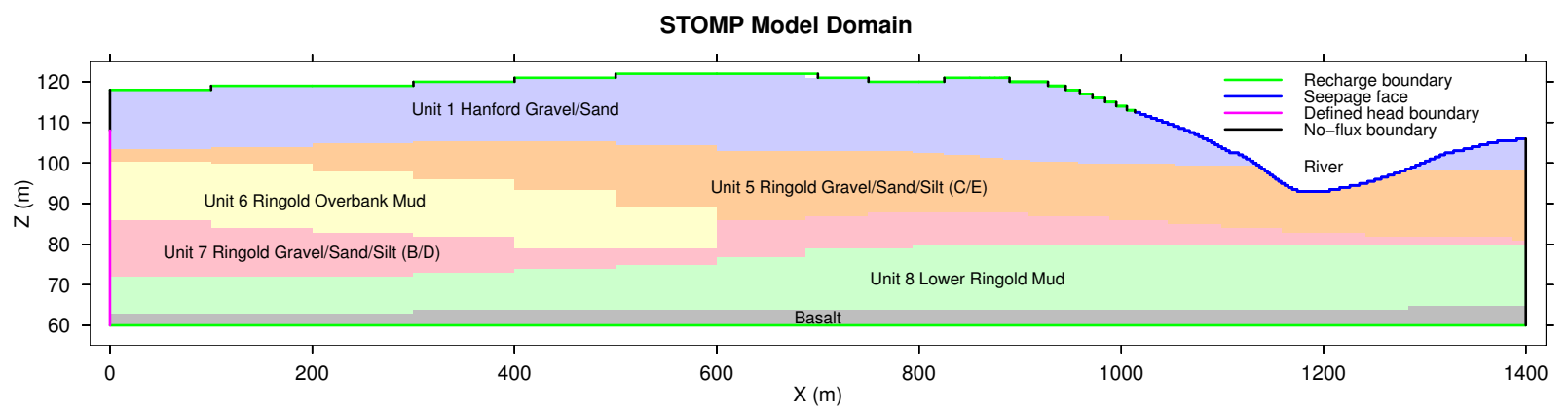

Figure 3.2. Discretized geology and STOMP boundary conditions, Grid 1.

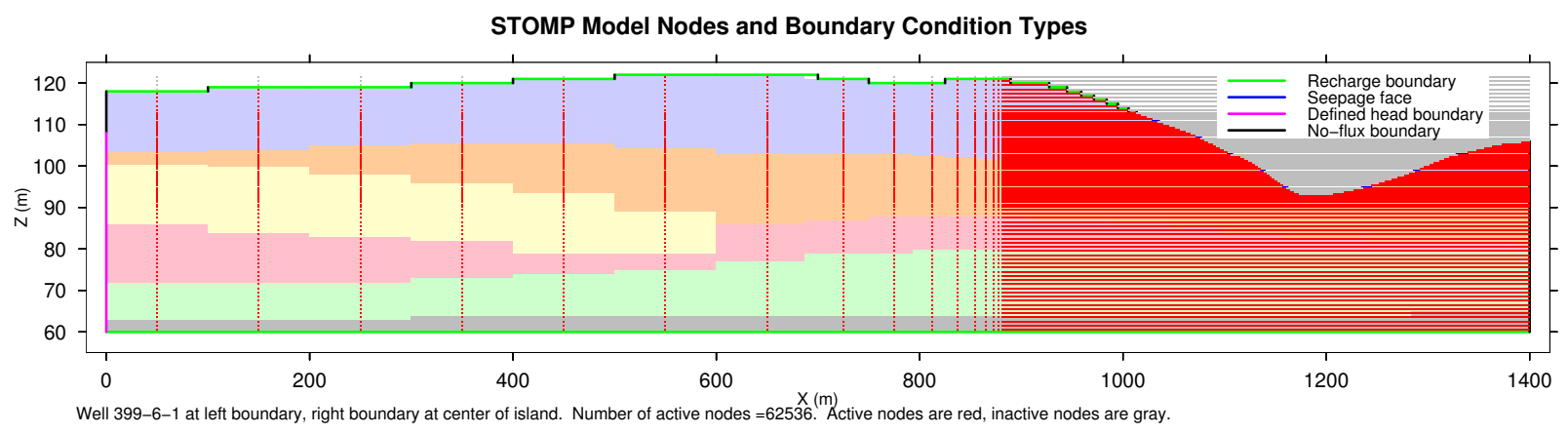

Figure 3.3. Nodes for Grid 1.

\subsection{Boundary Conditions}

Measured hourly water levels for the one-year period (3/1/92-2/28/93) in well 399-6-1 and river gage SWS-1 were the principal boundary conditions for the flow field. These were prescribed head-type boundary conditions at the west end of the domain and the riverbed surface (Figure 3.2), respectively. The interface between the river and the aquifer (both main shore and island), was simulated in STOMP as a dynamic seepage face where water can move in either direction if the node is submerged (i.e., has positive pressure from the river) or if the seepage face is exposed to air (i.e., release of bank storage).

Defined-flux boundary conditions at the top and bottom of the domain represented meteoric (surface) recharge and upward leakage from the basalt, respectively. Surface recharge of $60 \mathrm{~mm} \mathrm{y}^{-1}$ was based on a 23-year lysimeter dataset from the 300 Area (Gee et al. 2005). Upward recharge from the basalt aquifer was $0.9 \mathrm{~mm} \mathrm{y}^{-1}$ (Vermeul et al. 2003). The east boundary was a no-flux type and represented a groundwater divide at the center of the island (Figure 3.2).

Groundwater tracer concentration boundary conditions were set to unity at the west and bottom boundaries (groundwater inflow) and zero at the top boundary (meteoric recharge) and river. River water tracer concentration boundary conditions were set to 1.0 at the river and 0 at the other boundaries. River tracer moved into the aquifer from the river by both advection and diffusion 
and moved back into the river by advection only, because no concentration gradient to drive diffusion in that direction existed. Groundwater tracer moved only into the river and not from it into the aquifer because of the zero-concentration boundary condition at the riverbed, which is equivalent to assuming immediate and total dilution by the river of any groundwater constituents entering it.

\subsection{Initial Conditions}

Initial water level elevations and river tracer concentrations within the model domain were not known a priori. To attain a reasonably realistic initial flow and transport condition for the modeling test cases, the model was run with the same year of hourly boundary conditions repeated continuously. By the end of the fourth year, the model had attained a dynamic steady state where the simulated response was the same on an interannual basis (Figure 3.4) as determined from concentration time series at various locations. Following this model spinup, one more year was simulated to provide output for the reported test case results. The model was run in STOMP's regular transport mode, with Courant number not to exceed 0.25.

\subsection{Preliminary Results for Full Model Domain}

The initial simulation results for the specified model showed that in spite of the relatively thin saturated thickness of the U1 Hanford gravel/sand unit (approximately $5.7 \mathrm{~m}$ at the river shore), this zone of highly transmissive materials accounted for the highest flow velocities and volumetric flow (Figure 3.5). In contrast to the principal flow path of groundwater to the river through the U1 Hanford gravel/sand unit, the simulated flow in the basalt and Ringold mud units was predominantly vertical (upward) and had velocities more than four orders of magnitude smaller than the U1 Hanford and U5 Ringold C/E units. Groundwater velocities near the island were also small, for the most part. The net annual (eastward) water flux through a vertical plane below the river channel was only $2.25 \mathrm{~m}^{3}$, or 1.2 percent of the net flux to the river, and this occurred in units U5 and U7, the higher-permeability units above U8 and basalt.

\subsection{Reduced Model Domain}

The results from the initial simulation showed that some of the represented features (e.g., the basalt and Ringold mud units, the offshore island) were negligible contributors to the flow and transport behavior in the vadose zone aquifer river hydrologic system. Consequently, a smaller model domain was developed that resolves key features of the hydrologic system while providing computational efficiencies over the initial grid.

The updated Grid 2 excludes units U8 and basalt and the region east of the river channel center (Figure 3.6). Grid 2 had a domain of $1200 \mathrm{~m}$ lateral and $50 \mathrm{~m}$ vertical and contained 40,854 total nodes, of which 25,302 were active. Grid spacing, material properties, and control settings for running STOMP were the same as for Grid 1. Results discussed in the remainder of the report are from Grid 2 unless otherwise noted. 
Timeseries Results for Node 44330 ( $x=1075.25$ m, y=96.25 m)
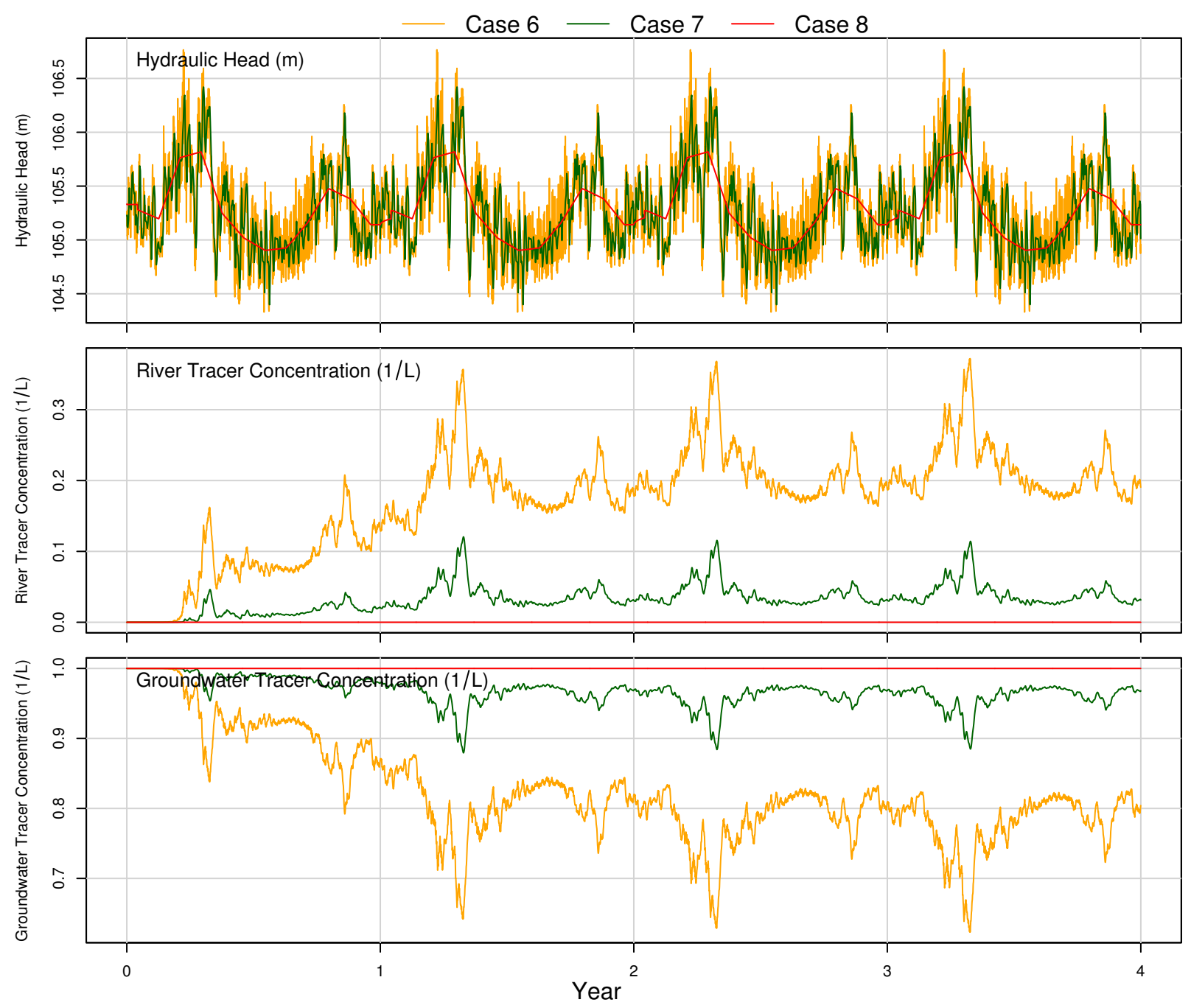

Figure 3.4. Spinup of model to interannual steady state. Four-year timeseries at a node approximately $23 \mathrm{~m}$ inland from the mean shoreline and $9 \mathrm{~m}$ below the mean water table, showing the spin-up from the initial state and attainment of dynamic (interannual) steady state in the last two years. This node is close enough to the river to experience significant diurnal change but far enough away to demonstrate that more than a year is required for the system to reach dynamic steady state from the initial conditions. 


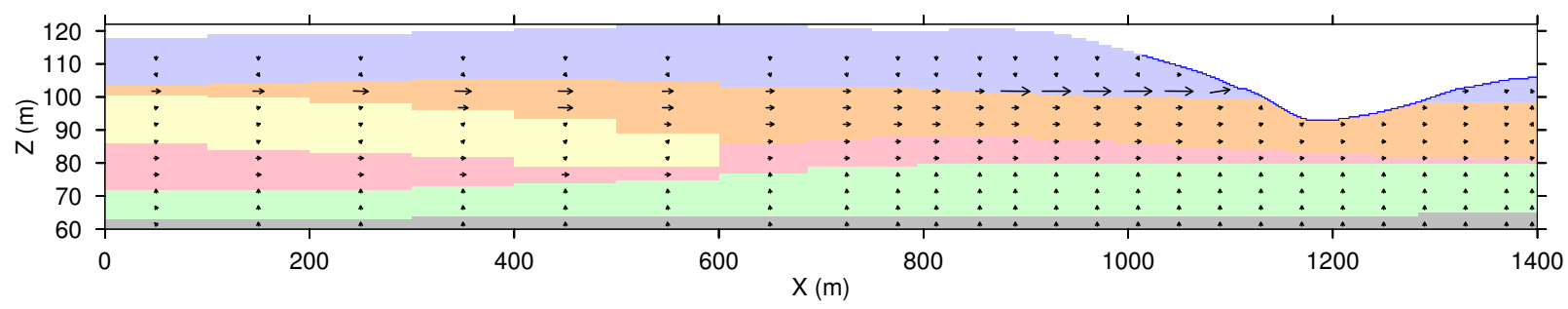

Figure 3.5. Darcy velocity vectors for steady state heads, nonuniform geology. This test case had steady-state boundary conditions (mean groundwater and river levels), and nonuniform hydraulic properties. Arrow shaft lengths are arithmetically scaled. Blue region is U1 Hanford gravel/sand. Grid 1.

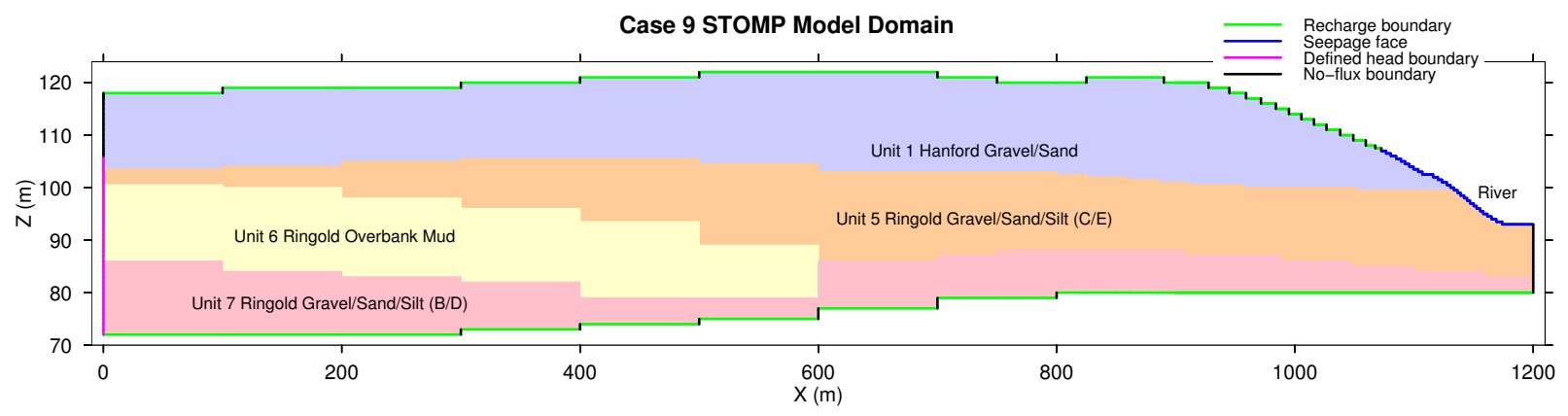

Figure 3.6. Discretized geology and model boundary conditions, Grid 2. Compared with Grid 1, the west and top boundaries are the same, but the bottom boundary is at the bottom of U7 and the east boundary is at the center of the river channel instead of the island.

\subsubsection{Cases}

For each test case, the model was run with three different schemes for temporal averaging of the water level data to investigate the effect of boundary condition timescale on the results. For the hourly boundary condition case, the hourly data were used directly. For the daily and monthly boundary condition cases, the hourly data for each period were averaged, and the mean was assigned to the midpoint of the period (for example, the mean value of groundwater head during the month of January was specified at day 15.5 of that month). The computational timestepping in STOMP was set at half-hourly for the hourly boundary condition case and hourly for the daily and monthly boundary condition cases. STOMP used linear interpolation to derive the boundary conditions at each timestep that fell between available input boundary conditions and used internal timestepping when needed to obtain solution during times of rapid change.

Three test cases were simulated: 1) base case, 2) lower river-stage datum ("low-river"), and 3) higher conductivity for the Hanford formation U1 gravel/sand unit ("high-K"). The low-river 
case was designed to test the sensitivity of the simulated flow and transport to a constant $11.9 \mathrm{~cm}$ decrement (the mean discrepancy between observed water levels in well 399-4-9 and river gage SWS-1) in the hourly river level boundary condition. The high-K case was designed to test the sensitivity of the simulated flow and transport to higher lateral hydraulic conductivities that have been interpreted from previous aquifer tests in the 300 Area Hanford formation. In this case, lateral hydraulic conductivity, $K_{l}$, in the Hanford formation U1 gravel/sand unit was increased by a factor of 10 to $15,000 \mathrm{~m} \mathrm{~d}^{-1}$.

Darcy's Law begins to lose validity in the range of Reynold's number $R_{e}=1-10$ (Bear 1972). A check on the applicability of Darcy's Law for the high-K case shows the threshold specific discharge is more than the maximum values simulated by STOMP [approximately $9 \times$ $\left.10^{-4} \mathrm{~m} \mathrm{~s}^{-1}\left(80 \mathrm{~m} \mathrm{~d}^{-1}\right)\right]$, indicating that Darcy's Law is still valid.

$R_{e}$ is the ratio of inertial to viscous forces during flow and is defined as

$$
R_{e}=\frac{\rho v d}{\mu}
$$

where

$$
\begin{aligned}
& \rho=\text { fluid density }\left(\mathrm{ML}^{-3}\right) \\
& v=\text { bulk velocity }\left(\text { specific discharge, } \mathrm{LT}^{-1}\right) \\
& d=\text { representative length dimension of the porous medium }(\mathrm{L}) \\
& \mu=\text { fluid viscosity }\left(\mathrm{ML}^{-1} \mathrm{~T}^{-1}\right)
\end{aligned}
$$

Applicability of Darcy's Law was checked by assuming $R_{e}=1, \rho=999 \mathrm{~kg} \mathrm{~m}^{-3}, d=1 \mathrm{~mm}$ and $\mu=$ $0.00115 \mathrm{~N} \mathrm{~s} \mathrm{~m}^{-2}$, which leads to $v=1.1 \times 10^{-3} \mathrm{~m} \mathrm{~s}^{-1}$.

\subsubsection{Preliminary Results}

Hydraulic head contours at the end of the simulation for the Grid 2 base case shows the vertical gradients at the top and bottom of the model domain and the riverward lateral gradient (Figure 3.7).

Wells along and near the model transect provided head data that were used to check the adequacy of the simulations. Four wells are within $100 \mathrm{~m}$ of the transect: 399-3-10, 399-3-11, 399-4-11, and 399-4-9; the others selected for comparison are within $300 \mathrm{~m}$ of the transect (Figures 1.1, 2.7a, 2.7b). To make the comparison as relevant as possible, simulated heads were linearly interpolated to the projected well locations along the transect, and when being compared with manually measured heads were also interpolated in time. Simulated, manually measured, and transducer-measured heads are plotted together for the base case in Figures 2.7a and 2.7b, and for the low-river case in Figures 3.8a and 3.8b. Well 399-4-9 was the only close-in well with hourly transducer data, and on average the simulated heads were $11.9 \mathrm{~cm}$ greater than the data. Differences between simulated heads and measured heads at the more distant wells were more variable but were also positive on average. Overall, however, simulated heads matched observed 


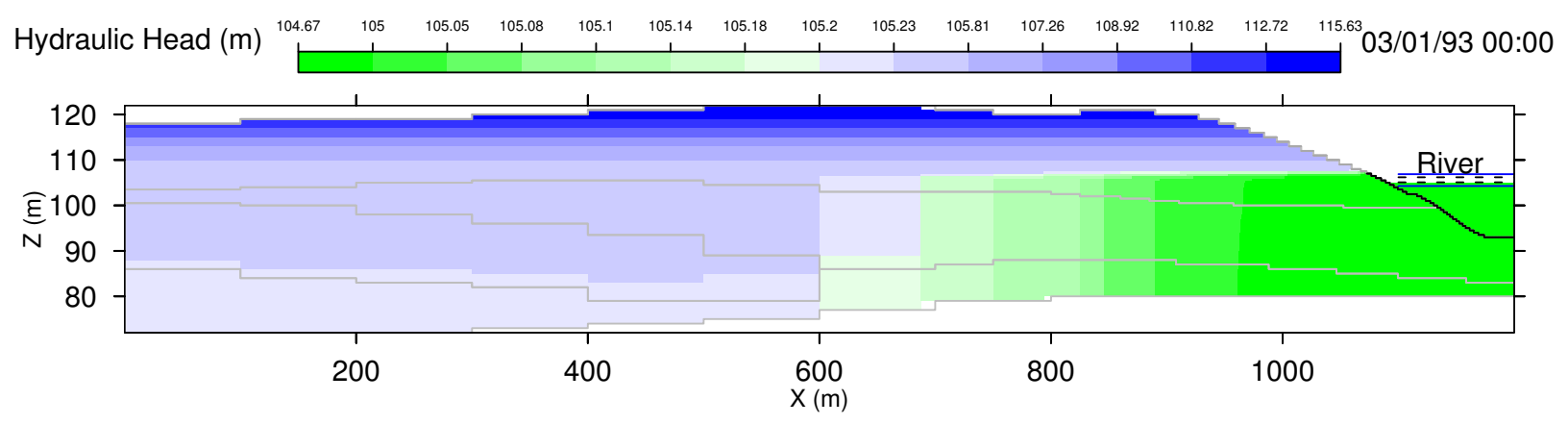

Figure 3.7. Hydraulic head at end of simulation (3/1/93), hourly boundary conditions, Grid 2 base case.

heads reasonably well and indicate that the model had meaningful predictive power. The match was better in the low-river case, as indicated graphically in the plots and in lower calculated mean absolute errors and greater efficiency (Table 3.2; see Appendix $\mathbf{C}$ for definitions of goodness-offit statistics). The relatively good match between simulated and observed heads in the absence of any model calibration reflects the importance of the boundary conditions and the ease with which they are conveyed in the high-permeability U1 Hanford gravel/sand unit.

Table 3.2. Model goodness-of-fit statistics indicating degree of agreement between observed and simulated heads. Smaller MAE and larger $\mathrm{E}_{1}$ indicate better fit. All locations were at some distance from the model transect, and simulated heads were linearly interpolated to the projected locations along the transect. Simulated heads used for comparing with manual measurements were also interpolated in time.

\begin{tabular}{|c|c|c|c|c|}
\hline Well & Data Source $^{(a)}$ & $\mathrm{n}^{(\mathrm{b})}$ & $\mathrm{MAE}^{(\mathrm{c})}$ & $\mathrm{E}_{1}{ }^{(\mathrm{c})}$ \\
\hline \multicolumn{5}{|c|}{ Base case } \\
\hline $399-4-9$ & EDR & 8760 & 0.123 & 0.540 \\
\hline $399-3-12$ & EDR & 8759 & 0.092 & 0.644 \\
\hline $399-4-1$ & EDR & 8759 & 0.067 & 0.737 \\
\hline All wells & HEIS & 64 & 0.149 & 0.500 \\
\hline \multicolumn{5}{|c|}{ Low River case } \\
\hline $399-4-9$ & EDR & 8760 & 0.086 & 0.678 \\
\hline $399-3-12$ & EDR & 8759 & 0.052 & 0.801 \\
\hline $399-4-1$ & EDR & 8759 & 0.066 & 0.740 \\
\hline All wells & HEIS & 64 & 0.105 & 0.649 \\
\hline
\end{tabular}

(a) $\mathrm{EDR}=$ Edrington hourly transducer measurements, HEIS = sporadic manual measurements

(b) $\mathrm{n}=$ number of data points

(c) $\mathrm{MAE}=$ mean absolute error $(\mathrm{m}), \mathrm{E}_{1}=$ first-degree efficiency (see Appendix C) 


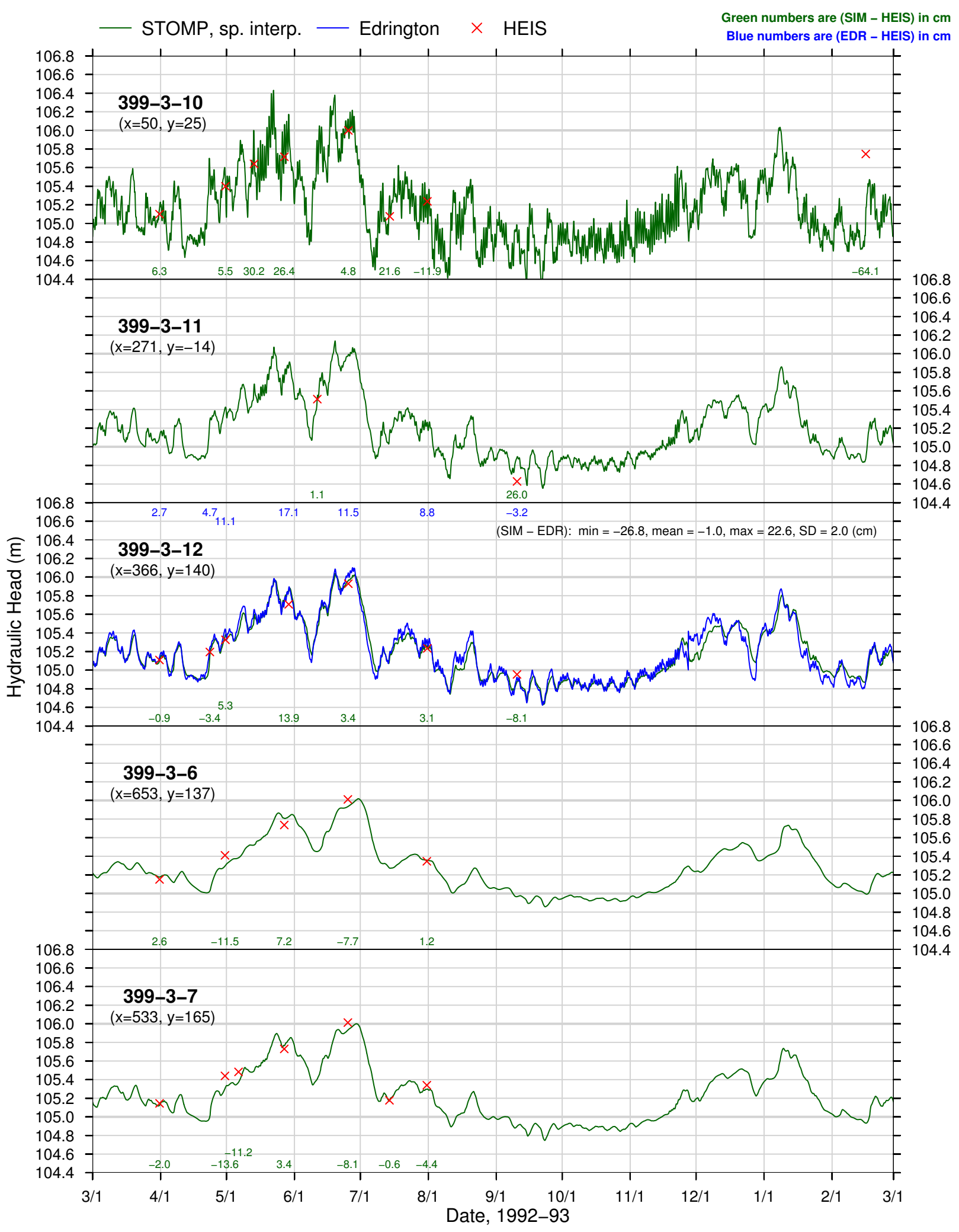

Figure 3.8a. Simulated and observed heads for selected wells, low-river case. SIM = simulated, EDR = hourly data, HEIS = manual data; $x$ and $y$ below well number are easting distance from shoreline and distance in meters north (south if negative) of cross-section line, respectively. 


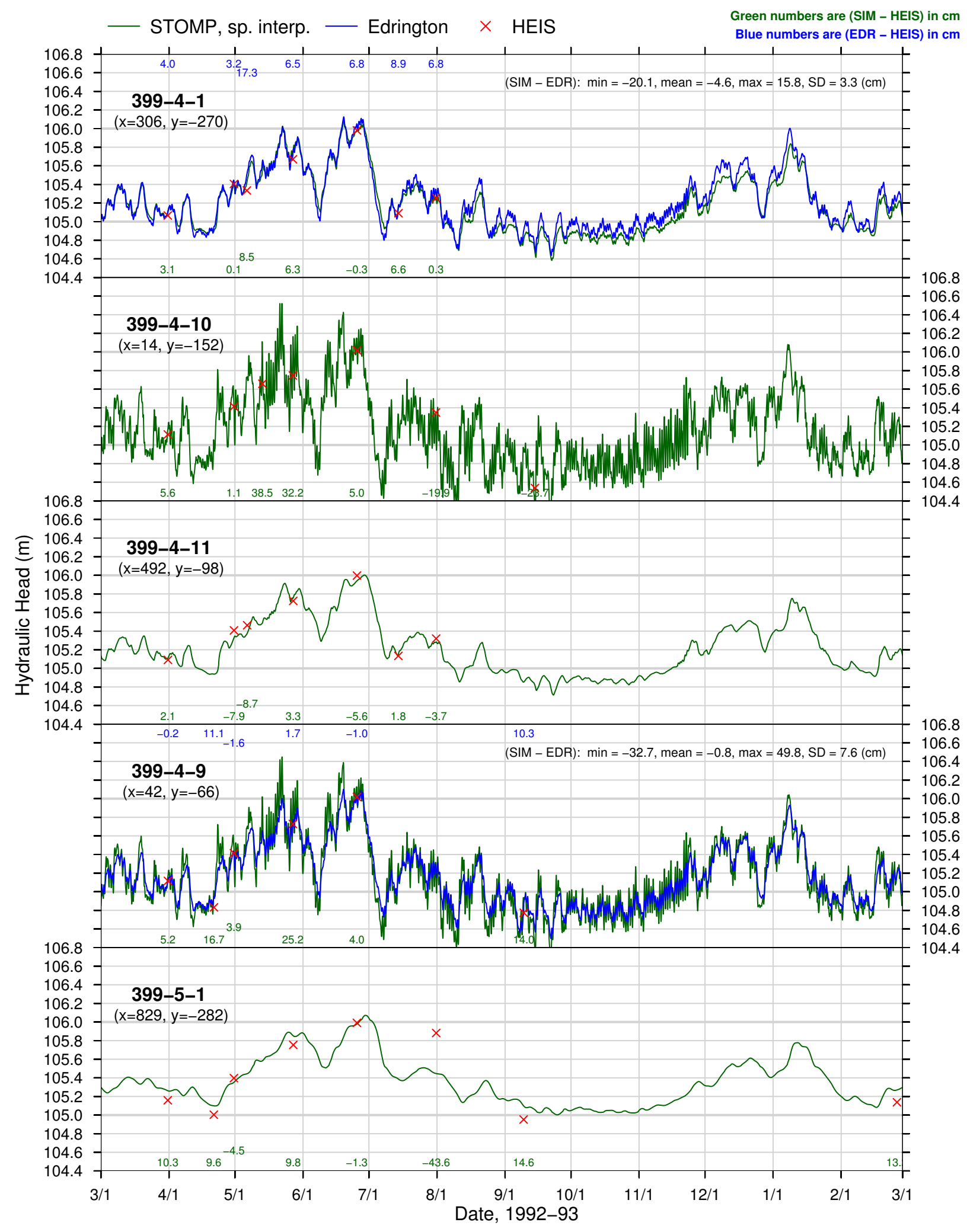

Figure 3.8b. Simulated and observed heads for selected wells, low-river case. SIM = simulated, EDR = hourly data, HEIS = manual data; $x$ and $y$ below well number are easting distance from shoreline and distance in meters north (south if negative) of cross-section line, respectively. 


\subsection{Model Results}

The flow and transport behavior simulated in the 300 Area aquifer was driven primarily by the temporal variation in the Columbia River stage. The relatively high-frequency river-stage changes associated with diurnal release patterns at the dams resulted in large but short-lived changes in groundwater flow, which generated significant mixing of the river and groundwater tracers. This was the essential mechanism for creating a fully developed mixing zone in the simulations. Although the size and position of the mixing zone did not change significantly on a diurnal basis, it did change in response to seasonal trends in river stage. The largest mixing zones occurred with the river-stage peaks in May-June and December-January, and the smallest mixing zone occurred in September when river stage was relatively low.

\subsection{Base Case}

Forcing the model with hourly boundary conditions resulted in frequent direction and magnitude changes of water flux across the riverbed (Figure 4.1). In comparison, the velocity fluctuations resulting from averaging the hourly boundary conditions over a day were considerably damped and for the monthly averaged boundary conditions were nonexistent. A similar pattern held for the river tracer, which could enter the aquifer and then return to the river later. By design, the groundwater tracer could only move into the river because tracer storage in the river was not simulated and the groundwater tracer boundary condition at the riverbed surface was concentration $=0$. When the river-stage boundary condition was aggregated to daily or monthly averages, much of the flow system dynamics were lost. Although cumulative net fluxes at the end of the simulated year were not very different for the hourly, daily, and monthly timescales, the shortterm fluxes at various times during the year were different, and aggregation to longer timescales reduced the degree of water and constituent exchange between river and aquifer. This is illustrated by the smaller extent of the mixing zone in the monthly boundary condition case than for the the hourly boundary condition case (Figure 4.2).

Total inflows, outflows, and tracer fluxes for the simulated year are given in Table 4.1. The difference between water inflows and outflows was essentially zero for all cases, indicating no change in storage and successful model spinup. Net water flow to the river (per $1 \mathrm{~m}$ width of shoreline) was $159 \mathrm{~m}^{3} \mathrm{y}^{-1}$ in the base case. The cumulative exchange or total flow back and forth across the riverbed was 34 times the net flux to the river, indicating a great deal of flow reversal across the riverbed.

A closer look at a typical day in November, a month with very regular diurnal changes in water level (Figure 2.2), further illustrates the water flow dynamics. River stage on 11/22/92 changed $1.2 \mathrm{~m}$, and water level in well 399-6-1 was essentially constant (Figure 4.3). The simulated velocity fields show a high degree of responsiveness to these river-stage fluctuations, and the highest velocities were in the Hanford Unit sediments (Figures 4.4 and 4.5). Within $300 \mathrm{~m}$ of the river, where all principal disposal facilities are situated, magnitude and direction changes in velocity closely followed river stage. At $300 \mathrm{~m}$ from the river, maximum hourly Darcy velocities were $1.5 \mathrm{~m} \mathrm{~d}^{-1}$ away from the river and $0.6 \mathrm{~m} \mathrm{~d}^{-1}$ towards the river in the $\mathrm{U} 1 \mathrm{Hanford}$ gravel/sand unit (velocities were not symmetric because the river-stage cycle was not symmetric). Corre- 
Comparison of Fluxes for Different Boundary Condition Timescales - Hourly Boundary Condition — Daily Boundary Condition — Monthly Boundary Condition
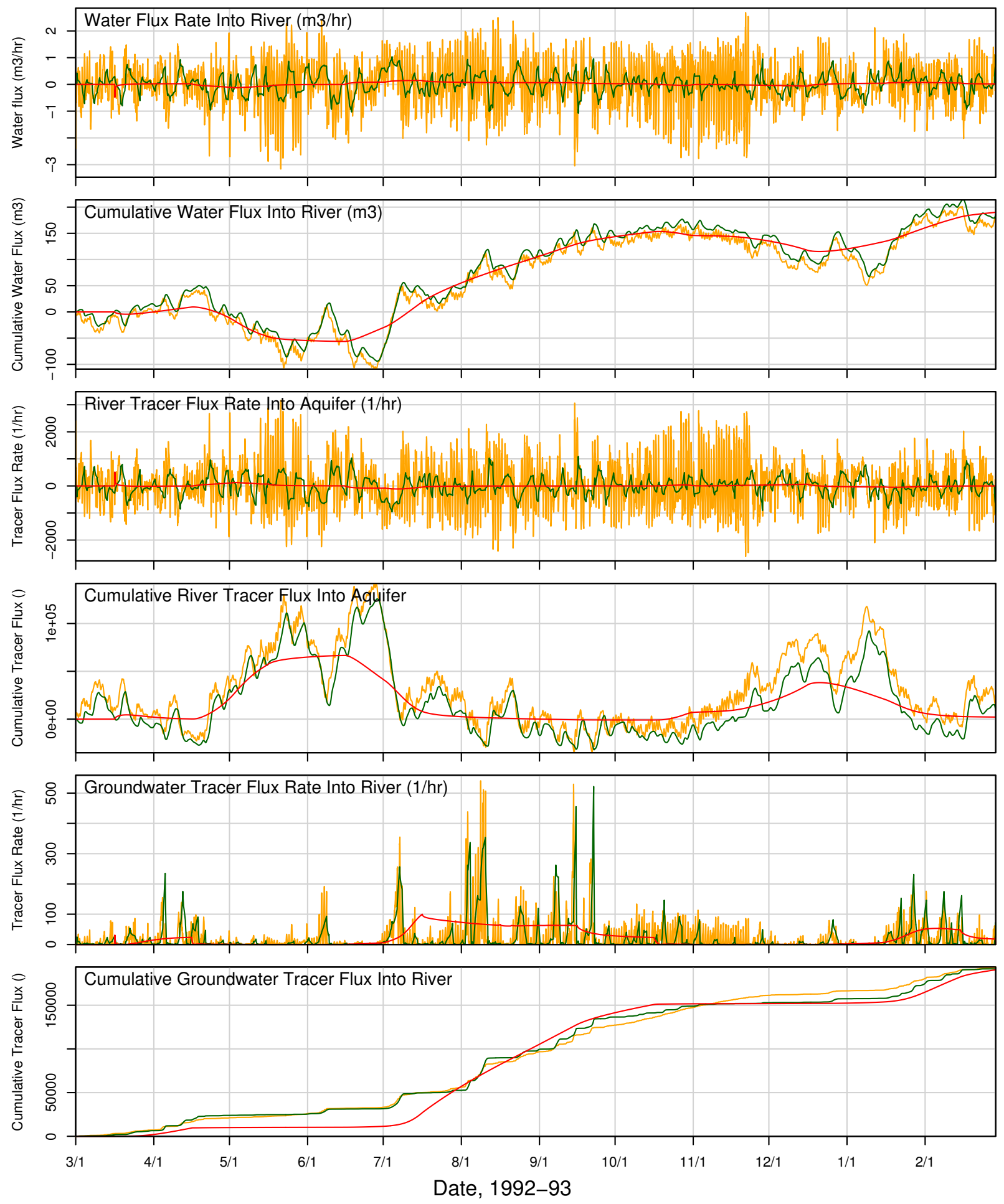

Figure 4.1. Comparison of simulated fluxes for hourly, daily, monthly boundary conditions. Grid 1 base case. 
(a)

River Tracer Concentration (1/L)

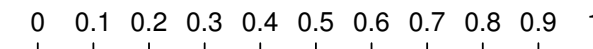

03/01/93 00:00

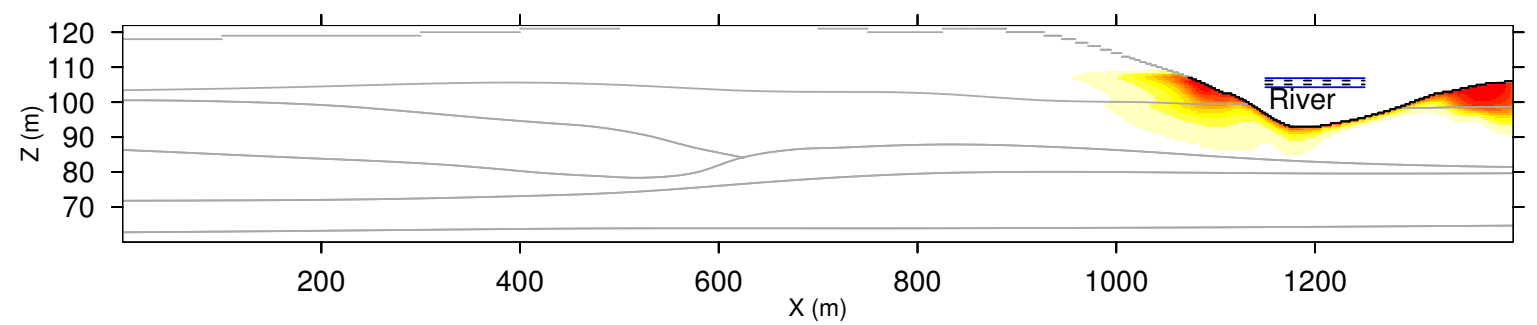

River Tracer Concentration (1/L)

$\begin{array}{lllllllllll}0 & 0.1 & 0.2 & 0.3 & 0.4 & 0.5 & 0.6 & 0.7 & 0.8 & 0.9 & 1\end{array}$

03/01/93 00:00

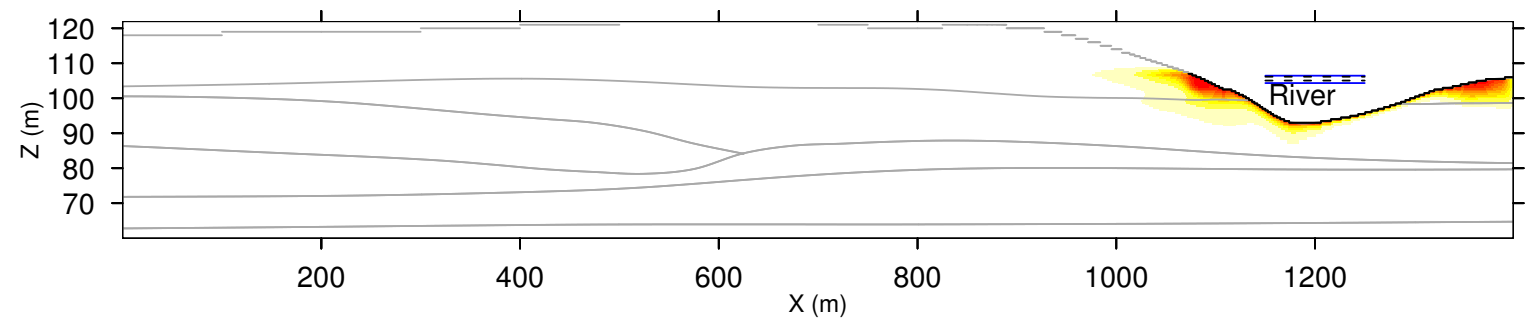

(b)

(c)

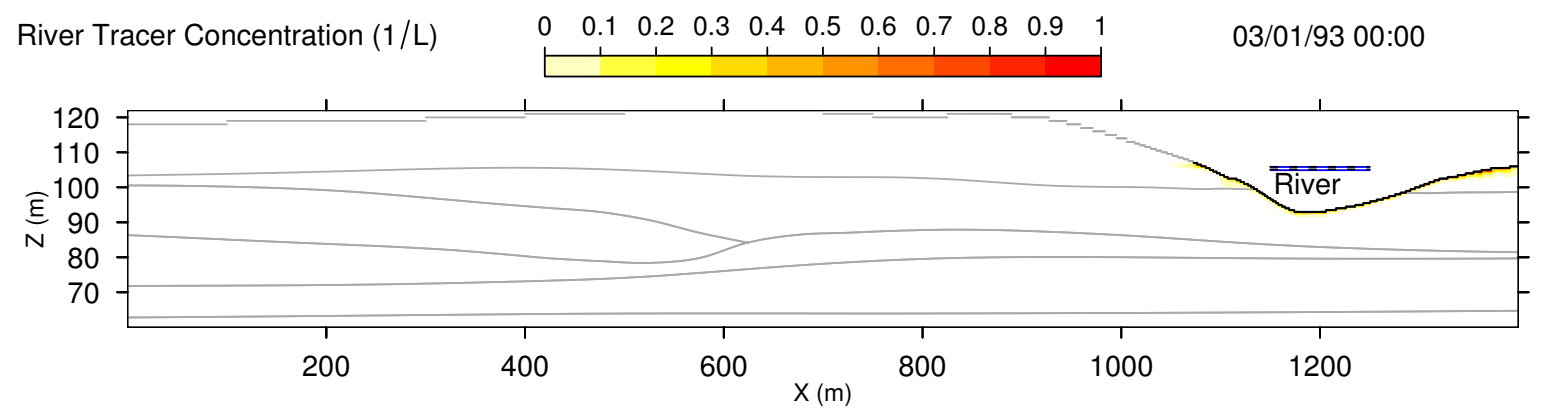

Figure 4.2. River water tracer concentration at end of simulation (3/1/93). Grid 1 boundary conditions are: (a) hourly, (b) daily, (c) monthly. 
Table 4.1. Simulated annual fluxes for all cases, Grid 2. Meteoric recharge was $64.3 \mathrm{~m}^{3} \mathrm{y}^{-1}$, and upward recharge from basalt was $1.08 \mathrm{~m}^{3} \mathrm{y}^{-1}$ per meter width for all cases. Fluxes are given as $\mathrm{m}^{3} \mathrm{y}^{-1}$ for water and unitless mass for tracers. Net flux is the difference between inflow and outflow. Cumulative flux is the sum of the absolute values of inflow and outflow, or $\mid$ inflow $|+|$ outflow $\mid$.

\begin{tabular}{lc}
\hline \multicolumn{1}{c}{ Bype } & $\begin{array}{c}\text { Flux } \\
\left(\mathrm{m}^{3} \mathrm{y}^{-1}\right)\end{array}$ \\
\hline \multicolumn{2}{c}{ Base case } \\
Groundwater inflow, west boundary & 94.1 \\
Net water flux to river & 159.5 \\
Cumulative water flux to/from river & 5392 \\
\hline \multicolumn{2}{c}{$\quad$ High-K case } \\
Groundwater inflow, west boundary \\
Net water flux to river \\
Cumulative water flux to/from river \\
\hline \multicolumn{2}{c}{225.9} \\
Groundwater inflow, west boundary \\
Net water flux to river \\
Cumulative water flux to/from river
\end{tabular}

sponding pore velocities in U1 (porosity $=0.25$ ) were $6 \mathrm{~m} \mathrm{~d}^{-1}$ and $2.4 \mathrm{~m} \mathrm{~d}^{-1}$.

Although these changes in groundwater flux were large, their lack of persistence meant that water moved only a few meters in a given direction before reversing in a typical diurnal cycle. As a result, the mixing zones for the tracers did not change much over the course of a day. For example, the portion of the model domain area having river tracer concentration greater than 0.5 ranged only between 14.4 and 17.1 percent during 11/22/92. However, seasonal changes in average water level were persistent enough to noticeably affect the mixing zone (Figure 4.6). The portion of the model domain area having river tracer concentration greater than 0.5 ranges between 7.2 and 25.5 percent in these monthly snapshots over the course of the year. The 0.2 concentration contour of the river tracer plume reached $170 \mathrm{~m}$ inland during the high river-stage months of January and June, but only $70 \mathrm{~m}$ inland during the low river-stage month of September. The fluctuations are noticeably greater in the saturated U1 zone; in the vadose zone and in the U5 unit, concentrations change more slowly. Concentrations in the vadose zone at least $20 \mathrm{~m}$ from the river tend to be greater than in the saturated zone below it during the low river-stage periods of February-April and July-October.

\subsection{Low-river Case}

Simulated hourly flux rates and cumulative net flux of water and the two tracers across the riverbed for the base and low-river cases are shown in Figure 4.7. Although hourly flux rates 


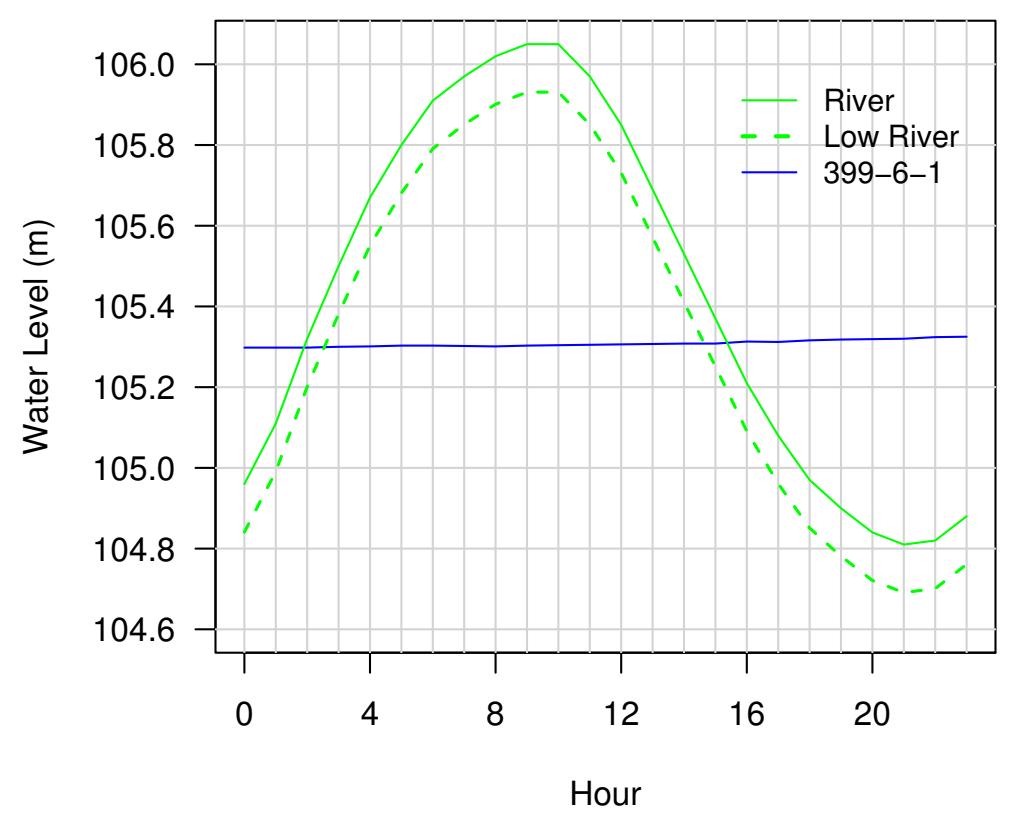

Figure 4.3. Diurnal cycle of river levels on 11/22/92. "Low river" is sensitivity case where all river levels were lowered $11.9 \mathrm{~cm}$.

are similar in both cases, the steeper long-term average gradient in the low-river case results in 1.8 times more water entering the river. Total inflows, outflows, and tracer fluxes for the simulated year are given in Table 4.1. Net water flow to the river was $291 \mathrm{~m}^{3} \mathrm{y}^{-1}$, and cumulative exchange or total flow back and forth across the riverbed was 18 times greater than this in the low-river case.

Concentration contours of the river and groundwater tracers at the end of the simulation for the base and low-river cases in Figures 4.8 and 4.9 indicate that lowering the river head boundary condition resulted in a somewhat smaller mixing zone, though even in that case the river tracer plume extends more than $100 \mathrm{~m}$ from the mean shoreline. The groundwater tracer concentrations in the vadose zone reflect the dilution from the initial condition of unity by the constant influx of meteoric recharge having a concentration of zero (Figure 4.9).

\subsection{High-K Case}

Simulated fluxes for the base and high hydraulic conductivity cases are shown in Figure 4.10. The high-K case has diurnal fluctuations of water and river tracer flux that are up to three times larger than the base case, and seasonally there is much more river tracer mass in the aquifer. The high conductivity case had velocities 10 times greater than the base case but, like the base case, the magnitude and direction of groundwater velocities were typically not sustained at similar levels or directions for more than a few hours in this zone. Net water flow to the river was $191 \mathrm{~m}^{3} \mathrm{y}^{-1}$ in the high-K case, or $19 \%$ greater than in the base case. The cumulative exchange or total flow back and forth across the riverbed was 80 times greater than net flow in the high-K case. In the high-K case, the river tracer plume extends almost $500 \mathrm{~m}$ inland (Figures 4.8 and 4.9), compared to just $150 \mathrm{~m}$ in the base case at the end of the simulated year. Sea- 


\section{X-Direction Darcy Velocity (m/d)}

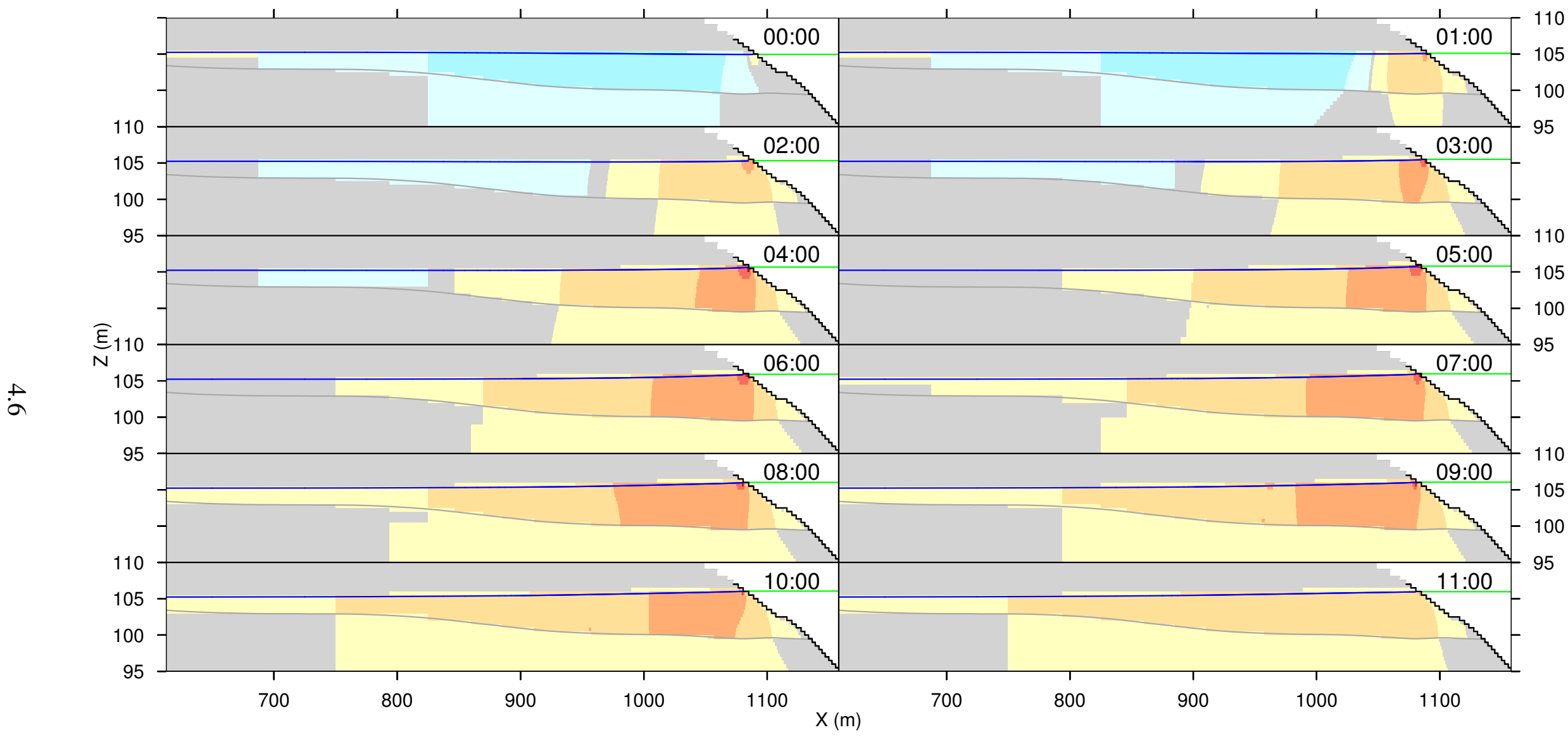

Figure 4.4. Base case diurnal-cycle groundwater velocities, 11/22/92 00:00-11:00. Velocities are hourly x-direction Darcy velocities. Region shown is the shallow, near-shore area. Blue line is water table, green line is river level, gray line is contact between Hanford and Ringold Formations, and black line is seepage face (riverbed). 


\section{X-Direction Darcy Velocity (m/d)}

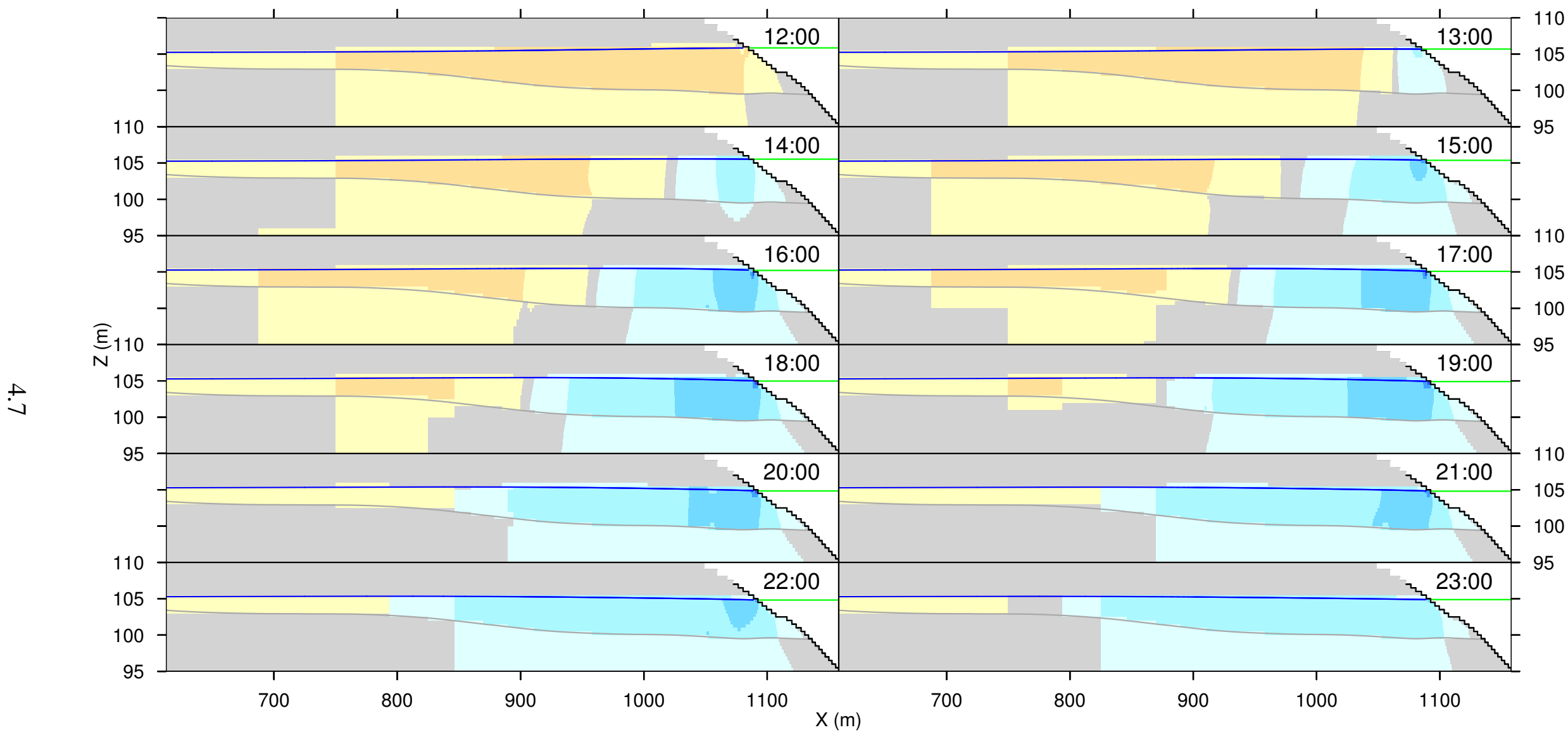

Figure 4.5. Base case diurnal-cycle groundwater velocities, 11/22/92 12:00-23:00. Velocities are hourly x-direction Darcy velocities. Region shown is the shallow, near-shore area. Blue line is water table, green line is river level, gray line is contact between Hanford and Ringold Formations, and black line is seepage face. 
River Tracer Conc. (1/L)

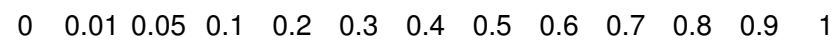

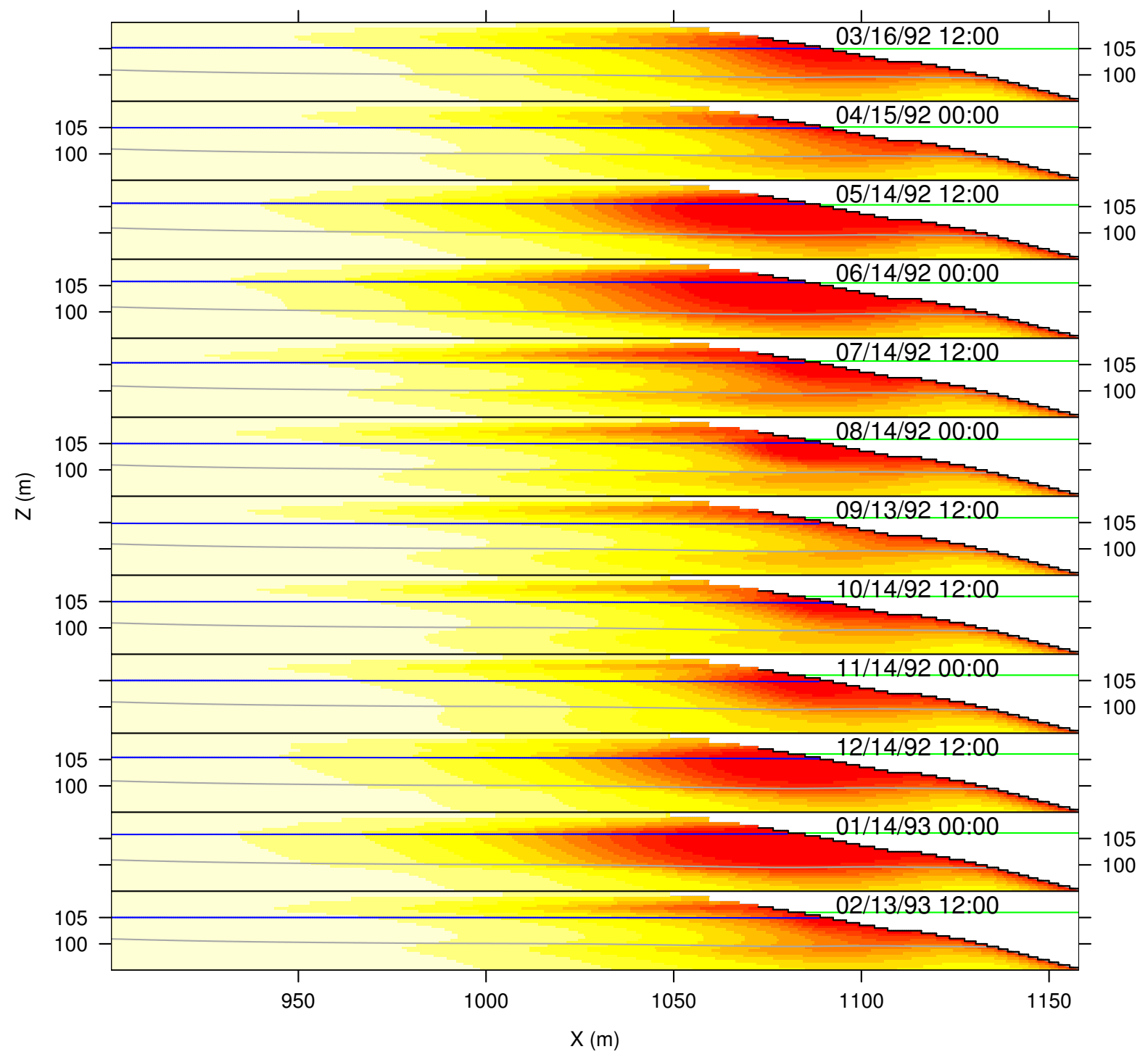

Figure 4.6. Base case monthly river tracer concentration contours. Mixing zone expanded and contracted in response to seasonal changes in river stage. Green line is river stage, blue line is water table, gray line is U1-U5 contact. 
Fluxes for Different River Boundary Conditions, Cumulative as Net

- Base case Low-river case
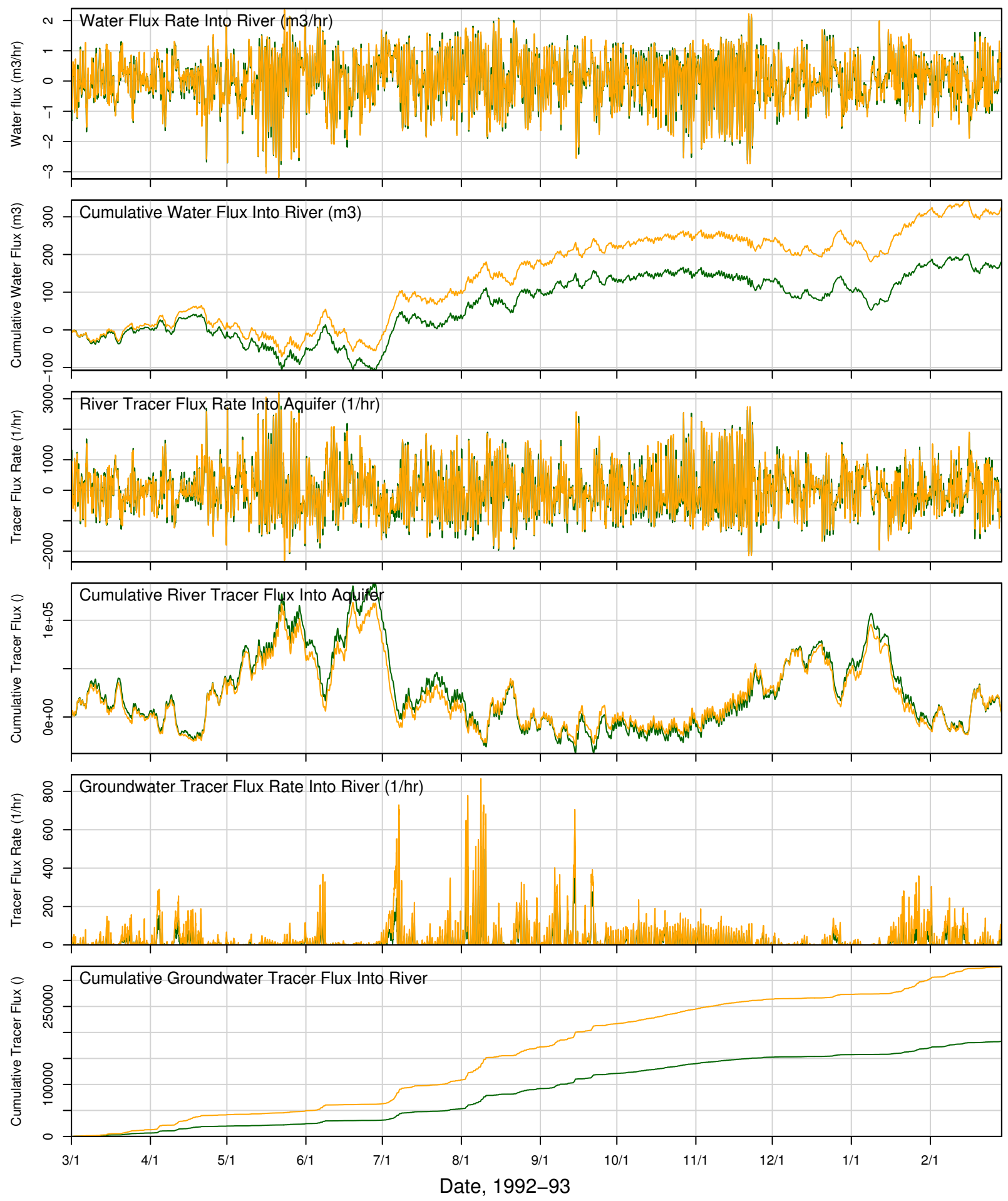

Figure 4.7. Comparison of simulated fluxes for base and low-river cases. Cumulative fluxes are the net of flow into and out of the river (Grid 2). 
(a)

River Tracer Concentration (1/L)

$\begin{array}{lllllllllll}0 & 0.1 & 0.2 & 0.3 & 0.4 & 0.5 & 0.6 & 0.7 & 0.8 & 0.9 & 1\end{array}$

03/01/93 00:00

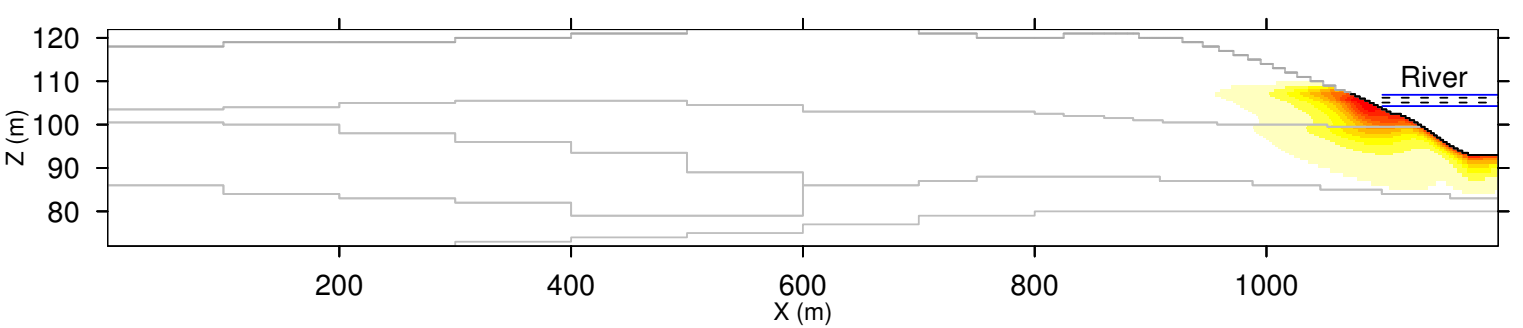

River Tracer Concentration (1/L)

$\begin{array}{lllllllllll}0 & 0.1 & 0.2 & 0.3 & 0.4 & 0.5 & 0.6 & 0.7 & 0.8 & 0.9 & 1\end{array}$

03/01/93 00:00

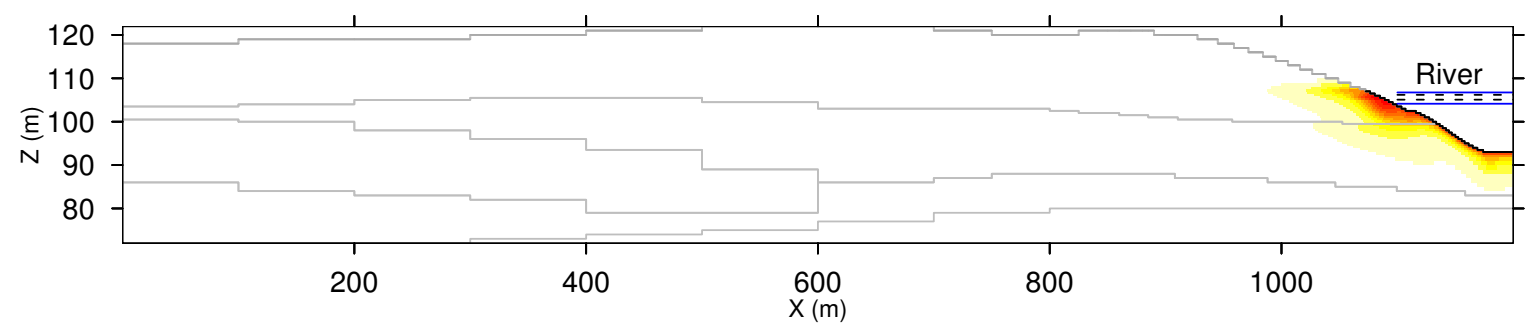

(b)

(c)

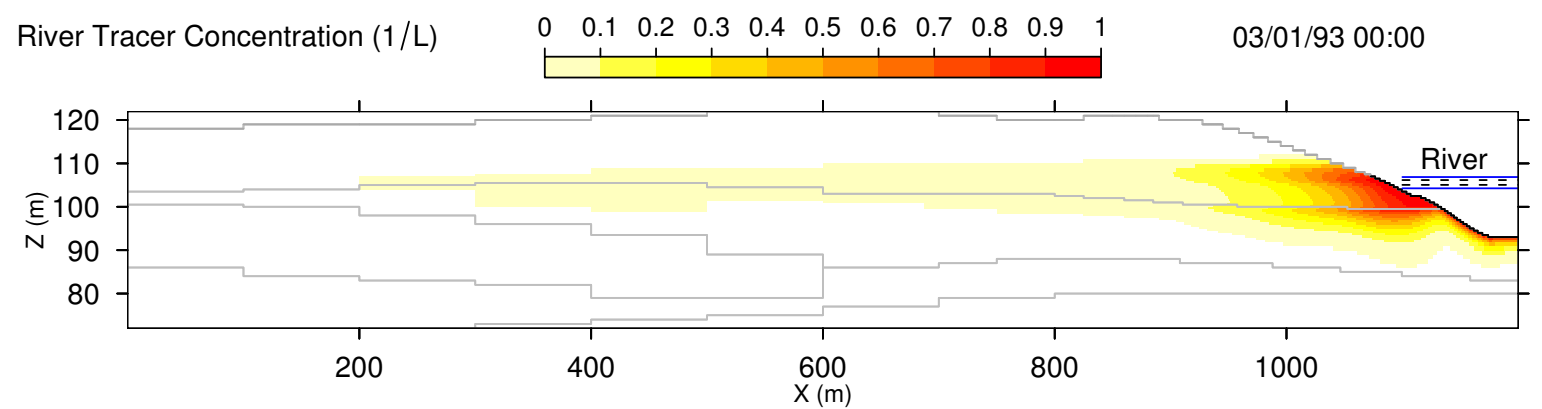

Figure 4.8. River tracer concentration at end of simulation (3/1/93). Simulation used Grid 2 and hourly boundary conditions for (a) base case; (b) low-river case; and (c) high-K case. 
(a)

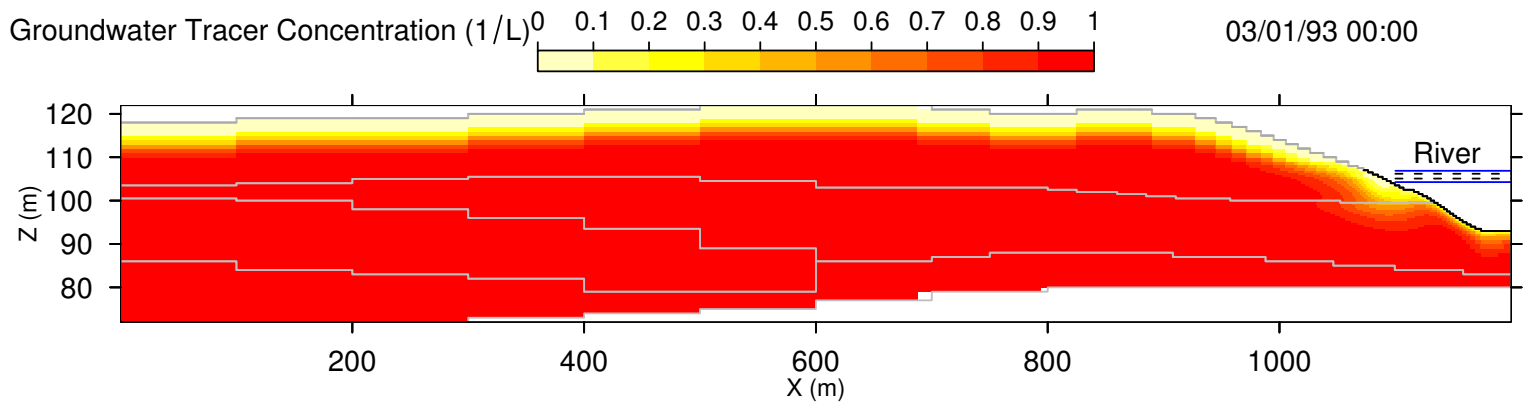

Groundwater Tracer Concentration (1/L) $\begin{array}{llllllllllllll}0 & 0.1 & 0.2 & 0.3 & 0.4 & 0.5 & 0.6 & 0.7 & 0.8 & 0.9 & 1 & 03 / 01 / 93 & 00: 00\end{array}$

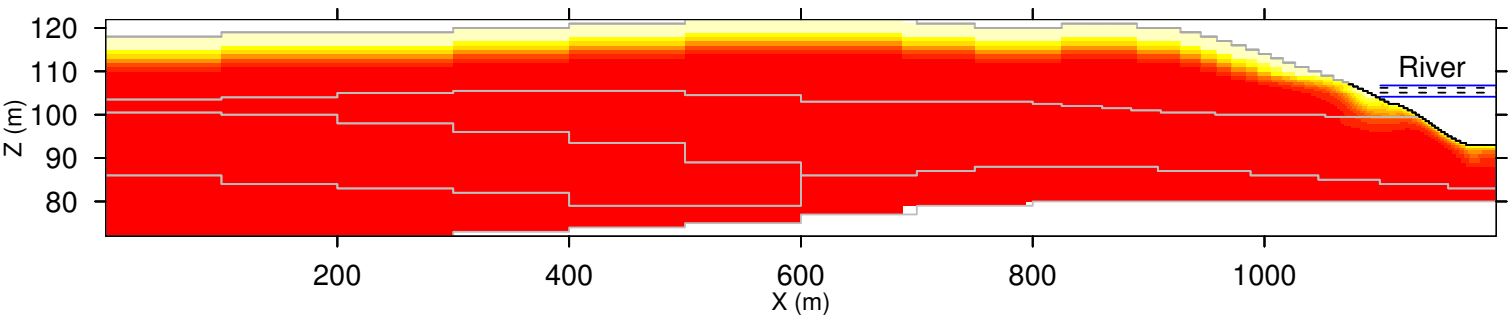

(b)
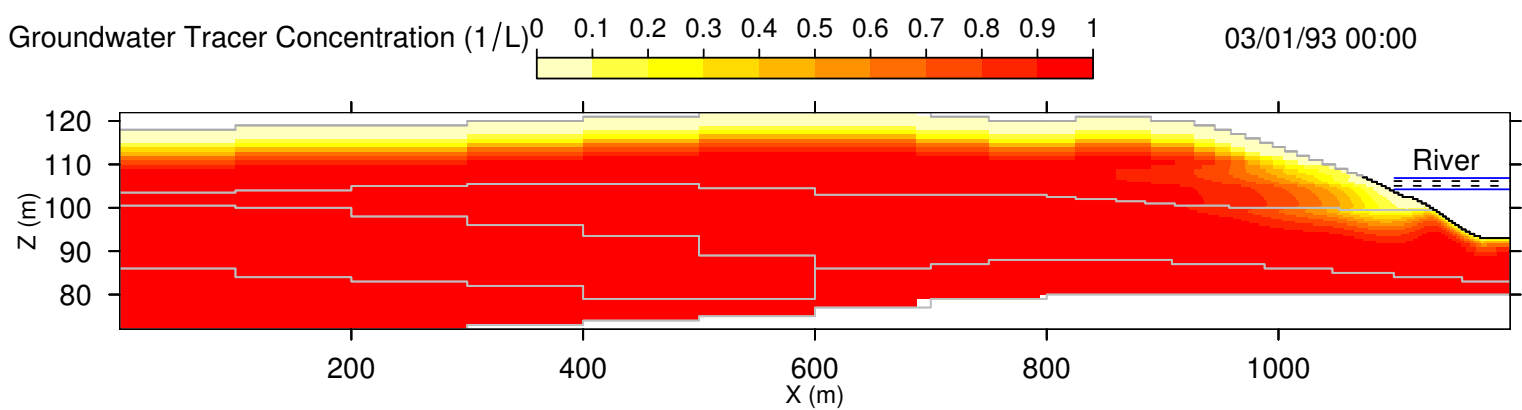

(c)

Figure 4.9. Groundwater tracer concentration at end of simulation (3/1/93). Simulation used Grid 2 and hourly boundary conditions for (a) base case; (b) low-river case; and (c) high-K case. 
Fluxes for Different Hydraulic Conductivities, Cumulative as Net
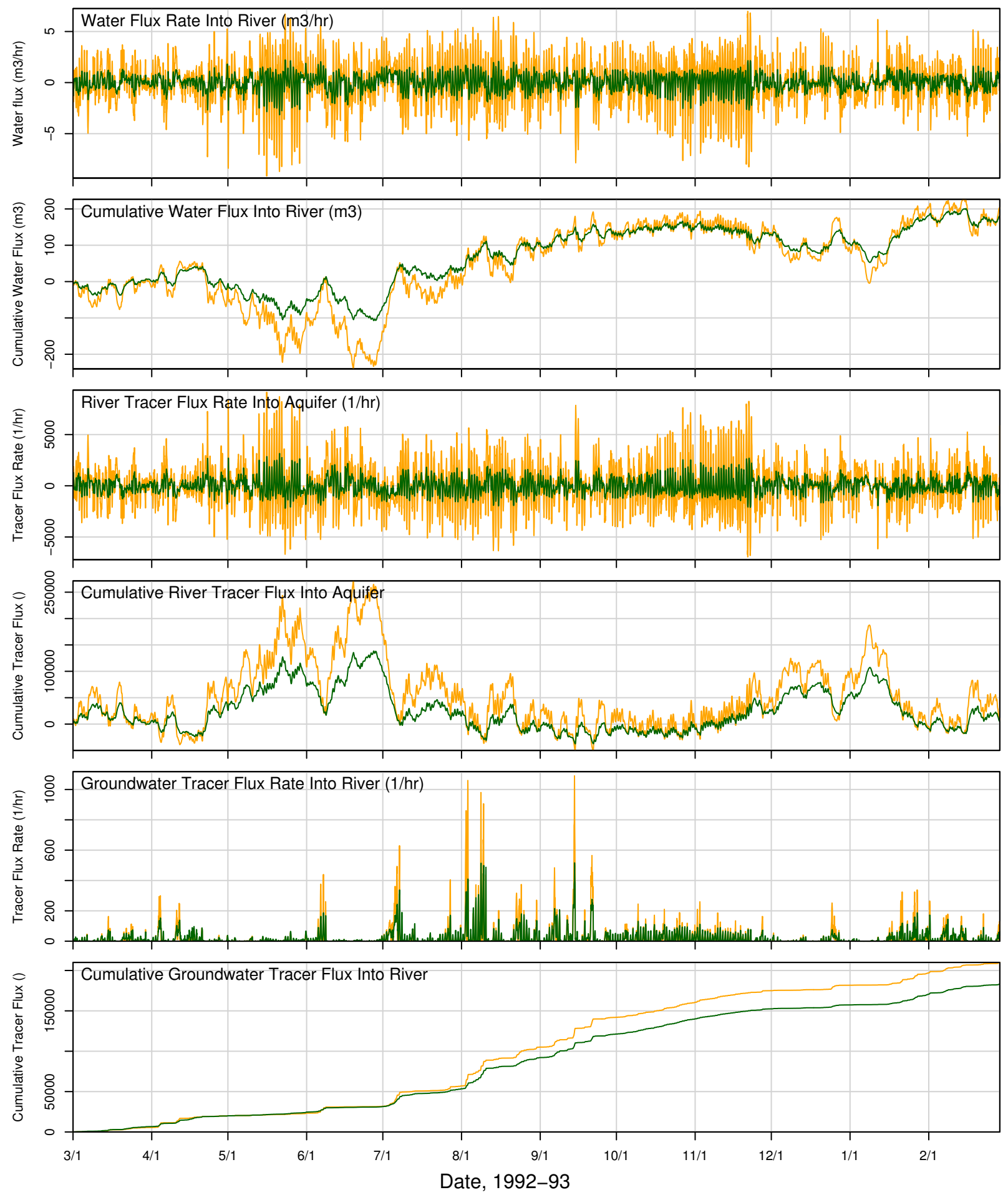

Figure 4.10. Comparison of simulated fluxes for base and high-K cases. Cumulative fluxes are net of flow into and out of the river. 
sonal changes in the mixing zone (Figure 4.11) are similar to those of the base case. The portion of the model domain area having river tracer concentration greater than 0.5 ranges between 19 and 48 percent in these monthly snapshots over the course of the year.

The fact that groundwater flux to the river is not 10 times greater than the base case (Table 4.1) is a result of having some flow in units other than U1. Some of the flow enters the river from the U5 unit, and some of the simulated inflow to the domain is from the defined-flux top and bottom boundaries, which were unchanged. Finally, even inflow within the U1 unit at the western boundary does not increase proportionally with hydraulic conductivity between the base and high-K cases because the non-horizontal contacts between formations create vertical flow paths that affect lateral inflow. Testing with horizontal contacts confirmed that inflow to the U1 unit does increase tenfold for the high-K case under those conditions. 

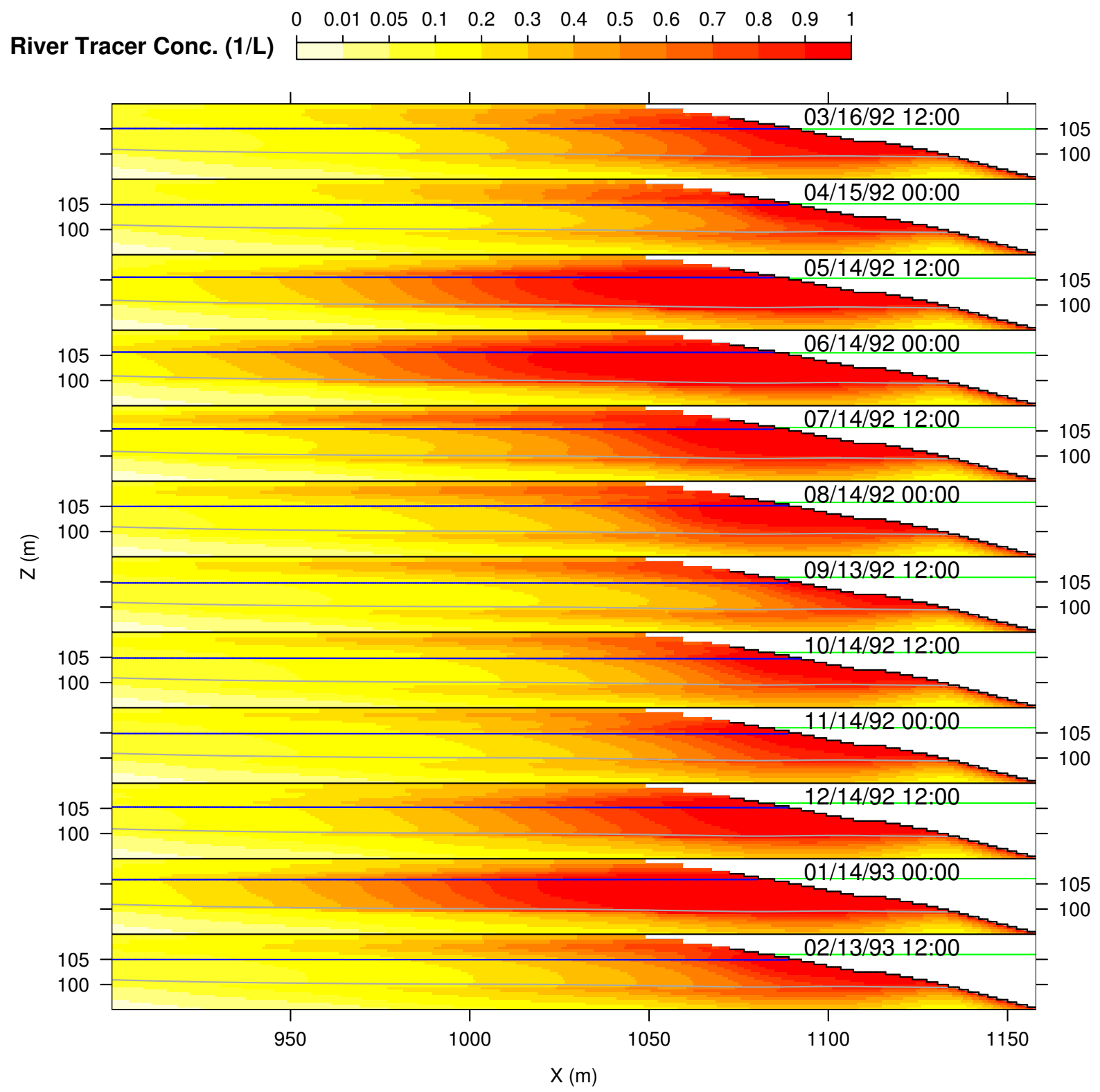

Figure 4.11. High-K case monthly river tracer concentration contours. The mixing zone expanded and contracted in response to seasonal changes in river stage. Green line is river stage, blue line is water table, gray line is U1-U5 contact. 


\subsection{Discussion}

The 2D cross-section flow and transport modeling studies were based on the most current characterization of material properties available for the 300 Area sediments and hourly water levels observed in the river and aquifer from March 1, 1992 to February 28, 1993. Water level data indicated that river stage has a strong influence on groundwater head more than $1 \mathrm{~km}$ inland. River levels at gage SWS-1 fluctuate greatly on a diurnal timescale (up to $1 \mathrm{~m}$ or more) and also exhibit a seasonal pattern with peaks in May-June and December-January. Water levels at well 399-6-1 generally lagged the river and were damped in comparison, but still exhibited significant correlation to river stage. While river stage in the 300 Area has been measured continuously at hourly intervals since late 1991, there are no hourly datasets available for the 300 Area wells other than the 1992-1993 data set.

During this time period, river stage measured at gage SWS-1 was consistently higher than water level measured in nearby wells, indicating an unresolved issue with the river-stage data. A resurvey of selected reference elevation points near the transect essentially confirmed the existing benchmark elevations and did not clarify the matter. To test sensitivity to this discrepancy, a low-river case was simulated where the river levels were lowered by $11.9 \mathrm{~cm}$, the mean annual difference between simulated levels at 399-4-9 and SWS-1. Overall model fit to observed heads in wells near the transect was good in both the base and low-river cases but somewhat better in the low-river case. For the three wells with hourly data (399-3-12, 399-4-1, and 399-4-9), the mean bias (simulated - observed) water level was $9.5 \mathrm{~cm}$ in the base case and $-2.1 \mathrm{~cm}$ in the low-river case. The low-river case led to different flow system dynamics, with 1.8 times the net groundwater flux into the river compared with the base case and a mixing zone size that was reduced by approximately the same amount. Another point of concern regarding the water elevation data was the difference between manual steel-tape measurements and transducer measurements in wells. The manual measurements were generally higher; for three wells more than $300 \mathrm{~m}$ inland, the average difference was $7.6 \mathrm{~cm}$. Although some discrepancies are to be expected in field measurements, the impact of measurement errors may be significant in modeling a flow system with small groundwater gradients.

Most of the groundwater flux occurred within the highly permeable U1 Hanford gravel/sand unit, which had a saturated thickness of $5.7 \mathrm{~m}$ at the mean shoreline. In Grid 1, groundwater velocities in the U8 lower Ringold mud unit and basalt were essentially vertical (upward) and four orders of magnitude smaller than the U1 Hanford and U5 Ringold C/E unit. Also, only 1.2 percent of groundwater flow to the river followed a pathway under the deepest part of the river channel in Grid 1. Therefore, to make a more efficient model, the Grid 2 domain was created by eliminating the U8 and basalt units and the region near the river island, making the bottom of the U7 Ringold B/D unit the lower boundary and the source of upward recharge and the vertical plane underneath the river channel a no-flux boundary.

The high degree of responsiveness of the aquifer to the river stage fluctuations underscored the importance of using hourly water levels to drive the model and also the highly transmissive nature of the U1 Hanford gravel/sand. Simulations based on hourly water level boundary conditions predicted an aquifer-river water mixing zone that reached $150 \mathrm{~m}$ inland from the river based 
on the river tracer concentration contours. In contrast, simulations based on daily and monthly averaging of the hourly water levels at the river and interior model boundaries were shown to significantly reduce predicted river water intrusion into the aquifer, resulting in underestimation of the volume of the mixing zone. The relatively high-frequency river-stage changes associated with diurnal release schedules at the dams generated significant mixing of the river and groundwater tracers. This mixing was the essential mechanism for creating a fully developed mixing zone in the simulations. Although the size and position of the mixing zone did not change significantly on a diurnal basis, it did change in response to seasonal trends in river stage. The largest mixing zones occurred with the river-stage peaks in May-June and December-January, and the smallest mixing zone occurred in September when river stage was relatively low.

The size of the mixing zone was also sensitive to the hydraulic conductivity of the aquifer. The Hanford formation has high permeability across the Hanford Site, and its permeability may be highest in the 300 Area. The high-K case was used to explore the effect of permeability of the order of magnitude found in several 300 Area aquifer tests, and in this case the mixing zone extended much farther inland. Because the river water chemistry is distinctly more dilute than typical aquifer water chemistry, water flux and mixing zone dynamics are critical modeling issues for uranium transport, whose mobility is sensitive to changing solution chemistry.

This study evaluated a single transect across the 300 Area. Other transects with different groundwater head boundary conditions and subsurface geology configurations may lead to significantly different outcomes. In particular, the fraction of saturated thickness along the west boundary that is in U1 Hanford gravel/sand is relatively small. Farther north, the Hanford formation is much thicker, and having a greater saturated thickness of this most transmissive unit at the primary inflow boundary would increase the net groundwater flux to the river. The results are also from a single year and do not represent any interannual variability in weather and river flows. Multiyear simulations would be needed to obtain a range of results that would be more representative of system variability. These results also do not take into account possible changes in future land use or climate.

Within $300 \mathrm{~m}$ of the river, where all principal disposal facilities are situated, changes in velocity, magnitude, and direction respond rapidly to fluctuations in river stage. For a day in November at a point $300 \mathrm{~m}$ from the river, maximum hourly Darcy velocities in the base case were $1.5 \mathrm{~m} \mathrm{~d}^{-1}$ away from the river and $0.6 \mathrm{~m} \mathrm{~d}^{-1}$ toward the river in U1 Hanford gravel/sand. Corresponding pore velocities in $\mathrm{U} 1$ (porosity $=0.25$ ) were $6 \mathrm{~m} \mathrm{~d}^{-1}$ and $2.4 \mathrm{~m} \mathrm{~d}^{-1}$. In the high-K case, the velocities were approximately 10 times larger and rendered an even more dynamic river-aquifer interaction. However, because of the diurnal cycling, the magnitude and direction of groundwater velocities were typically not sustained at similar levels or directions for more than a few hours in this zone.

The tracer dispersion in groundwater was an essential aspect of the simulated mixing zone and was engendered by frequent groundwater velocity changes. Execution of a full 3D model for the entire 300 Area at an hourly timestep is still prohibitively expensive for current computer resources, but a 2 to 12 hour timestep might be acceptable. In the future, the $2 \mathrm{D}$ model could be tested to see whether sufficient dispersion can be maintained under larger timesteps and 
thereby make feasible a larger, 3D model domain. Other possible ways to maintain dispersion while reducing computational demand would be to increase dispersivity (the material property) or define lower-frequency boundary conditions as step changes where the whole timestep is simulated with the same value instead of allowing STOMP to interpolate between the timestep midpoints.

The most important finding of this study is that large swings in water flow caused by diurnal river-stage cycles, together with the highly permeable Hanford formation, are important components of the near-shore hydrologic system at the 300 Area. The net flux across the riverbed or aquifer-river interface (i.e., the difference between the total inflow and outflow) was much less than the sum of inflow and outflow, indicating tremendous flushing of the subsurface zone within several meters of the river. Seasonal changes in average water levels do control the size of the mixing zone and the extent of river water penetration into the aquifer and vadose zone, but the higher-frequency changes in water level create the dispersion necessary for full mixing zone development. 



\subsection{References}

Bear J. 1972. Dynamics of Fluids in Porous Media. Dover Publications, Inc., New York.

EPA. 1996. Declaration of the Record of Decision for the 300-FF-1 and 300-FF-5 Operable Units. U.S. Environmental Protection Agency, Washington D.C.

Gee GW, JM Keller, and AL Ward. 2005. "Measurement and Prediction of Deep Drainage from Bare Sediments at a Semiarid Site." Vadose Zone Journal 4:32-40.

Haney WA. 1957. Dilution of the 300 Area Uranium Wastes Entering the Columbia River. HW-52401, General Electric Company, Richland, Washington.

Lindberg JW and FW Bond. 1979. Geohydrology and Ground-Water Quality Beneath the 300 Area, Hanford Site, Washington. PNL-2949, Pacific Northwest Laboratory, Richland, Washington.

Peterson RE and MP Connelly. 2004. "Water Movement in the Zone of Interaction Between Groundwater and the Columbia River, Hanford Site, Washington." Journal of Hydraulic Research 42(EXTRA):53-58.

Schalla R, RW Wallace, RL Aaberg, SP Airhart, DJ Bates, JVM Carlile, CS Cline, DI Dennison, MD Freshley, PR Heller, EJ Jensen, KB Olsen, RG Parkhurst, JT Rieger, and EJ Westergard. 1988. Interim Characterization Report for the 300 Area Process Trenches. PNL-6716, Pacific Northwest Laboratory, Richland, Washington.

Vermeul VR, MP Bergeron, CR Cole, CJ Murray, WE Nichols, TD Scheibe, PD Thorne, SR Waichler, and Y Xie. 2003. Transient Inverse Calibration of the Site-Wide Groundwater Flow Model (ACM-2): FY 2003 Progress Report. PNNL-14398, Pacific Northwest National Laboratory, Richland, Washington.

Waichler SR, WA Perkins, and MC Richmond. 2005. Hydrodynamic Simulation of the Columbia River, Hanford Reach, 1940-2004. PNNL-15226, Pacific Northwest National Laboratory, Richland, Washington.

WHC. 1993. Sampling and Analysis of 300-FF-5 Operable Unit Springs and Near-Shore Sediments and River Water. WHC-SD-EN-TI-125, Westinghouse Hanford Company, Richland, Washington.

White MD and M Oostrom. 2000. STOMP, Subsurface Transport Over Multiple Phases v. 2.0 Theory Guide. PNNL-12030, Pacific Northwest National Laboratory, Richland, Washington.

White MD and M Oostrom. 2004. STOMP, Subsurface Transport Over Multiple Phases v. 3.1 User's Guide. PNNL-14478, Pacific Northwest National Laboratory, Richland, Washington. 



\section{Appendix A}

Water Level Hydrographs and Statistical Plots 



\section{Appendix A - Water Level Hydrographs and Statistical Plots}

Hydrographs of hourly river head measured electronically and sparse 399-6-1 head measured

manually are given in Figures A.1-A.4. Bargraphs, boxplots, and histograms of monthly and daily river stage are given in Figures A.5-A.14. 


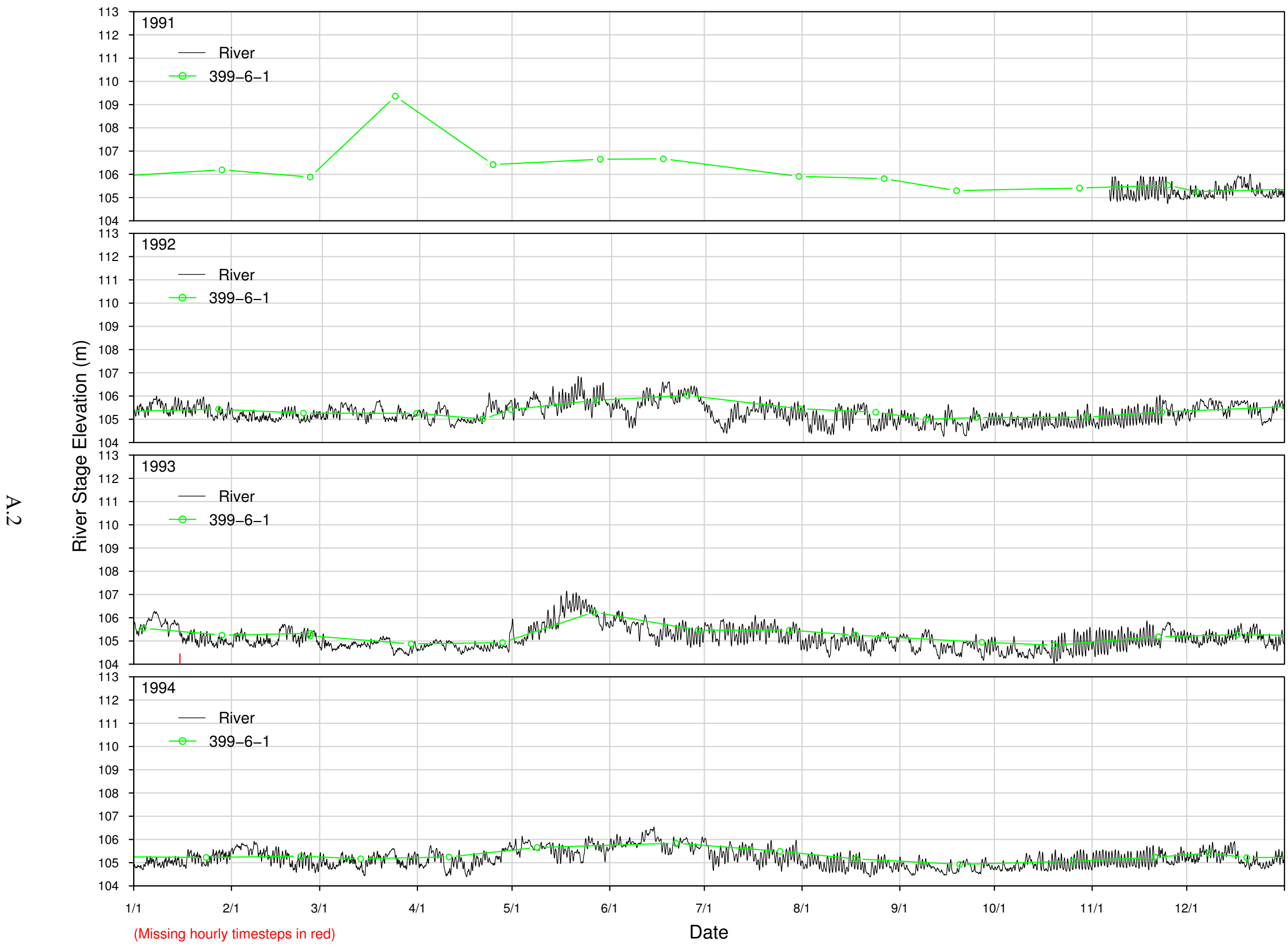

Figure A.1. River and well 399-6-1 water levels, 1991-1994. 


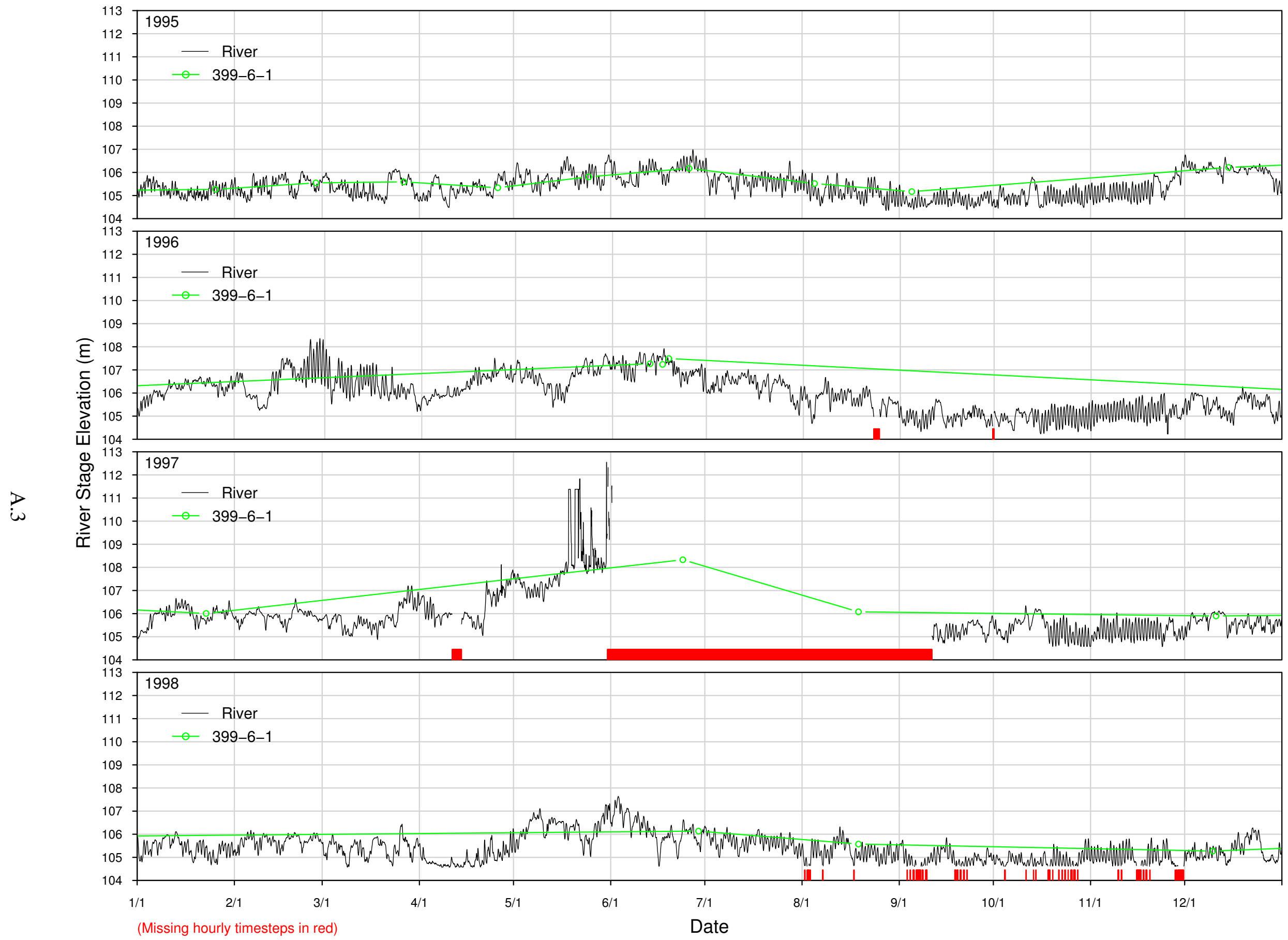

Figure A.2. River and well 399-6-1 water levels, 1995-1998. 


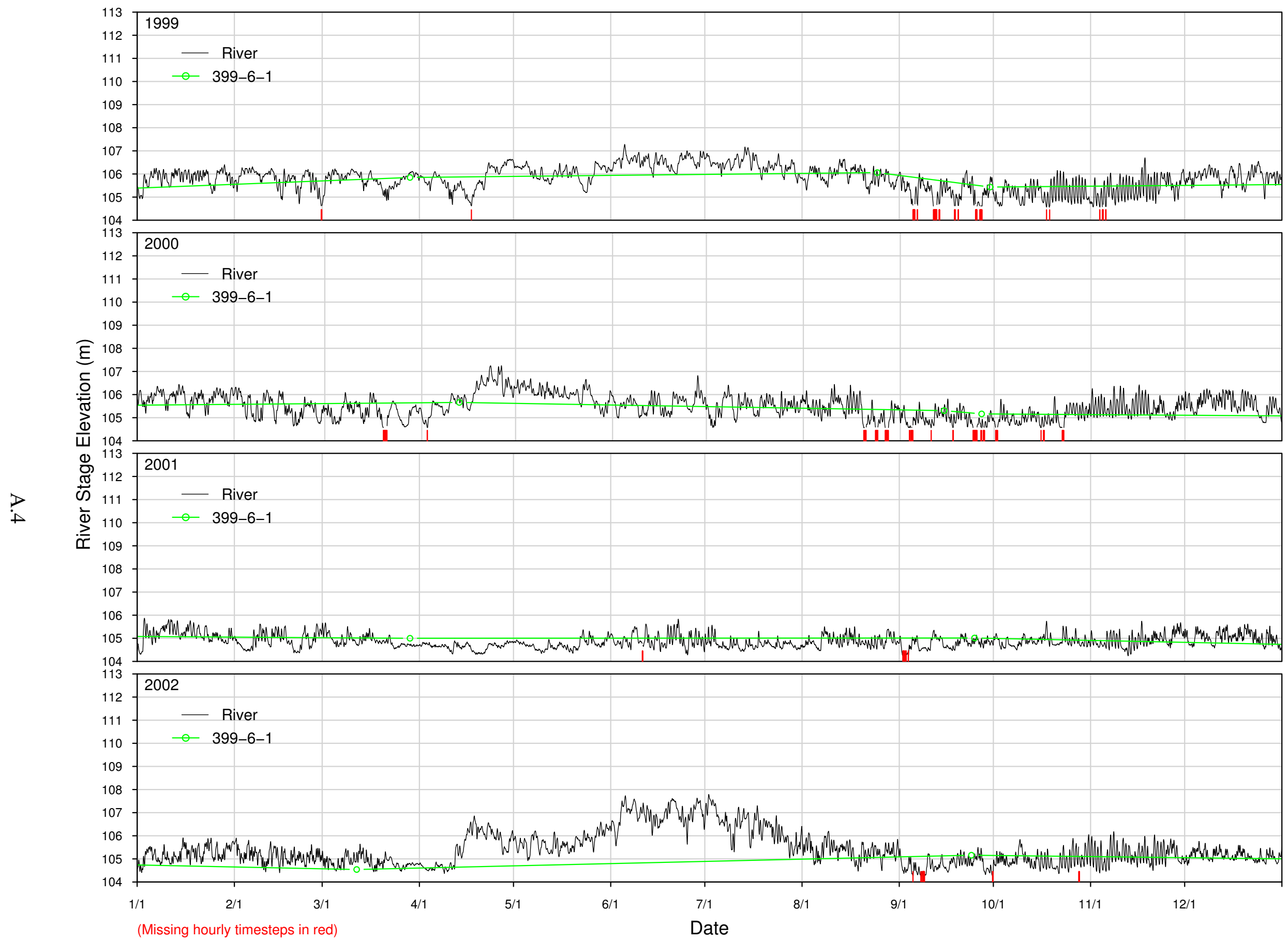

Figure A.3. River and well 399-6-1 water levels, 1999-2002. 


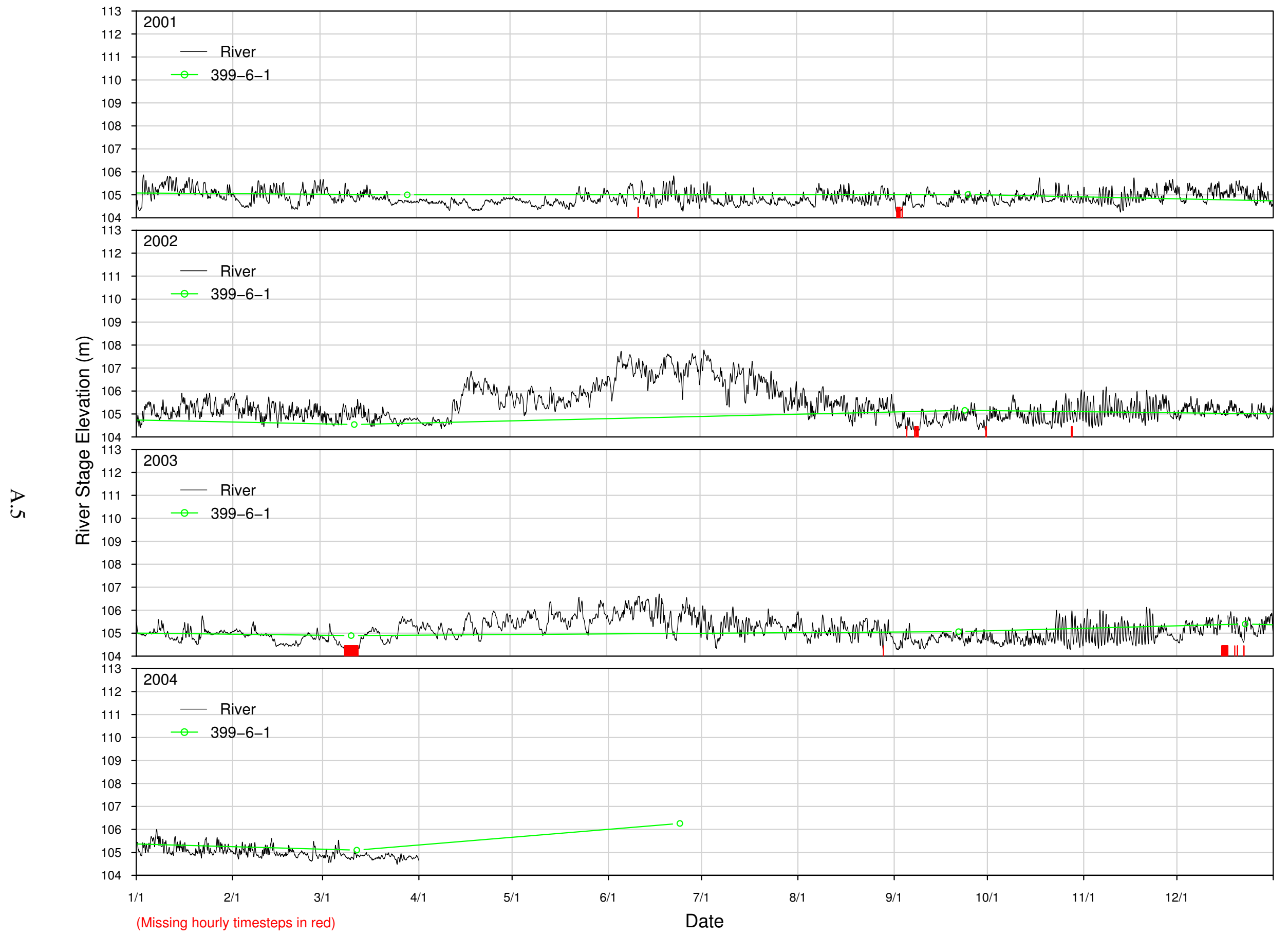

Figure A.4. River and well 399-6-1 water levels, 2001-2004. 


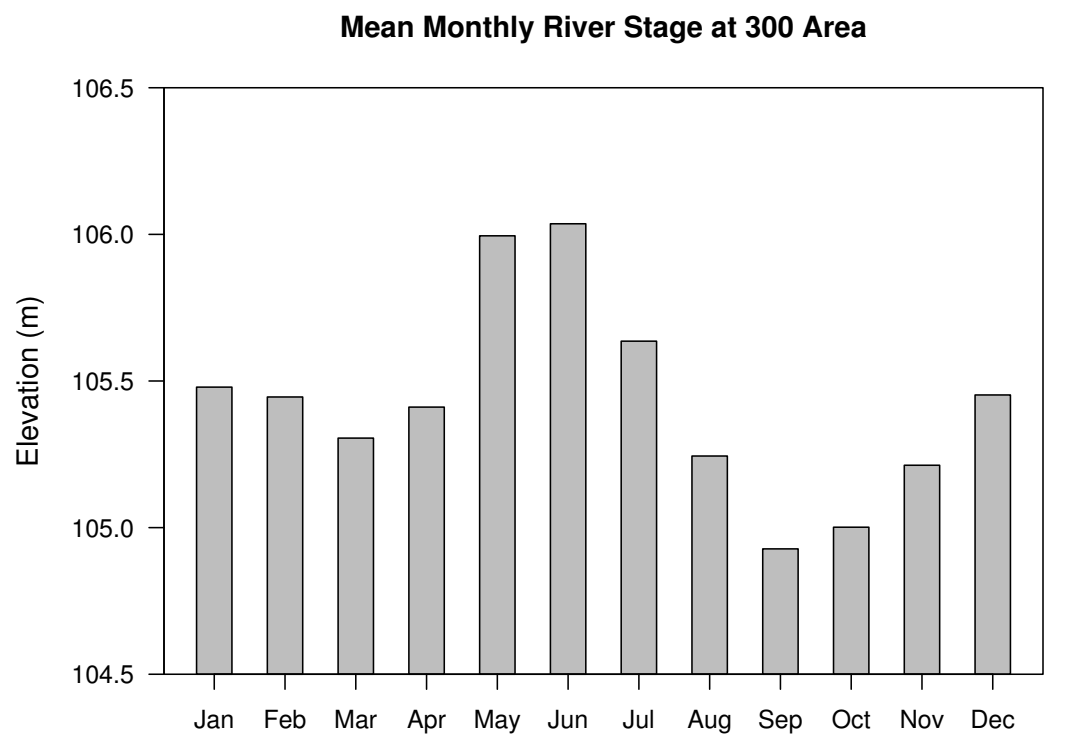

Figure A.5. Mean monthly river stage at SWS-1, 1991-2003.

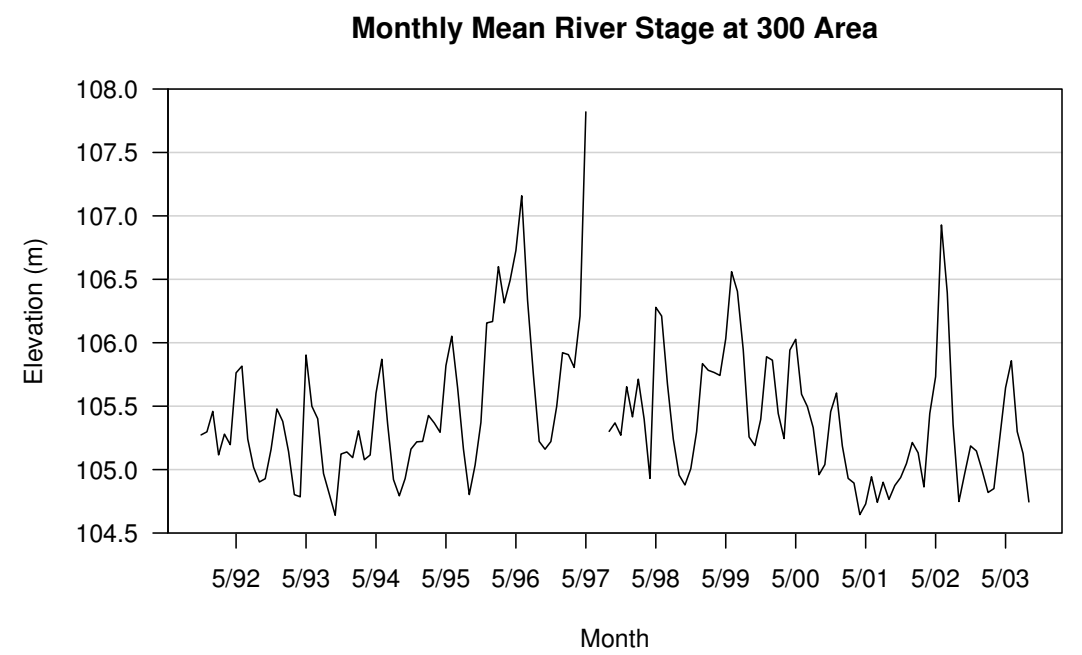

Figure A.6. Monthly mean stage, 1991-2003. 


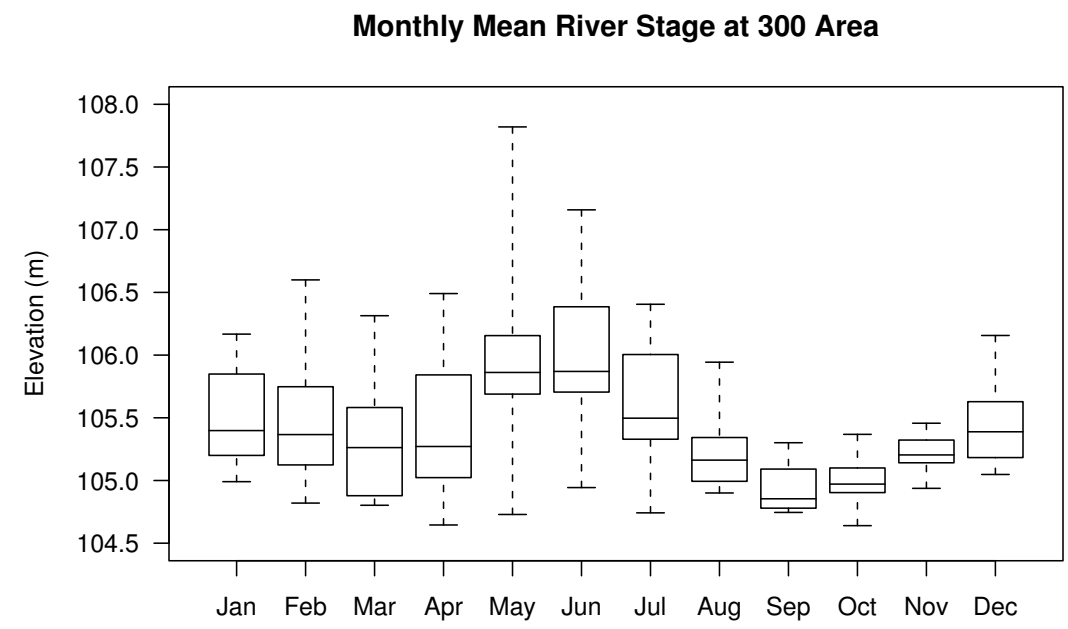

Figure A.7. Boxplot of mean monthly stages by month, 1991-2003.

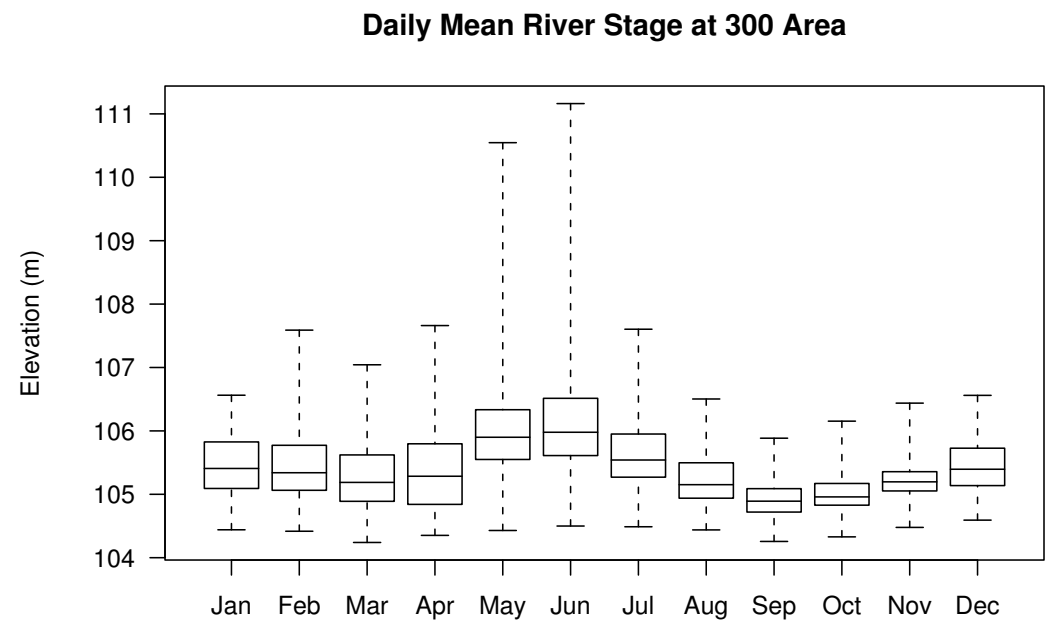

Figure A.8. Boxplot of mean daily stages by month, 1991-2003. 


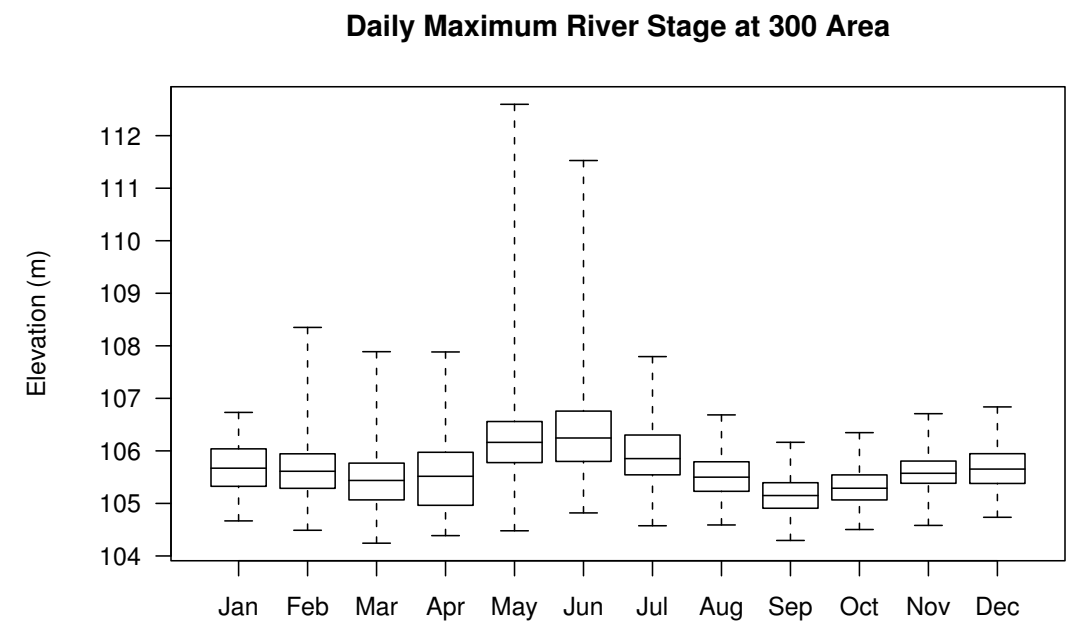

Figure A.9. Boxplot of maximum daily stages by month, 1991-2003.

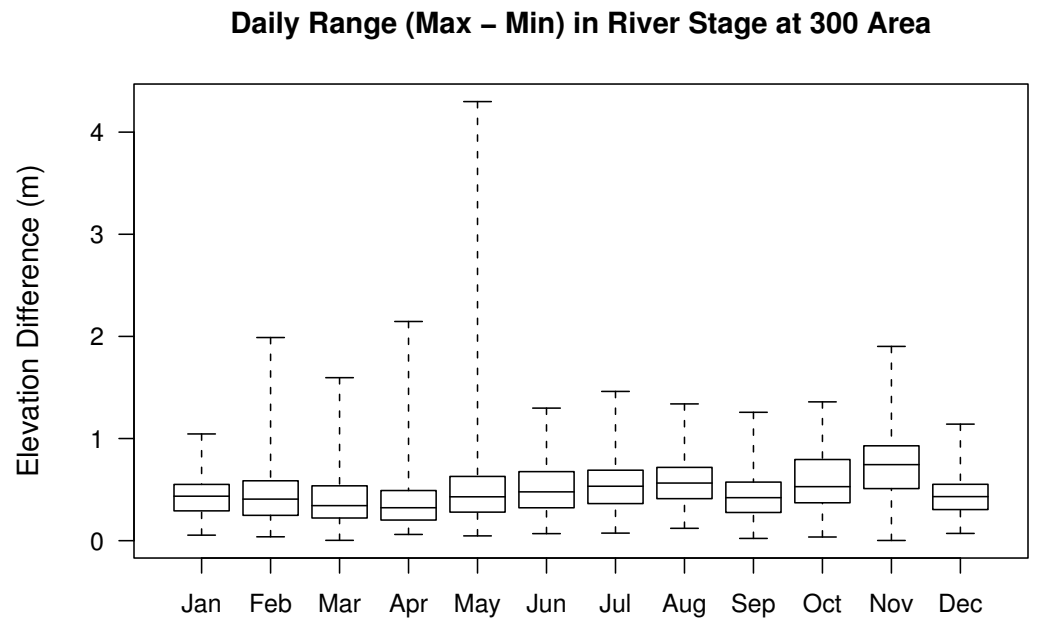

Figure A.10. Boxplot of daily stage ranges by month, 1991-2003. 


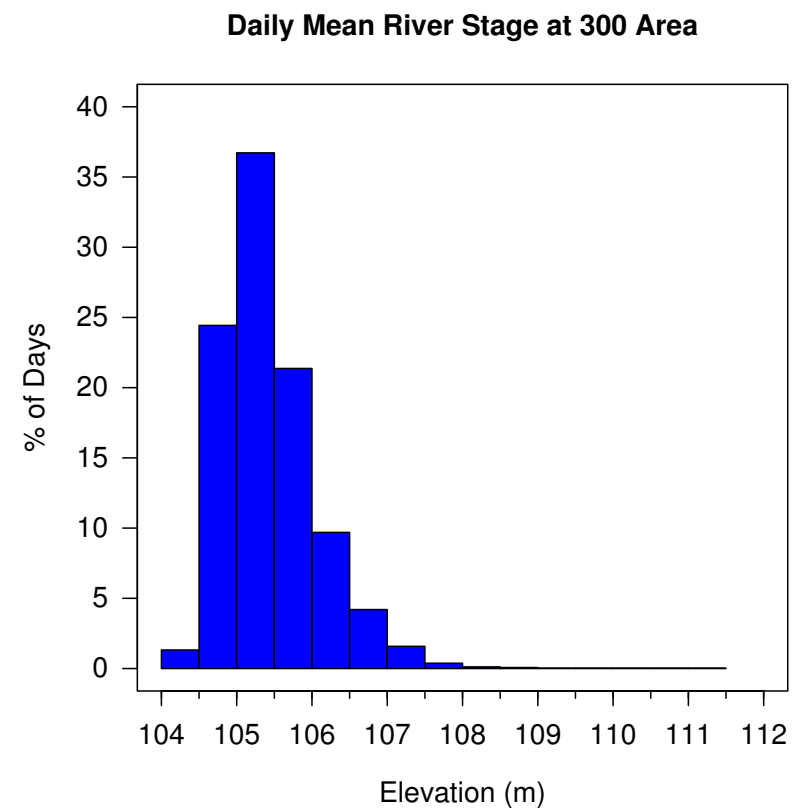

Figure A.11. Histogram of daily mean stage, 1991-2003.

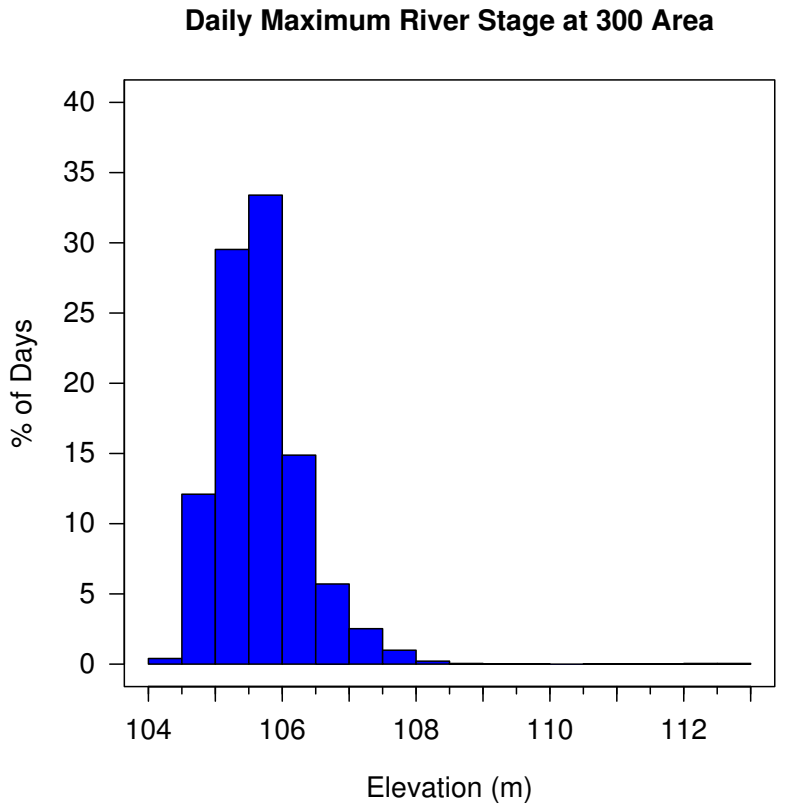

Figure A.12. Histogram of daily max stage, 1991-2003. 


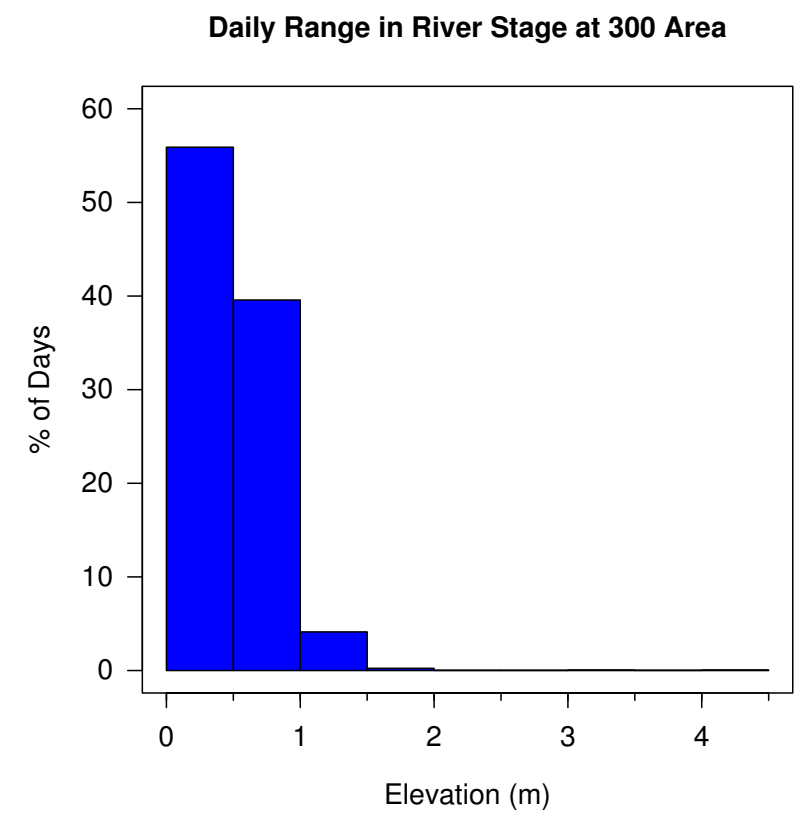

Figure A.13. Histogram of range in daily stage, 1991-2003.

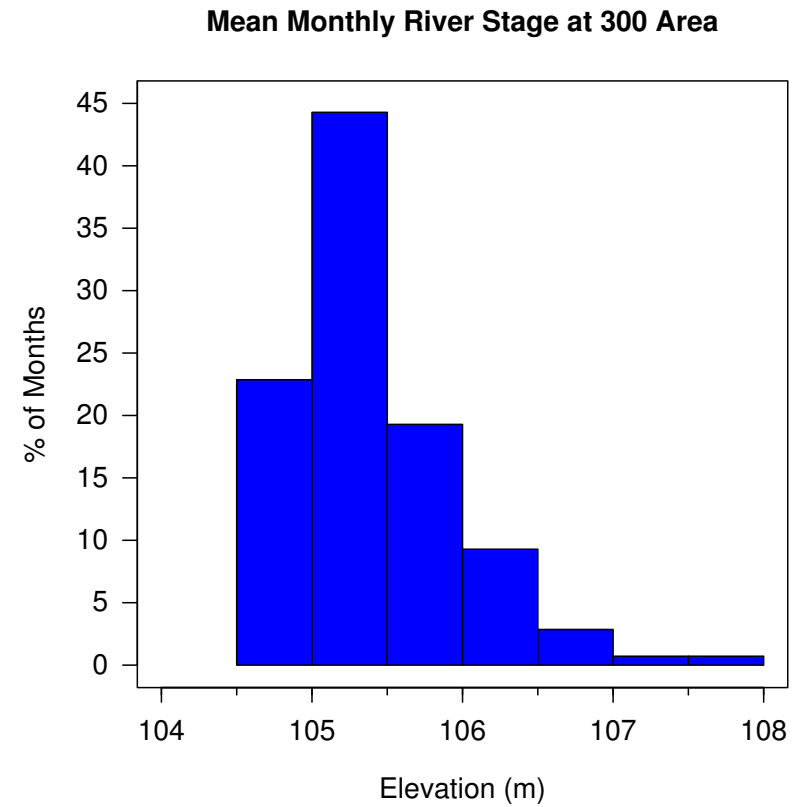

Figure A.14. Histogram of mean monthly stage, 1991-2003. 
Appendix B

Resurvey of Selected 300 Area Water Level Measurement Points 



\section{Appendix B - Resurvey of Selected 300 Area Water Level Measurement Points}

Table B.1. Results of resurvey of selected 300 Area measurement locations.

\begin{tabular}{|c|c|c|c|c|c|c|}
\hline Name & SWS-BM & AT3-3a.410 & SP9a-19 & $399-6-1$ & $399-4-9$ & SWS-1 \\
\hline Latitude (WGS84) & $46 ø 22^{\prime} 04.13310 " \mathrm{~N}$ & $46 ø 22 ' 18.57120 " \mathrm{~N}$ & $46 ø 22 ' 20.07603 " \mathrm{~N}$ & $46 ø 22 ' 07.52674 " \mathrm{~N}$ & 46ø22'04.89263"N & $46 ø 22 ' 06.09393 " \mathrm{~N}$ \\
\hline Longitude (WGS84) & 119ø16'15.72835"W & $119 ø 16^{\prime} 17.45896 " \mathrm{~W}$ & 119ø16'18.21194"W & $119 ø 17^{\prime} 03.78061 " \mathrm{~W}$ & $119 ø 16^{\prime} 16.54437 " W$ & 119ø16'14.44525"W \\
\hline Northing (WASP83m) & 115718.686 & 116163.831 & 116210.037 & 115807.538 & 115741.862 & 115779.646 \\
\hline Easting (WASP83m) & 594555.632 & 594511.706 & 594494.892 & 593527.125 & 594537.828 & 594582.109 \\
\hline Elevation (NAVD88) & 114.197 & 104.788 & 104.142 & 118.792 & 116.772 & 107.798 \\
\hline Horiz. Precision (m) & 0.008 & 0.006 & 0.006 & 0.006 & 0.006 & 0.008 \\
\hline Vertical Precision (m) & 0.012 & 0.011 & 0.014 & 0.012 & 0.009 & 0.013 \\
\hline RMS & 0.005 & 0.006 & 0.001 & 0.002 & 0.006 & 0.003 \\
\hline Maximum RDOP & 1.569 & 1.779 & 4.208 & 1.795 & 3.476 & 2.334 \\
\hline Maximum HDOP & 0.895 & 0.78 & 1.6 & 0.868 & 1.936 & 1.246 \\
\hline Maximum VDOP & 1.289 & 1.599 & 3.892 & 1.571 & 2.887 & 1.973 \\
\hline Number of GPS positions & 426 & 3 & 11 & 364 & 303 & 266 \\
\hline Minimum Satellites & 7 & 7 & 6 & 6 & 8 & 8 \\
\hline Comment & $\begin{array}{l}\text { Transferred } \\
\text { Benchmark }\end{array}$ & Aquifer Tube & Spring & Brass Cap at Well & Brass Cap at Well & $\begin{array}{c}\text { Brass Cap on River } \\
\text { Gage Platform. } \\
\text { Cap was tagged } \\
\text { 'SWS-1'. }\end{array}$ \\
\hline \multicolumn{7}{|c|}{$\begin{array}{l}\text { Notes: } \\
\text {-Survey was initiated using the National Geodetic Survey 'N323' benchmark (PID SA0992) } \\
\text {-Survey crew was: Andre Coleman, Berhon Dibrani, and Jacylyn Newell, all of PNNL. } \\
\text {-Survey conducted on December 10, } 2004 \text {. } \\
\text {-Survey was collected in Washington Stateplane South, NAD83, NAVD88 }\end{array}$} \\
\hline
\end{tabular}

Table B.2. Quality assurance for resurvey of selected 300 Area measurement locations.

\begin{tabular}{|c|c|c|c|}
\hline \multicolumn{4}{|c|}{ Quality Assurance (units in meters) } \\
\hline \multicolumn{4}{|l|}{ RTK GPS Survey: } \\
\hline Name & Northing & Easting & Elevation \\
\hline 399-6-1 & 593527.125 & 115807.538 & 118.792 \\
\hline $399-4-9$ & 594537.828 & 115741.862 & 116.772 \\
\hline \multicolumn{4}{|l|}{ USACE Survey: } \\
\hline Name & Northing & Easting & Elevation \\
\hline 399-6-1 & $593,527.183$ & $115,807.142$ & 118.773 \\
\hline 399-4-9 & $594,537.847$ & $115,741.450$ & 116.77 \\
\hline \multicolumn{4}{|l|}{ Comparison: } \\
\hline Name & Northing & Easting & Elevation \\
\hline 399-6-1 & -0.058 & 0.396 & 0.019 \\
\hline $399-4-9$ & -0.019 & 0.412 & 0.002 \\
\hline \multicolumn{4}{|c|}{ SWS-1 Coordinate Difference (units in meters): } \\
\hline \multirow{2}{*}{\multicolumn{4}{|c|}{$\begin{array}{l}\text {-Compares difference between Robert Edrington supplied data and RTK GPS Survey } \\
\text { Robert Edrington Supplied Data: }\end{array}$}} \\
\hline & & & \\
\hline Name & Northing & Easting & Elevation \\
\hline SWS-1 & 115781 & 594587 & 107.787 \\
\hline \multicolumn{4}{|l|}{ RTK GPS Survey: } \\
\hline Name & Northing & Easting & Elevation \\
\hline SWS-1 & 115779.646 & 594582.109 & 107.798 \\
\hline \multicolumn{4}{|l|}{ Comparison: } \\
\hline Name & Northing & Easting & Elevation \\
\hline SWS-1 & 1.354 & 4.891 & -0.011 \\
\hline
\end{tabular}





\section{Appendix C}

\section{Definitions for Goodness-of-Fit Statistics}





\section{Appendix C - Definitions for Goodness-of-Fit Statistics}

Mean absolute error (MAE) and first-degree efficiency $\left(\mathrm{E}_{1}\right)$ were used as goodness-of-fit measures in describing the match between observed and simulated groundwater heads.

MAE is defined as

$$
\mathrm{MAE}=\frac{1}{N} \sum_{i=1}^{N}\left|P_{i}-O_{i}\right|
$$

where

$$
\begin{aligned}
P_{i} & =\text { predictions } \\
O_{i} & =\text { observations }
\end{aligned}
$$

First-degree efficiency is defined as

$$
E_{1}=1.0-\frac{\sum_{i=1}^{N}\left|O_{i}-P_{i}\right|}{\sum_{i=1}^{N}\left|O_{i}-\bar{O}\right|}
$$

where

$$
\bar{O}=\text { mean of the observations }
$$

When applied to a single location (well), $\bar{O}$ was the grand mean of all data. When applied to multiple wells, $\bar{O}$ was the mean of data for the well corresponding to $i$. Efficiency has a possible range of $-\infty$ to 1.0. When efficiency $=0$, the model is no better or worse than the observed mean as a predictor. Efficiency greater than about 0.7 is typically considered good. The closer the baseline mean is to the individual observations, the lower the efficiency is likely to be. 



\section{Distribution}

Distribution method is email notice of PDF availability from the PNNL publications website, unless noted with $*$, which specifies a paper copy.

No. of

Paper

Copies

ONSITE

DOE Richland Operations Office

BL Charboneau

RD Hildebrand

JG Morse

KM Thompson

AC Tortoso

Bechtel Hanford Inc.

JA Lerch

SG Weiss

Fluor Hanford, Inc.

JV Borghese

RS Edrington

BH Ford

VG Johnson

Washington State Department of Ecology

R Bond

J Price
No. of

Paper

Copies

\section{U.S. Environmental Protection Agency}

DA Faulk

LE Gadbois

C Cameron

7 Pacific Northwest National Laboratory

MP Bergeron

MD Freshley

JS Fruchter

TJ Gilmore

MJ Hartman

JP McDonald

CJ Murray

TG Naymik

GW Patton

RE Peterson

ML Rockhold

PD Thorne

SR Waichler (2)

MD Williams

SB Yabusaki (3)

JM Zachara

Information Release (2)
K9-36 *

$\mathrm{P} 8-55 *$
K9-36 *

(a) http://www.pnl.gov/main/publications/

Distr.1 